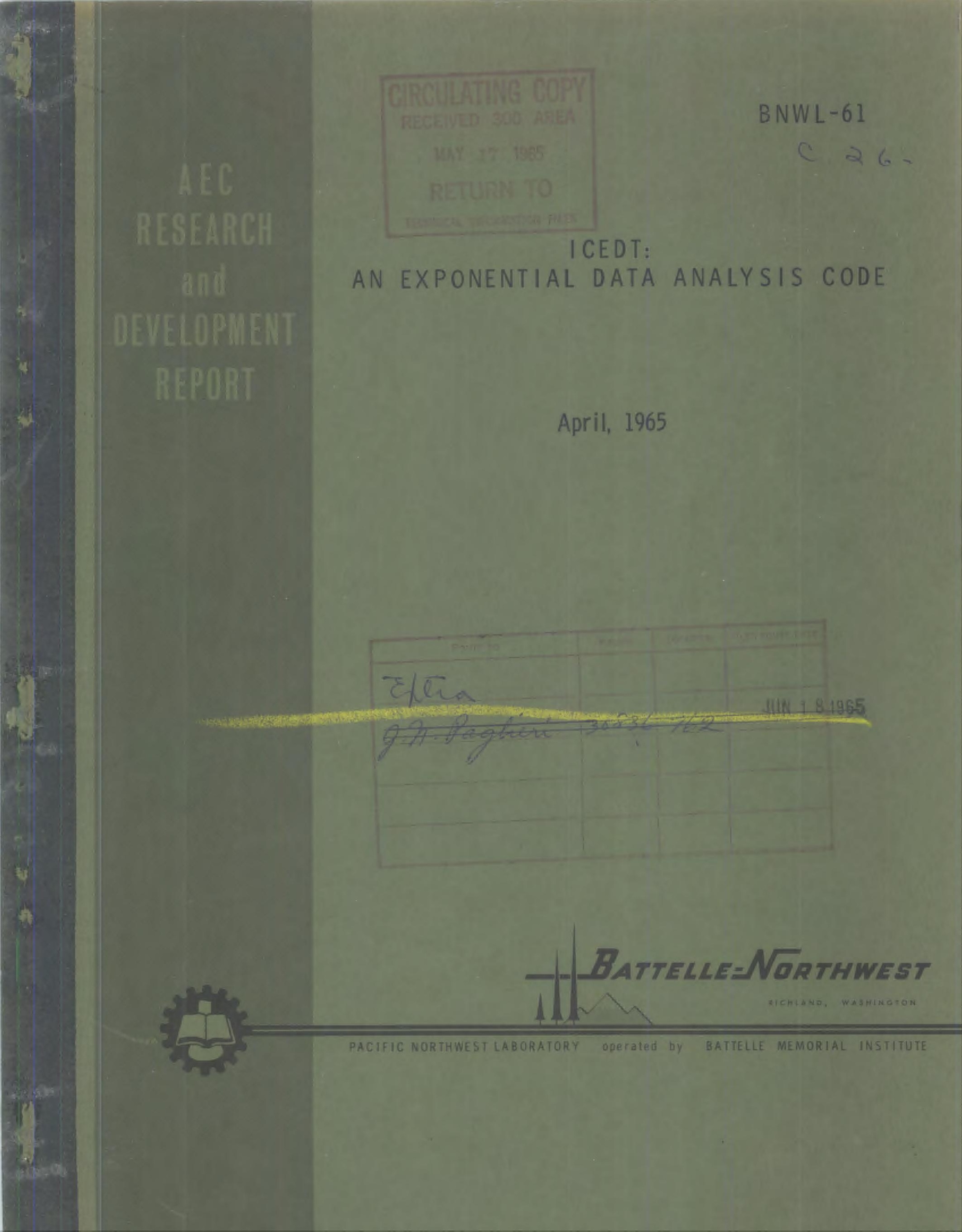




\section{LEGAL NOTICE}

This report was prepared os an account of Government sponsored work. Neither the United States, nor the Commission, nor any person acting on behalf of the Commission;

A. Makes any warranty or representation, expressed or implied, with respect to the accuracy, completeness, or usefulness of the information contained in this repart, or that the use of any information, apparatus, method, or process disclosed in this report may not infringe privately owned righits; or

B. Assumes any liabilities with respect to the use of, or for domages resulting from the use of any information, apparatus, method, or process disclosed in this report.

As used in the above, "person acting on behalf of the Commission" includes any employee or contractor of the Commission, or employee of such contractor, to the extent that such employee or contractor of the Commission, or emplayee of such cantrector preporas, disseminates, or provides access to, any information pursuant to his employment or contract with the Commission, or his employment with such contractor.

\section{PACIFIC NORTHWEST LABORATORY}

RICHLAND, WASHINGTON

Operated By

BATTELLE MEMORIAL INSTITUTE

For The

U. S. ATOMIC ENERGY COMMISSION Under Contract No. AT(45-1)-1830

I'RINTEU AY/FOR THE U.S. ATOMIC ENERGY COMMISSION 
BNWL-61

$\mathrm{UC}-32$

\title{
ICEDT: \\ AN EXPONENTIAL DATA ANALYSIS CODE
}

\author{
By \\ Dis \\ D. D. Matsumoto \\ Reactor Physics \\ Physics and Instruments
}

April, 1965

PACIFIC NORTHWEST LABORATORY RICHLAND, WASHINGTON 


\section{ABSTRACT}

ICEDT is a comprehensive program for the reduction and analysis of exponential pile data. Geometrical buckling, horizontal or vertical extrapolation, or any combination are available under option. Standard output includes an analysis of the valiaity of data and aids to the location of possible input errors. Pile dimensions and counter data from horizontal and/or vertical traverses are required for input. Sample data forms and a complete description of input, output, and operation are given in the descriptive document. The symbolic deck consists of about 3000 Fortran and FAP cards. A $32 \mathrm{k}$ computer is required. 


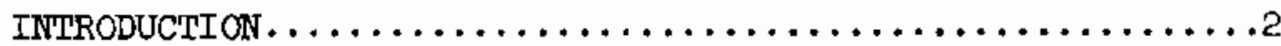

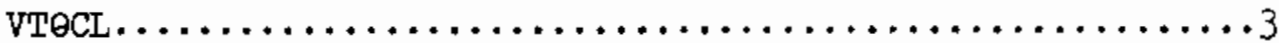

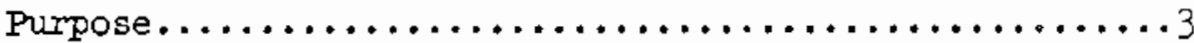

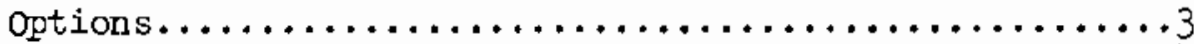

Procedure.................................

Formulation - Data Reduction..................

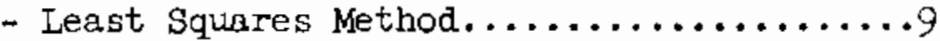

- Harmonic and End Corrections...........II

Description of output - Input Data Report...........15

- Corrections only..............15

- Data Reduction Report.........15

- Least Squares F1ts............17

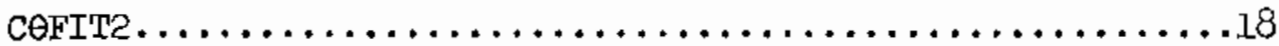

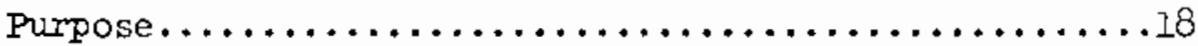

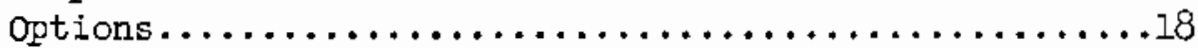

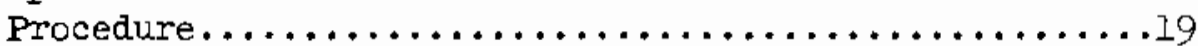

Formulation - Data Reduction.................21

- Harmonic and End Corrections...........2l

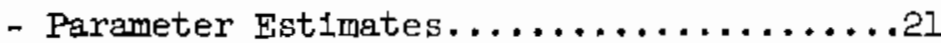

- Least Squares Method................22

Description of Output - Input Data Report..........27

- Correct1ons omly...........27

- Data Reduction Report........27

- Least Squares Fits.........28

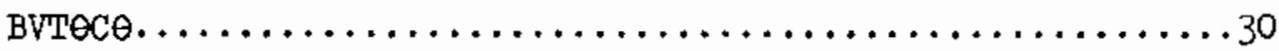

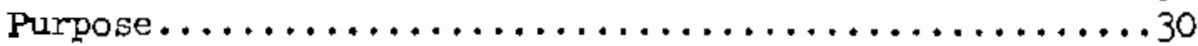

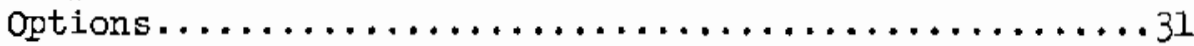

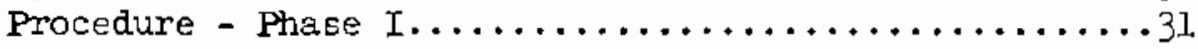

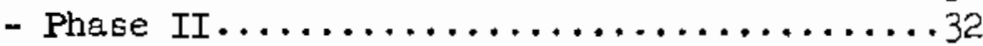

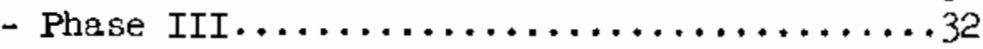

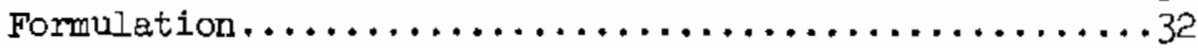

Description of output - Phase I................33

- Phase II.....................

- Phase III..................33

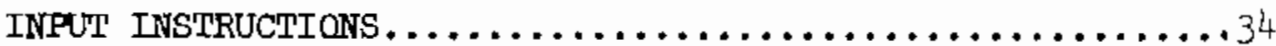

Case Numbering System......................... 34

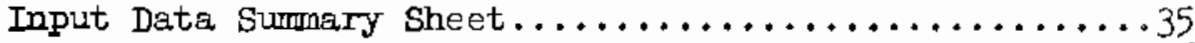

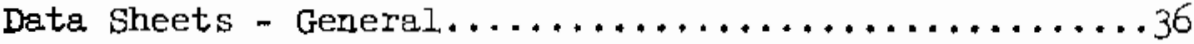

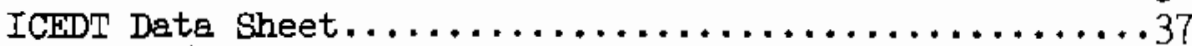

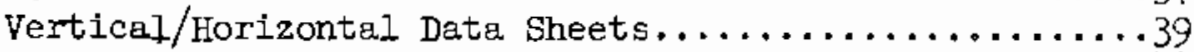

Vertical Data Sheet.......................48

Horizontal Data Sheet.....................49

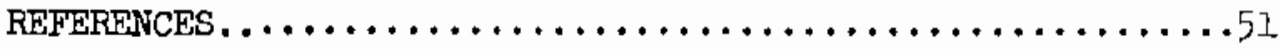

(cont'd. next page) 
TABLE OF CONTENTS - cont'd.

APPENDIX A

Figure 1 - Diagram of 2-region Pile..............52

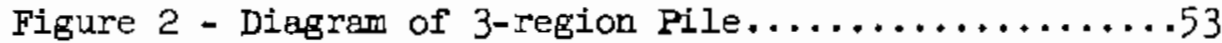

Figure 3 - VT $\theta$ CL Fit Selection....................

APPENDIX B

Table 1 - Vertical Traverse option Restrictions.......55

Table 2 - Horizontal Traverse Option Restrictions......56

APPEIDIX C

Input Data Summary Sheet..................57

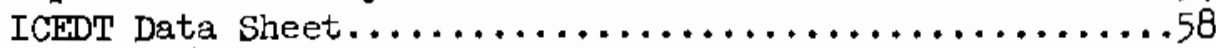

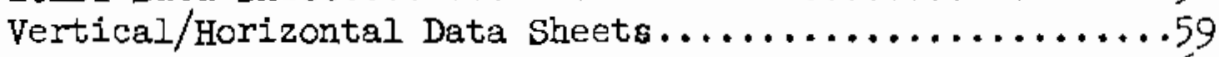

Vertical Data Sheet.......................61

Horlzonta1 Data Sheet....................62 


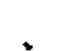

.

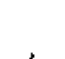

-

. 
2.TTEOLUCTION

The uses, methods of anelysis, and irput reguirements of ICEDT are deschiled by this docutient. It is primanily intended for the use of those individuis involved in the taking and analysis of exponential pile data. A familianity

with axpoitutial theory $(1)$ and measurement practices at hanford(2) is cissured.

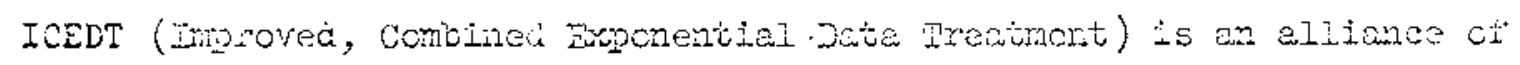
three existing exponential data codes: (1) Voci computes relaxation ier th. and geometrical buckling from vertical travense data. (2) CQFIT2 detcrmines horizontal extrapolation length from horizonaz thaverse data. (3) Evveo uses VTECL and COEIT2 to determine ventical extrapolation by an iterative procecure. In combination, the three codes form a comprehersive prograti fus the reduction and analysis of exponential pile data. ICEDT processes intenmixed cases of all three kinds, makins obsointe the existing programs and thieir descriptive documents. $(3, i)$

The three coles are now individualiy descrined. 
$\cdots$

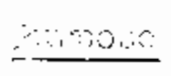

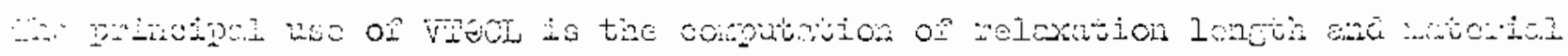

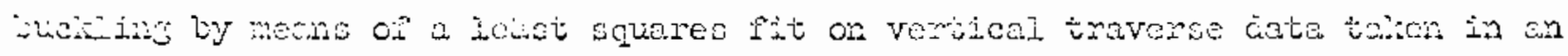

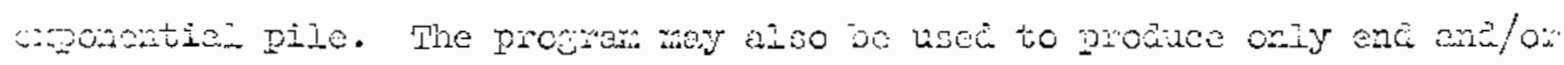

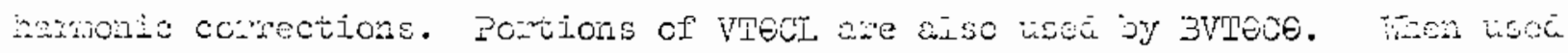

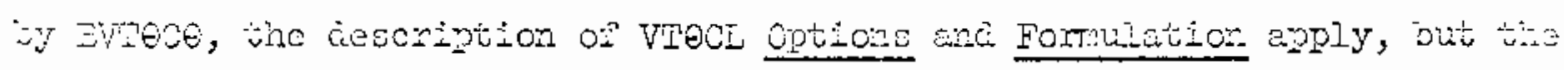
Wes: procedure is inaplicaíle.

\section{$\cos$}

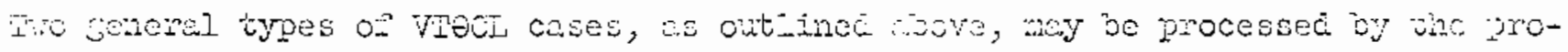

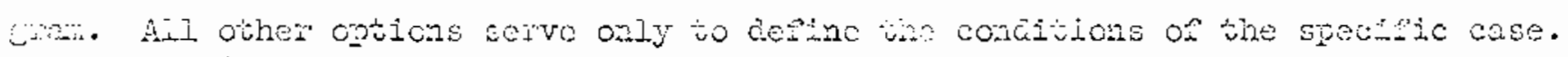

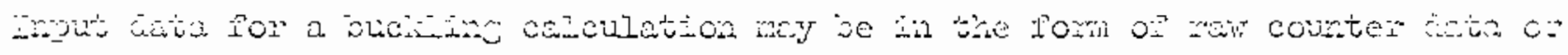

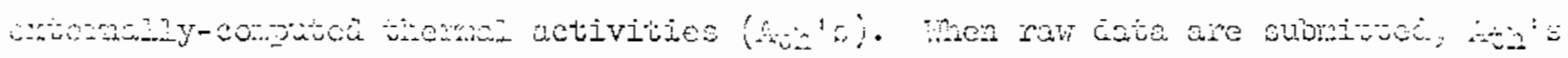

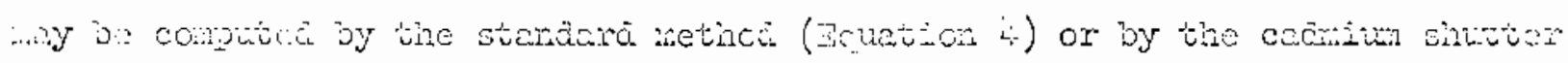

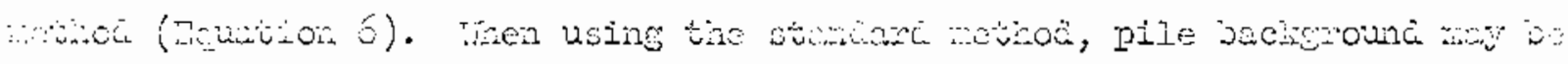

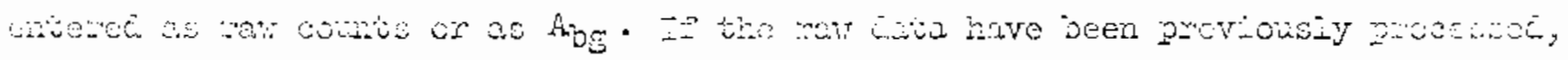

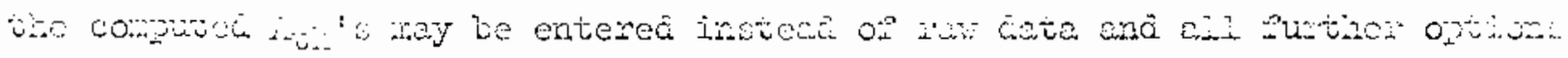

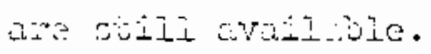

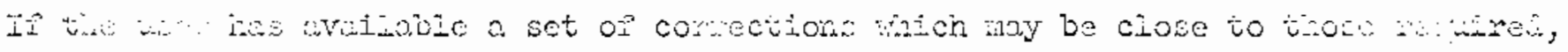

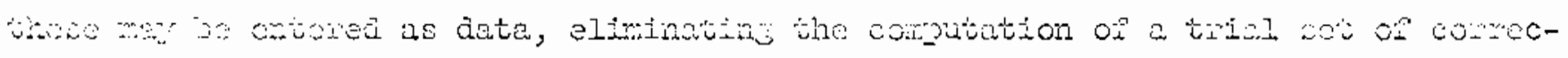

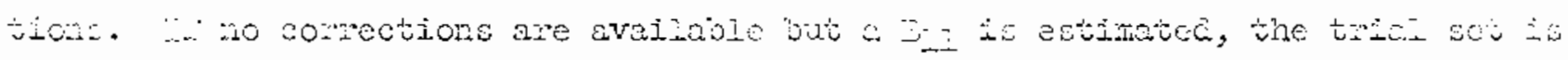

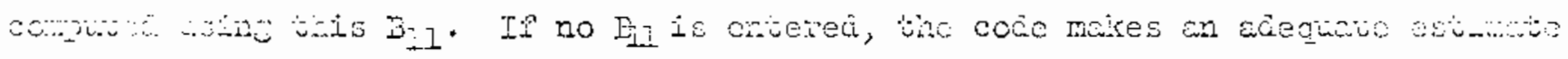

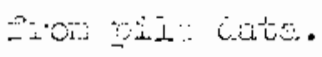

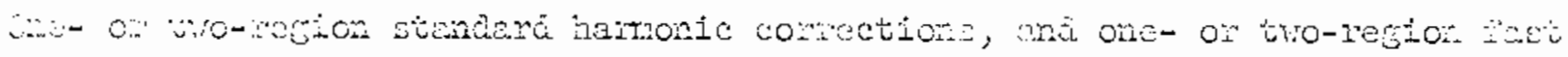

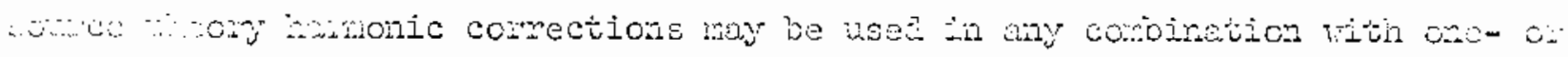

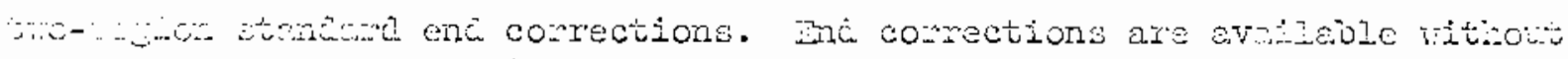


VIECL

Options - cont'd.

hamonics, also. All options on corrections are operable whether a buckling is being computed or corrections are computed alone.

It is possible to exclude any slot or slots from all least-squares fits. The back-fit is printed for these excluded slots, but they are not considered in making the fit.

Intermediate values which are normaliy of no interest may be printed as an option. This option is used principaliy when the results of a given run seen questionable, and it is desirable to renun to obtain more information. At this date, the only values given are intentifite results saved during the caiculation of harmonic and end corrections of ail types. It is possible to expand this option whenever required.

\section{Procedure}

Data are read and checked to assume that all input required for the requastod options has been subnitted. If necessery input values are missing on patentiy unreasonable, the erron is defined in a message and the prognam proceeds to tine next case. Counting data are processed as read, so that a case may be partialiy completed before being teminated because of an error.

If no data errors are discovered, the program determines to which of the two possible types the case belongs. If only corrections are recuined, these and computed and the program proceeds to the next case. If a buckling is recuircd, the following procedure applies (see Figure 3 ).

If corrections are not entered as inpt, they ane computed from a programesimated $B_{11}$ unless the user has onsered a $Z_{11}$ guess. These correctiors ane 
YTOCL

Focedure - cont'd.

applied to the $A_{t h}$ 's which woe either entered as data or computed from ravi Cuta, and a least squares fit is made to the comected $A_{t h}$ 's producing a bucking and an output $B_{11}$. If the $\Delta B_{11}$ (/fit input $B_{11}$ - fit output $B_{11} /$ ) is not within the limit specified by the irput, the fit output $\mathrm{B}_{12}$ is used to compute a new set of corrections. These are applied to the $\hat{A}_{\text {th }}$ 's anci a new it is made. This process continues until $\Delta B_{21} \leq \Delta B_{1}$ iimit from irput data. This situation is refermed to as a converged fit.

At this point a converged fit has jeen nade ving data from all slots (neasurement positions). Throughout this procedure, slots excluded by inptit option enc not considered. "All slots" means 211 those to be considered. Throu rope converged fits are now made: witi the Eirst (iowesi) slot omitted, with the last slot onitted, and with both zinst and iast slots omitted. If any one of these four converged fits is a satisfactory fit, the progran continues to the next case. A satisiactory fit is defined as a converged fit in hisici no resicuil is greater than the $\Delta L$ linit specified by the input.

If norc of the foun is satisfactory, two nore converged fits are made; one

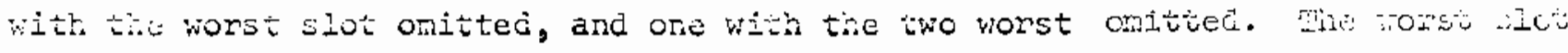

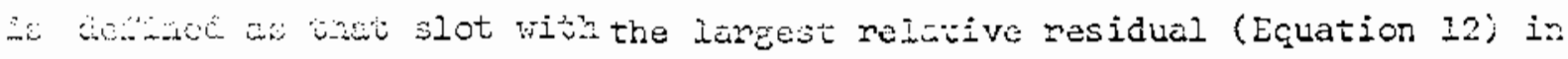
the fine fit (all slots included). If eition of the preceding fits is setisacury, the program contirues to the nexi case.

If nei...w of the preceding fits is satisfactory, seven more converged fits ate man. omiting slots in these combinations: (1) first and worst; (2) finst a.te seconó worst; (3) Iast and worst; (4) last and second worst; (ङ) Énst, last, and worst; (6) first, lest, and second worst; and (7) first, 
VTEST

Procedure - cont'd.

lest, worst, and second worst. Less than sevcn fits wi!l result from this step if one or more would be a repeat of ore of the first four, or if

onission of the specified slots would not leave three points, the minimain number necessary to make a fit.

After completion of these seven converged fits, the progran proceeds to the rext case whether or not a satisfactory fit has been found. 
vasis- $\operatorname{cost}^{i} \bar{\alpha}$.

Fonulation - Deta Rounction

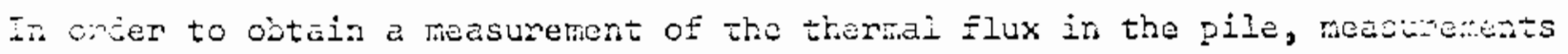
ane takon with a baro detector, with a camilim-covered detector, and with a Dare cetector while solnces are cemoved From the pile (pile backgrounc maesurement). Comrected counting rates for bahe $\left(f_{\text {bare }}\right)$, cadmilin-covered $\left(A_{C \bar{c}}\right)$, ard beckground $\left(A_{\mathrm{bg}}\right)$ conditions are computed at each measurement position by

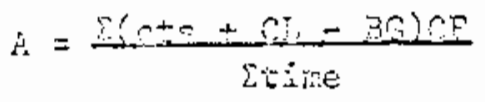

where $C L$ is coinciscree loss, $C_{i}^{n}$ is a counter standardization factor, and $\ddot{E}=$ time $x$ (counten background/minute).

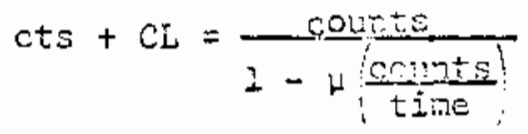

where $\mu=$ courter dead tine $=7 . \overline{0} \times 10^{-6}$ see. $=1.27 \times 10^{-7}$ minutes. The quantitios

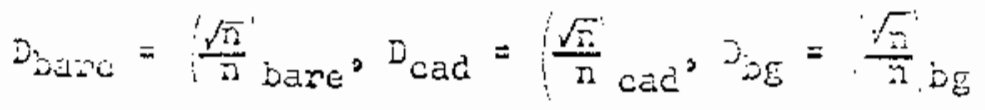

ane computed, where $\mathrm{n}$ is the total number of iare, cadmium-covered, or background counts at the measurement poution.

Thermal Elux in a standard experiment is computed by

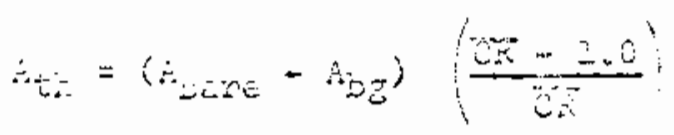

uacro

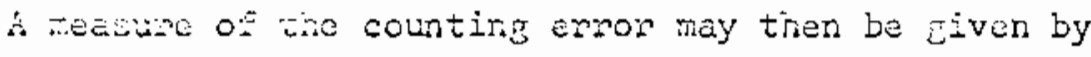

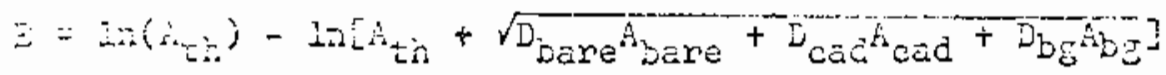


30

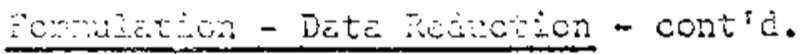

Wisen using the cacmila shltter technigue to nake the measuretient, data are teken with and without a cadmium shutter which shields the detector from the sources, Corrected counting rates for both conditions in a cadmiurn shutter experiment ere computed by Equation 1 , and thermal flux by

$$
A_{\text {tis }}=\text { (Abere, no shutien }-A_{\text {bare, with shutter }} \text { ). }
$$

Tho measure of counting error is thon

$$
E=\ln \left(A_{t h}\right)-\ln \left[A_{\text {th }}+\sqrt{D_{\text {bare }} A_{\text {Daie }}+D_{\text {shutter }} A_{\text {shutter }}}\right]
$$




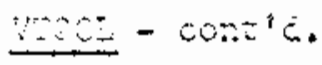

Fonmulation - Leest Scuraes Wathoc

mo ojudin the buckling of a pile, corrected vaiues of $A_{\text {th }}$ are assumed to fit a line of the fons ln $y=a_{0}+\beta x$. In raking the lecst squares $x_{i t} n=$ number of poirts, $x=$ distance from source plane to detecion ( $z$ in Figures 1 anci 2 ), Fnd $Y=I_{n}\left(A_{t h} C_{e} C_{h}\right)$. In finding the intercept $a_{0}$ and slope $B, \Sigma$ indicates $i_{i=1}^{i}$

$$
\begin{aligned}
& \bar{c}_{0}=\frac{\Sigma y+\Sigma X^{2}-\Sigma X Y \Sigma X}{\Sigma \Sigma X^{2}-(\Sigma X)^{2}} \\
& \beta=\frac{n \sum X Y X X \sum Y}{n \Sigma X^{2}-(\Sigma X)^{2}}
\end{aligned}
$$

The values of the fitted equation are given jy

$$
\bar{y}_{i}=a_{0}+B x_{i}
$$

and resicuals between data values and the titud equetion by

$$
\delta Y_{i}=Y_{i}-\tilde{Y}_{i}
$$

For the purpose of later detemining wich points are to be eropped in onden to maxe a better fit, a "relative resiculal," $n \bar{c}_{2}$ is computed for interior siots:

$$
\vec{R} \hat{o}=\left|\delta Y_{i}-i Y_{i-1}\right|+\left|\delta Y_{i+1}-\delta Y_{i}\right|
$$

zae output $\bar{B}_{21}$ (relaxation length) is complited by

$$
3_{i 1}=i / \hat{i}
$$

anc the bucking by

$$
\equiv=\frac{a^{2}}{a^{2}}+\frac{z^{2}}{b^{2}}-\frac{i}{B_{1 I}{ }^{2}}
$$

The sachanc weviations of the inverse relaxation length, $S_{b}$ and of the buckling, and then computed. 
$\underline{\operatorname{VaCL}}$

Eommation - Least Selanes Wathos - cont'd.

$$
\left.s_{b}=\frac{5 \delta y ?}{(n-2)\left(\sum x^{2}-\frac{(\Sigma X)^{2}}{n}\right)}\right]_{j}^{1 / 2}
$$

$$
d^{2}=\frac{2 S_{3}}{E_{23}}
$$


Meci- $\operatorname{cost}^{p} \mathrm{C}$

Ooriution - Iamonic anc End Cortections

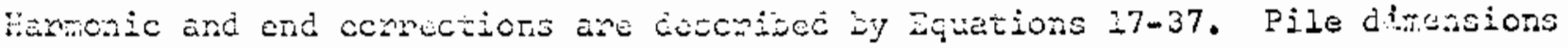
lued in these eguations are (see Ficrumes 1 end 2):

$$
\begin{aligned}
& \bar{c}=\text { effective width } \\
& \dot{D}=\text { efective depth } \\
& Z=\text { distance rom source plaro to offective top of pile } \\
& z=\text { distance from sounce plarc to measumement plano } \\
& z^{\prime}=\text { distance from effotive totcom oi pile to somce piane }
\end{aligned}
$$

In adition, in a multi-region piza (sos ficure 2):

$$
\begin{aligned}
s= & \text { distarce from source plane to the boundary plane between regions tne } \\
& \text { and two } \\
C= & \text { distance Exom source piane to joundary plane between regions two and } \\
& \text { thres }
\end{aligned}
$$

In eithen case, $x^{4}$ end $y^{\prime}$ denote betccton positicn, while $x_{i}$ and $y_{i}$ deino scurce positions, and $S_{i}$ are Eractional scurce strengths.

It should ie noted thet the assumptons made in the cerivation of hannonic and erc correction equations make then valid only when the sources are syristricaily piacos with respect to both the $x$-axis and $y$-axis.

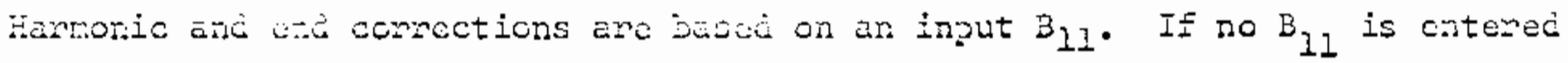
as inpit dets. wh program makes the estimate

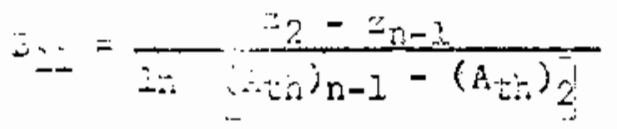

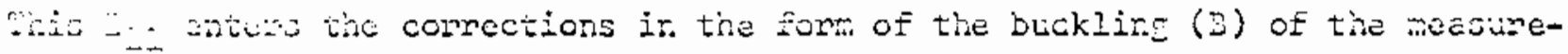
rent pestus in Equation 22 or 24 by setting

$$
\dot{\nu}=\frac{a^{2}}{a^{2}}+\frac{x^{2}}{i^{2}}-\frac{1}{B_{1 i^{2}}}
$$




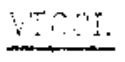

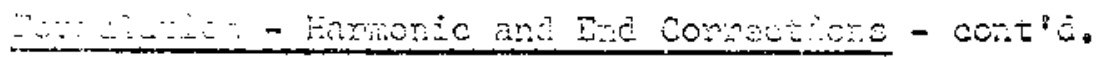

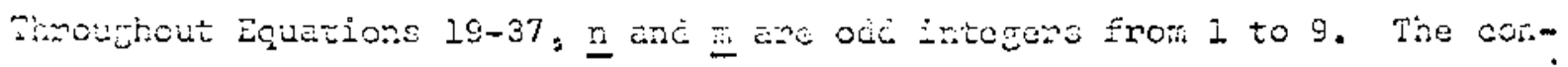

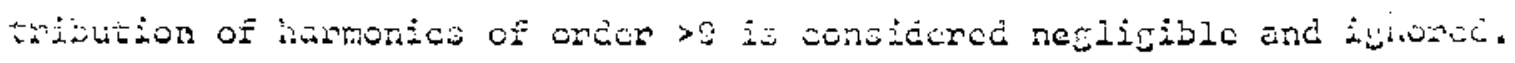

unc-region hemonic and end corrections are given in Equations 19 to 20.

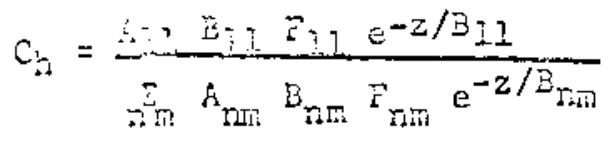

$$
\begin{aligned}
& c_{e}=i-e^{-2(Z-z) / B_{1}}-1
\end{aligned}
$$

whare

$$
\begin{aligned}
& \hat{A}_{n m}=2 \overline{\bar{j}}-\cot \left(z^{\prime} / \bar{B}_{n m}\right) \bar{j}
\end{aligned}
$$

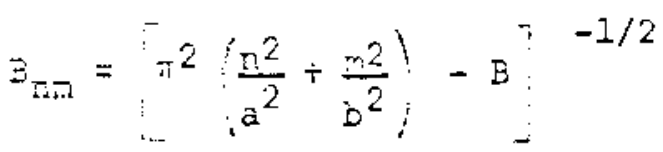

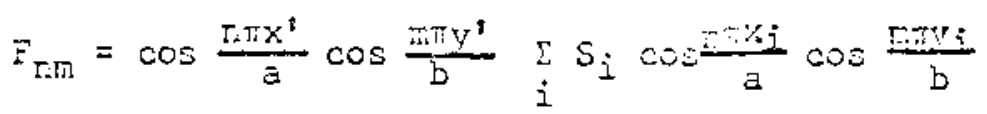

Wher two-recion hartonic on end comectionsty; are required, the introcuce the notarion

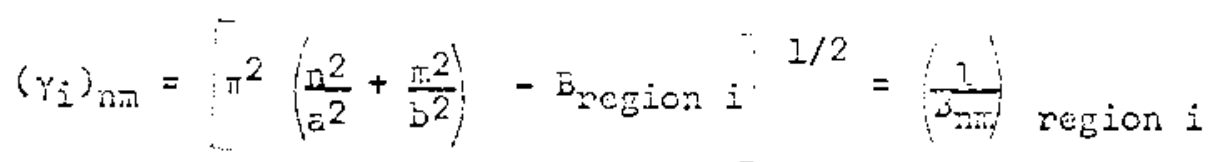

Where region 1 is the base region, negion 2 is the measurenent region, und region 3 is the top region. Ther

$$
c_{n}=\frac{F_{1} P_{2} e^{-z}\left(\gamma_{2}\right)_{1}}{\sum_{n m} F_{n m} F_{n \pi t} e^{-z}\left(\gamma_{2}\right)_{n i m}}
$$

whene

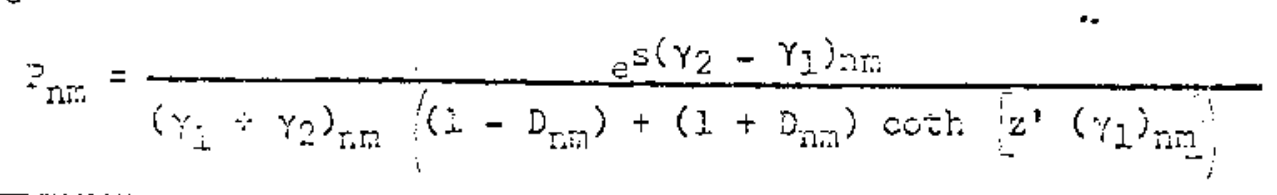

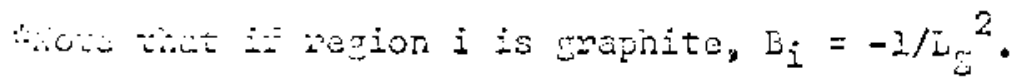




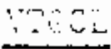

Fomingation - Vamonic end End Conrections - cont'c.

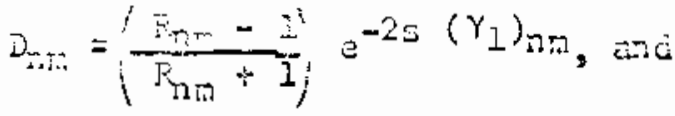

$$
\begin{aligned}
& z_{n=1}=\left(\gamma_{2}\right)_{n m} /\left(\gamma_{2}\right)_{T n}
\end{aligned}
$$

Wen tro-nagion enc corrections are lued, $C_{n}$ lay be computed from cne- or tworecicn corrections as reçuired and

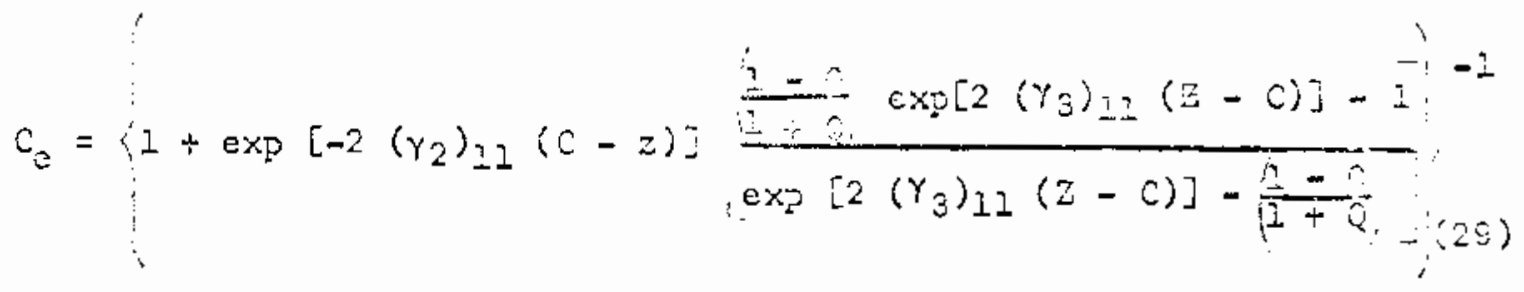

Hites

$$
C=\left(\hat{i}_{3}\right)_{11} /\left(\hat{T}_{2}\right)_{1 I}
$$

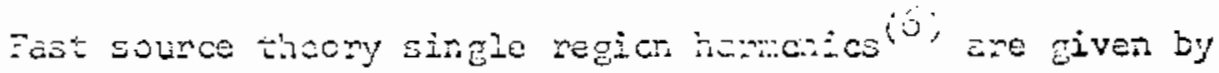

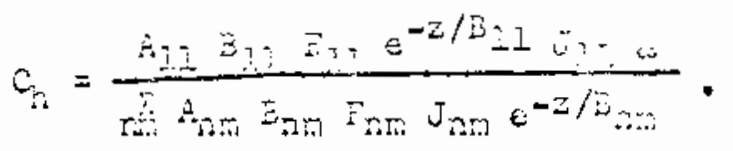

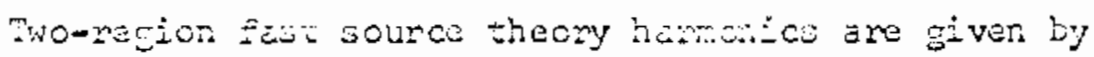

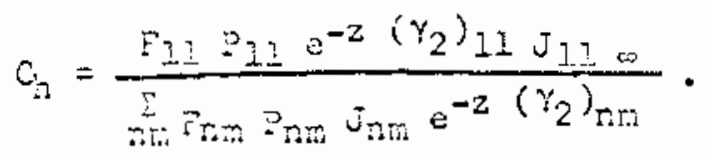

In oither case:

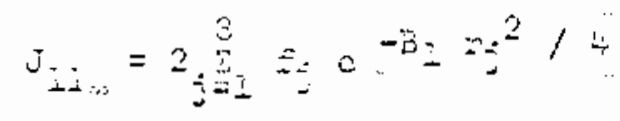

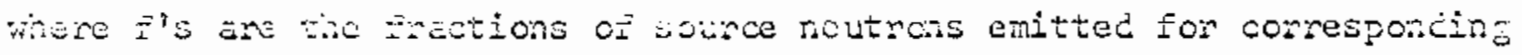
source vangs $(n i s)$ anc $D_{1}$ to she bucking of the graphite base region. $\left(-i / z^{2}\right)$

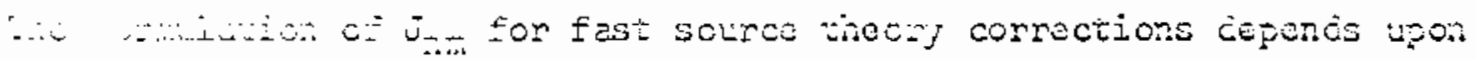

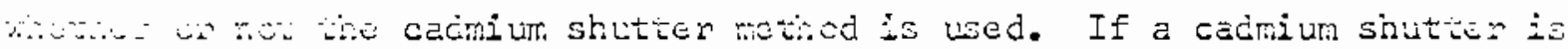
quast in tro piles 
VTaCL

Fomulation - Harmonic and Enc Corrections - cont'd.

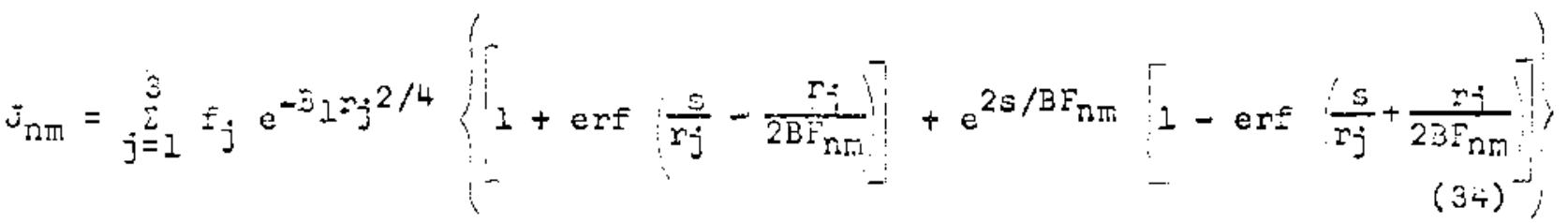

If a cadinim shutter is not used, $J_{\mathrm{nin}}$ is computed by

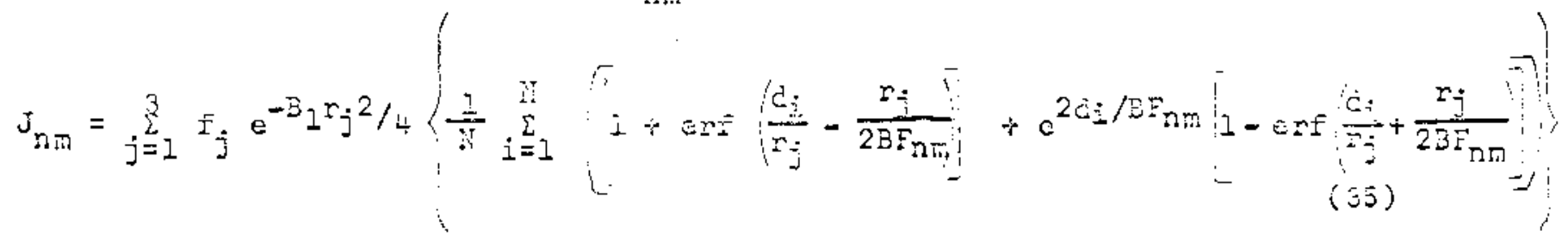

whene $\mathrm{N}$ is the number of sources ard $d_{2}$ is the diatance from the source (at $\left.x_{i}, y_{i}, 0\right)$ to the meciurement position $\left(x^{\prime}, y^{\prime}, z\right)$.

$$
d_{i}=\left[\left(x^{\prime}-x_{i}\right)^{2}+\left(y^{\prime}-y_{i}\right)^{2}+z^{2}-1 / 2\right.
$$

In both Equations 34 and 35 ,

$$
B F_{n i n}=\pi^{2}\left(\frac{\omega^{2} r^{2}}{a^{2}}+\frac{\omega_{b}^{2} m^{2}}{b^{2}}\right)-E_{L}{ }^{-i / 2}
$$

Tre $\omega_{a}^{2}$ and $\omega_{j}^{2}$ of Equation 37 provide a struaring correction basect upon retios of diffusion lengths perpendicuiar and parallel to streaning ciane:a.*

*xis can be wone fully explained by referrtog to Richey ano Biock, (7) pafs i4. winere for caed $(a), \omega_{a}=1.0$ and $\omega_{b}=\frac{1}{-j}$ but for case $(b), \omega_{a}=\omega_{b}=\frac{1}{b_{i i}}$. 
$\underline{\operatorname{lng}}-\cos ^{\circ} \dot{0}$

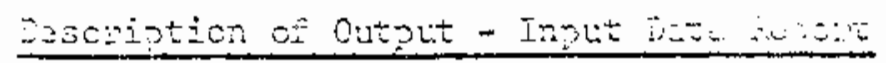

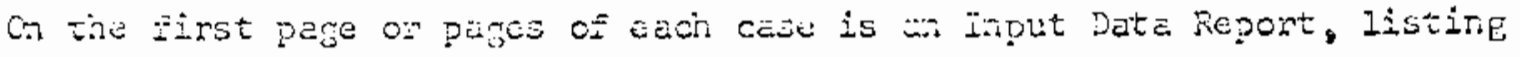

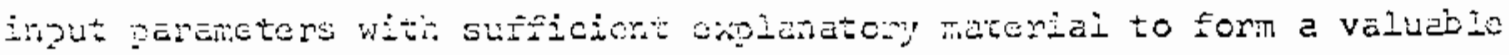
acition to the permanent output reconc. This report also provides aseistance in tracing possibie input enrore. Inciude are all idontification carcs, pic deninsions, sounce positions and strengths, detector positions, är an

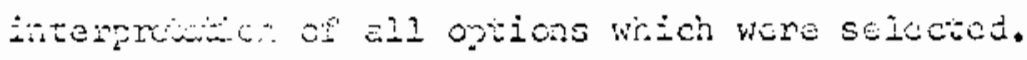

Eisciption of Cutput - Conrections Coly

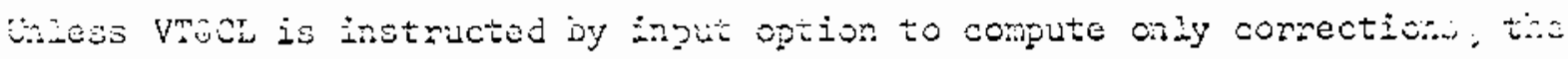

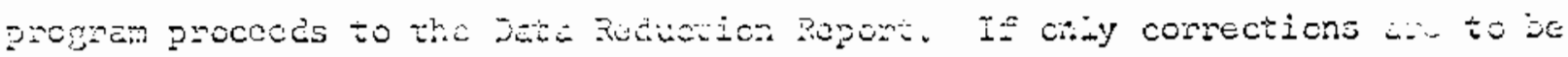

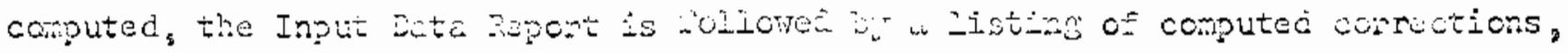

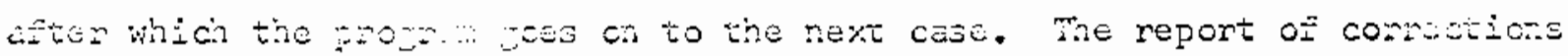

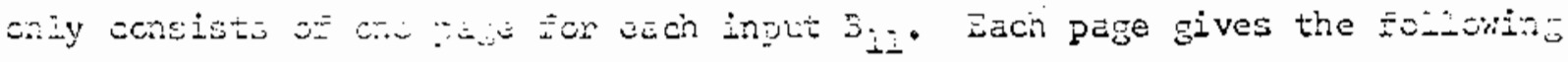
informition Fon Every mentrencre pesition?

\begin{tabular}{|c|c|}
\hline SLOM & Pile Iayen number \\
\hline$\Xi$ & 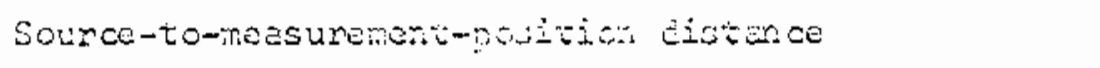 \\
\hline 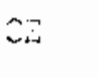 & 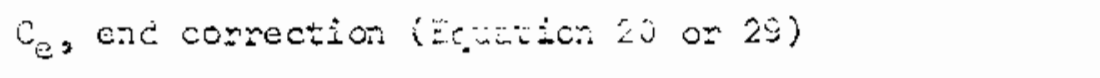 \\
\hline 8 & 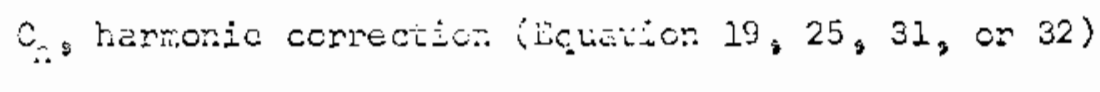 \\
\hline Us & $\mathrm{C}_{\mathrm{e}} \mathrm{C}_{\mathrm{H}}$ \\
\hline
\end{tabular}

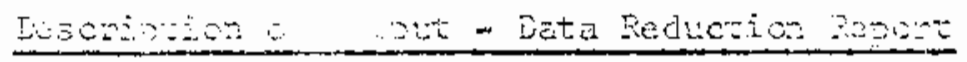

Folichin- the aput Dete Report is a sumbry ci counter data reduction resüts.

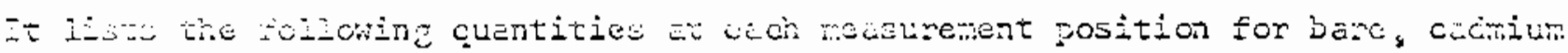

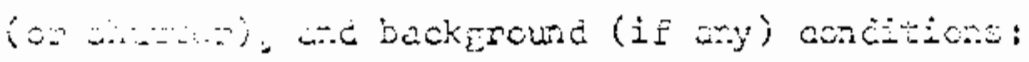

H... Pile layer nurise:

200.28

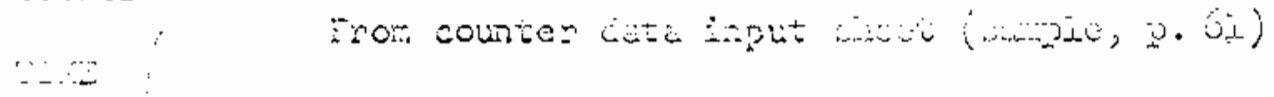




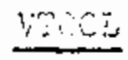

Descriation oz Outsut - Data Recuction Report - Cont'd.

CIR DG/NIN

CIR FACTOR ? From counter data input shoet

A Conrocted colating rate (Equation I)

I/SR N D(Equation 3)

Titis is followed by a summary of the fthermal culculation. In standare experimert, the Ath sumery lists the Folloving quantities at each measurenant position:

Siot Dile iaver number

$A-B C R:$

A-CRD EOUAtion :

A-EC

A-TEEREL

Equation 4

Li A-THERAL First tern of Equation 5

Wit CTNS ERRCR Second ten of Ecuation 5

DIFF $\quad$ E (Egerion 5$)$

Fon cadnimu-shutwon experiment, the Ath sumany gives

Siem $\quad$ Pile layer number

ATAR NO SIRT Equazion 1

A-BAKE HITHSETR EQUESEC I

A-TEERTAL Equation 6

ZA-TENAL Enst term of Equetion 7

$\because$ CWE ERROR Second tun of Eruation 7

E (Equetion 7) 
$\underline{\operatorname{Vacos}}-\operatorname{cost}^{\circ} \mathrm{d}$

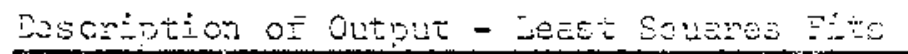

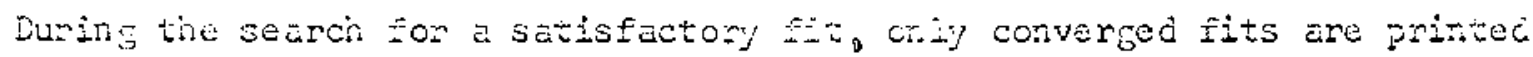

(see Procedure). For each converice fit, thene is one set of output listine

the following quantities for caci r.usurarent position:

$\operatorname{Sos}$

Pile Iayer nurite:

A-THEFHAL

Ath (Equation is on ó;

YAR: CORR.

$c_{e} c_{n}$ (Product of ond and harnonic corrections)

CORT. A-MH

$A_{\operatorname{tin}} C_{e} C_{n}$

r.:.

L:1 $\left(A_{t=1} C_{0} C_{i}\right)=Y$ of Equetions 8 and 9 .

$\because \therefore C K T$

Y (Ecuivion 10)

DIFERENG

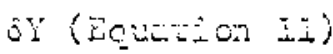

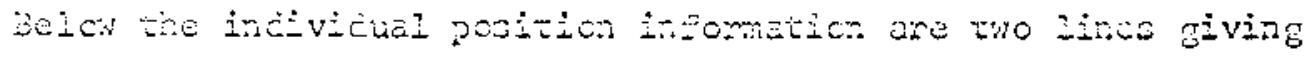

$\operatorname{Min} 3=$

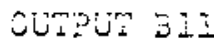

EUCKIIEG

$S-S L+j-3$

$\Xi 2-S Q$
32, with which corrections were computed

Outout Bj. (Equation is)

Output buckling (Equation 14)

Standard deviation ef I/EI (Equation I5)

Stakcerd deviation of hucking (Ecuation i6)

Ii disy masurenont poitions were omitred from the fit, their deviation ans computec. The information given above Fon fitted positions is then listed for these onittec measunerents. 
$\underline{C+2}$

Plippese

Horizontal extrapolation lenth of an expontiol pile is corputed by means

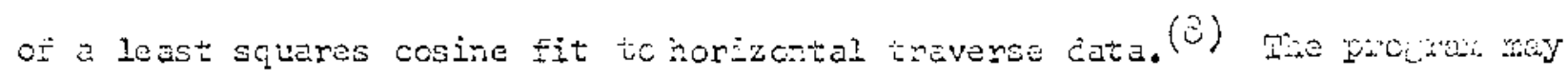
aiso be used to produce only end and/on hamonic corrections. Portions of CofIT2 are also lisec by EVTACo.

\section{Opticns}

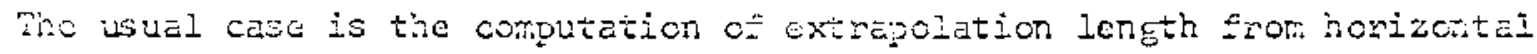
traverse data. It is also possibje to compute only exd anc/or hamonic conzorics:

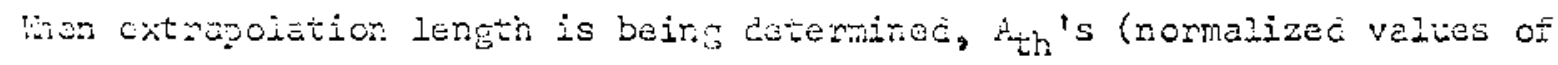

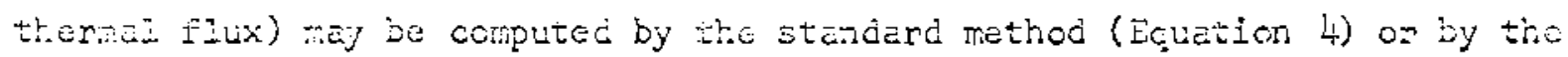
cadmin shuttei mothce (Equation 6 ).

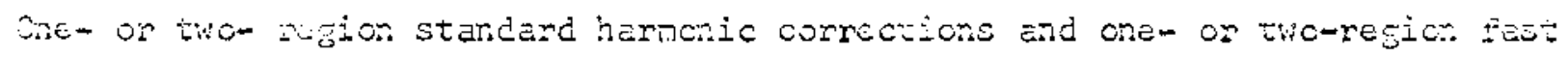
scurce theory hamonic corrections wey be used in any conbination wth one- or two-berion studerd end corrections. End connections are availajie without hamoitcs, aleo. All above options on competions are operablo whether extra-

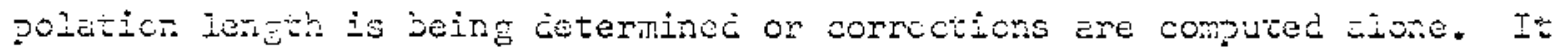

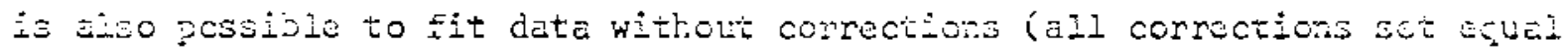
to $1.0 \%$

Fes:use of the least squares andysis are nomaily printed onjy after convi-

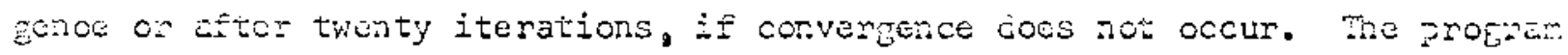
way do dinected, howeven, to print every itondtion during the fitting procecure.

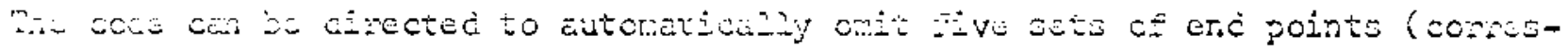

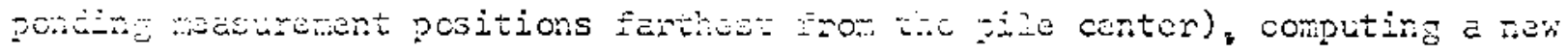

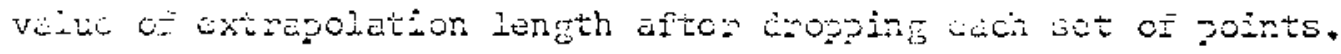




\section{$\operatorname{CotiT2}$}

Sotions - cont'c.

It is possible to exciuce any position on positions from all cosine fits. The back-itt is computed for these fositions, but tiney are rot considered in neking tire fit.

Intermediete values wich are nomally of no interest may be printed as an option. This option is wed principaliy when the results of a given run seem

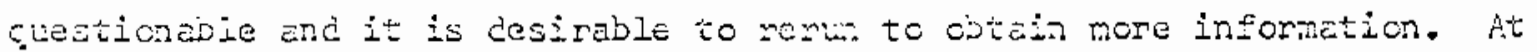
this date, the on $1 \mathrm{y}$ values given and itcmeçate resuits saved during the

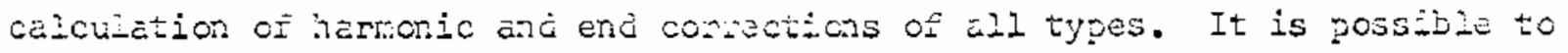
expand this optich whereven required.

\section{Procecure}

Datu are read and thecked Fon validity. Fr necessary quentities are missir. or i. certain quantities or option corbinaticns are ln reasonabie, the enor Is deftred in a ressage and the progran pooceds to the next case. Cowntro ¿eta are proosesed as read: so that a case may be partially completed bezono being terinated because on an enrow

If no date ertons are recognized, the progran determines to which of the two gencrai types the case beicnes. If anly conreotions are recuired, these are computal and the program proceds to the next case.

Whe extropotion length is to be compted, ccrrections are computed using

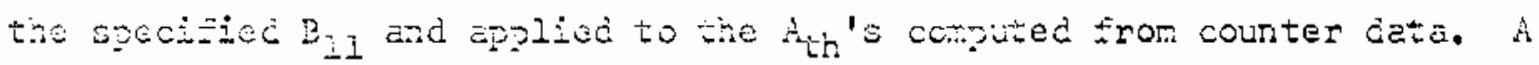

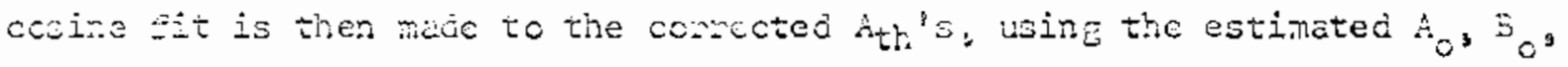
and $C_{0}$; thus obtainirg an output $A_{,} \Xi_{5}$ and $C$. If all three parameters meet

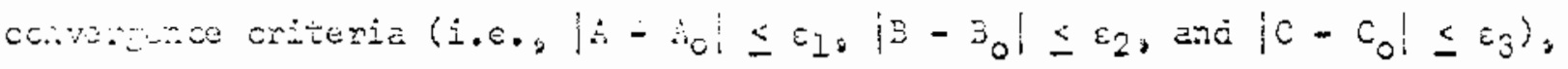


CQEIT2

Procedure - cont $^{\circ}$.

the results aro priated. It any of tin throe paramoters has rot convered, $A_{0}, B_{C}$ and $C_{0}$ are repiaced by $A_{0} D_{2}$ and $C_{5}$ and a rew cosine fit is made.

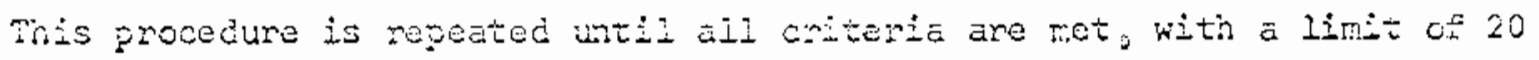
iterations. If the input option does not specizy dropping and points, tino program then continues to the next case.

If enc points are to be chopped, a converged fit is made omitting the point farthest from the sounce on eitier end of the traverse. Converged fits and then r...de with successive pairs of end points cropped until oniy n-10 ( on 3 , if $n$ (13) points remin. The case is then terminated.

In selectine enc points to be dropped, postitons excluded by input option from the oricinai cosine fit ane consdoned. Fon example; cowiter dzta were entered for ten positions, and ingut poiton spcofied the dropping of and points and the exclubion of one of the cutsicte points only. The first converged fit is nade with nine points (all except the excibud poirt). Converged fiss tinen arc nace with 8,6 , and 4 points. 
$\cos 12-\cos ^{2} \mathrm{~d}$

Fonmidation - Deta Reducticn

Corrected couting rates, Ach's, and coviting enror ane computed for each neasurement position by metiocs identical to those used in vioct. Equations $i-7$ apoly.

The litilization of the described date in a least squarec cosine fittine method also recuires computation of the quantity

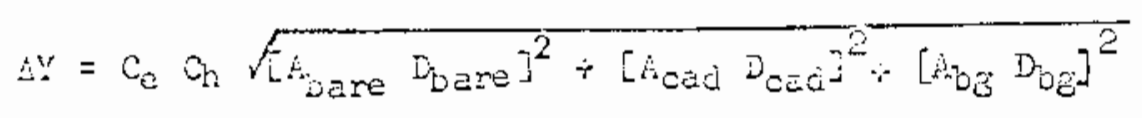

Fon a caimitirn shutter exporiment,

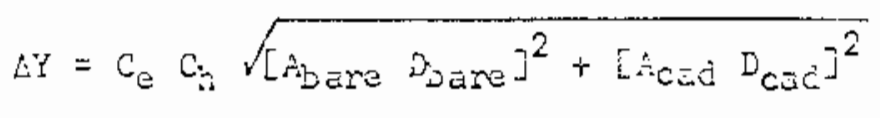

Eominition - Harmic and End Comections

Farnonic and end conpections are ccrputed fow oct. medeurement position by methoss icenticail to those used by VTeCL. Eglidions 17-37 apply.

Enmulation - Pencueter Estinatos

Sirce $i$ is the value of the flux at the cffective center of the pile, whe coce will we $C_{e} \hat{C}_{\mathrm{n}}$ Ath of the center pont (siot 03 ) as $A_{0}$. If no mesure-

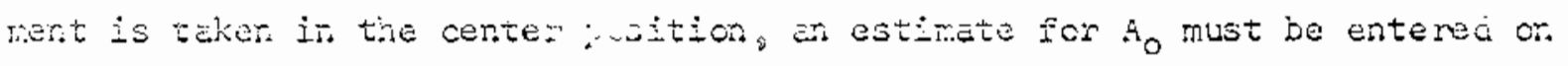
the data sheat. Fon a sice-to-sice theverse, the program computes

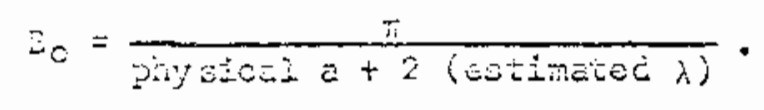

Eon a anco-jo-rocn traverse, jiysical b repiecos physical a in the above

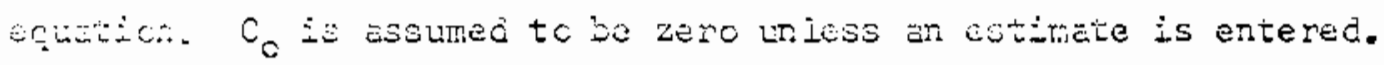




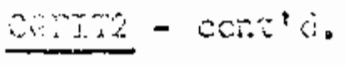

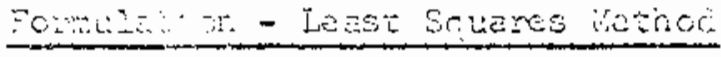

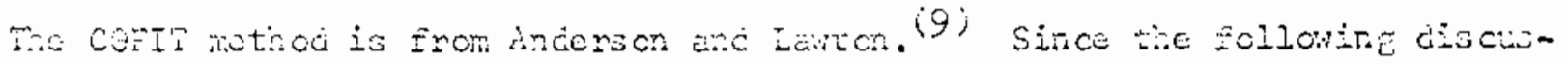

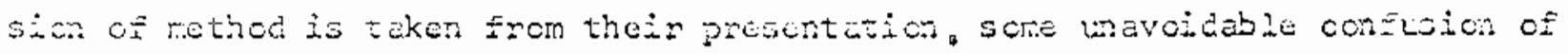

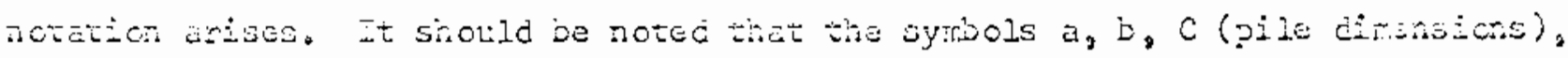

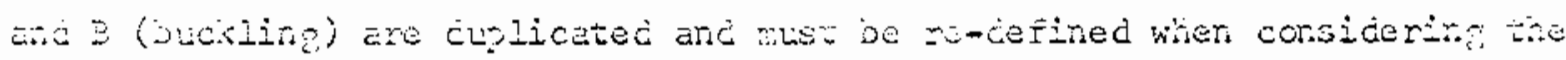
lenst a

in oncer to decemine extrepclation length, the thenel flux across the pis Is assumed to fit a cosine function of tre forn $y=A \cos [5(X-C)]$ whas $Y=$ contected thermal Flux and $x=$ signod dituce from pile centerleno to Wesurament positzon.

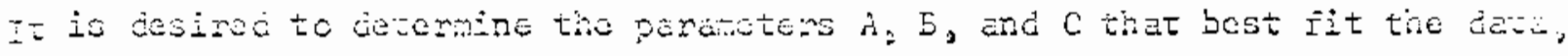

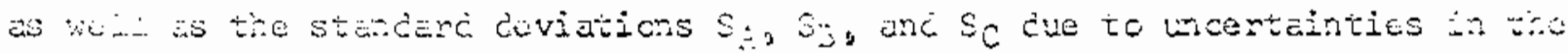

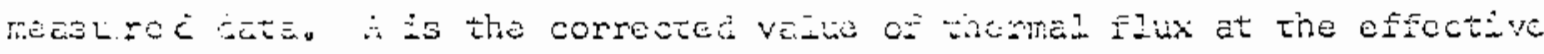
center of the zie. $C$ is the diepocument of the effective pile centen from

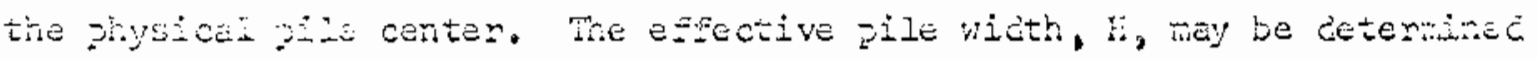

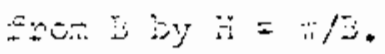

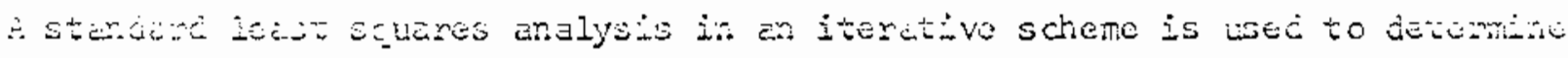

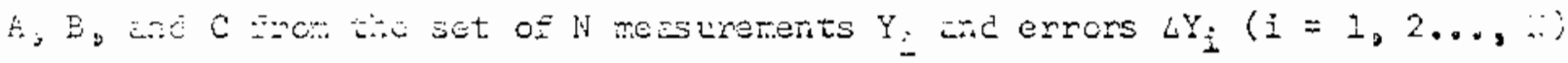

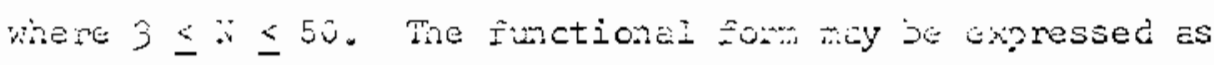

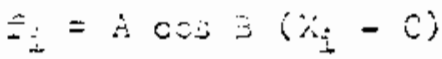

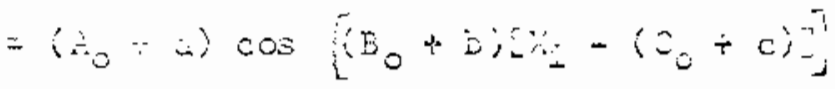

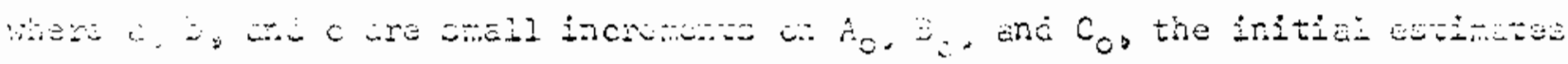

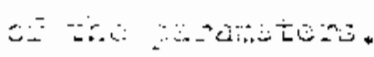


Cost2

Eormilation - Least Scuares Werhoc - cont'd.

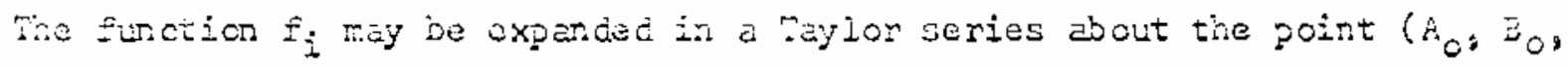
$\left.0_{0}\right)$

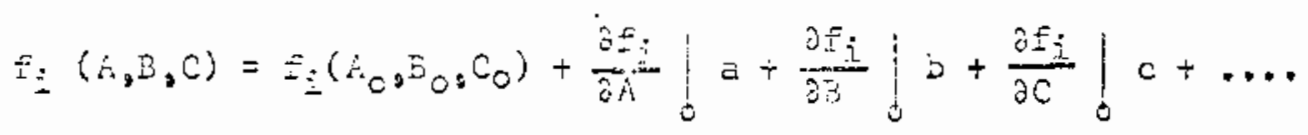

Define

$$
\frac{\partial \bar{I}_{i}}{\partial \mathrm{A}}=u_{i}, \frac{\partial \hat{f}_{i}}{i_{i}}=v_{i}, \frac{\partial E_{i}}{\partial C}=w_{i}
$$

then

$$
\begin{aligned}
& u_{i}=\cos \bar{B}_{0}\left(x_{i}-c_{0}\right)_{2} \\
& v_{i}=-\left(x_{i}-c_{0}\right) A_{0} \sin \bar{B}_{0}\left(x_{i}-c_{0}\right), \\
& w_{i}=A_{0} D_{0} \sin B_{0}\left(x_{i}-c_{0}\right) .
\end{aligned}
$$

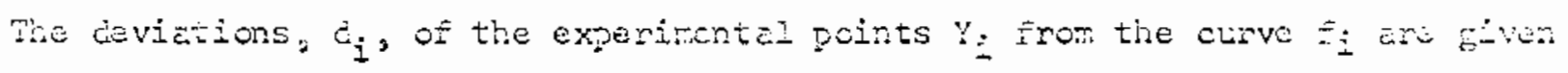
sy

$$
\begin{aligned}
& d_{i}=y_{i}-f_{i}\left(A_{c}, \hat{E}_{0}, c_{0}\right)-u_{i} a-v_{i} b-w_{i} c, \\
& d_{i}=F_{i}-u_{i} c-v_{i} j-w_{i} c .
\end{aligned}
$$

nisere

$$
F_{i}=Y_{i}-\hat{I}_{i}\left(A_{0}, \hat{B}_{0}, C_{0}\right)
$$

The least squared principio now assentz that the quantity

$$
\delta^{2}=\sum_{i=i}^{\infty} \sum_{i}^{2}
$$

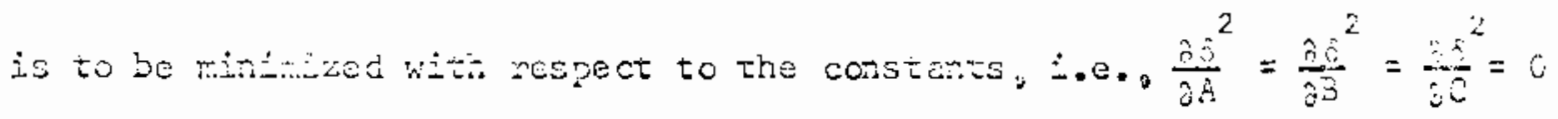
are the detirsis equations for $k, b, c$. 


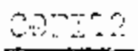

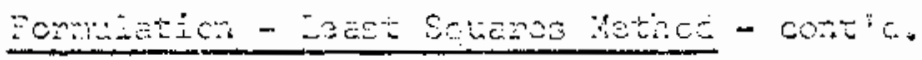

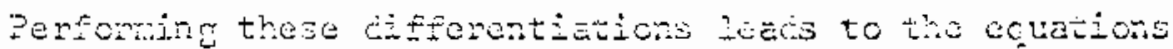

$$
\begin{aligned}
& \sum_{i} \sum_{i}^{2}\left(F_{i}-L_{i} a-v_{i} b-w_{i} c\right) u_{i}=0 \\
& \sum_{i=1}^{i} \sum_{i}^{2}\left(F_{i}-u_{i} a-v_{i} b-w_{i} c\right) v_{i}=0
\end{aligned}
$$

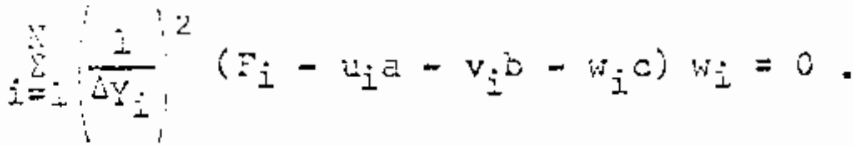

Setting

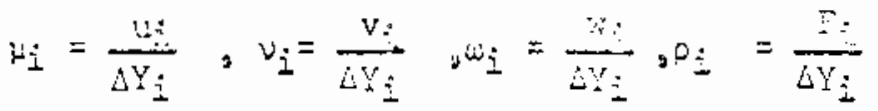

Eives the following scintons for as j, c.

$$
\begin{aligned}
& \left(p_{i} \mu_{i}\right)\left(\mu_{i} v_{i}\right)\left(\mu_{i} \omega_{i}\right) \\
& \left(p_{i} v_{i}\right)\left(v_{i} v_{i}\right)\left(v_{i} \omega_{i}\right) \\
& a=\frac{\left(p_{i} \omega_{i}\right)\left(\omega_{i} v_{i}\right)\left(\omega_{i} \omega_{i}\right)}{D} \text {. }
\end{aligned}
$$

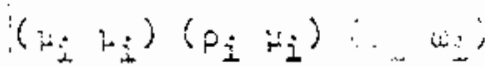

$$
\begin{aligned}
& \left(\mu v_{i}\right)\left(\rho_{i} v_{i}\right)\left(v_{i} \omega_{i}\right) \\
& t=\frac{\left(w_{i} w_{i}\right)\left(p_{i} \omega_{i}\right)\left(\omega_{i} w_{i}\right)}{D}, \\
& \left(i_{i} i_{i}\right)\left(i_{i} v_{i}\right)\left(p_{i} \mu_{i}\right) \\
& \left(\because i v_{i}\right)\left(v_{i} v_{i}\right)\left(p_{i} v_{i}\right) \\
& a=\frac{\left(\nu_{i} \omega_{i}\right)\left(v_{i} \omega_{i}\right)\left(p_{i} \omega_{i}\right)}{D} \text {, }
\end{aligned}
$$

nisco

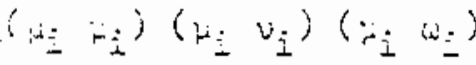

$$
\begin{aligned}
& D=\left(w_{i} v_{i}\right)\left(v_{i} v_{i}\right)\left(v_{i} u_{i}\right) \\
& \left(\ddot{m}_{i} \omega_{i}\right)\left(v_{i} \omega_{i}\right)\left(\omega_{i} \omega_{i}\right)
\end{aligned}
$$


$\cos z^{-2}-2$

Ponuiation - Loast Soliares Yethoc - cont'c.

and parentheses incicate sumaticn, $\dot{i} \cdot 0 .$,

$$
\left(\mu_{i} \mu_{i}\right)=\sum_{i=1}^{i} \dot{H}_{i} \mu_{i}
$$

By defining the following minors

$$
\begin{aligned}
& D_{I I}=\left(v_{i} v_{i}\right)\left(\omega_{i} u_{i}\right)-\left(v_{i} u_{i}\right)^{2} \\
& D_{22}=\left(\nu_{i} \dot{H}_{i}\right)\left(w_{i} \omega_{i}\right)-\left(\mu_{i} w_{i}\right)^{2} \text {. } \\
& D_{33}=\left(\mu_{i} u_{i}\right)\left(v_{i} v_{i}\right)-\left(v_{i} i_{i}\right)^{2} \\
& D_{12}=D_{21}=\left(\omega_{i} v_{i}\right)\left(H_{i} w_{i}\right)-\left(w_{i} v_{i}\right)\left(w_{i} w_{i}\right), \\
& D_{13}=D_{31}=\left(i_{i} v_{i}\right)\left(v_{i} \omega_{i}\right)-\left(\mu_{i} \omega_{i}\right)\left(v_{i} v_{i}\right) \text {, } \\
& \tilde{L}_{23}=D_{32}=\left(v_{i} \dot{i}_{i}\right)\left(\mu_{i} \dot{u}_{i}\right)-\left(y_{i} \mu_{i}\right)\left(v_{i} \dot{u}_{i}\right),
\end{aligned}
$$

$a, b, c$, in $;$ be expressed as

$$
\begin{aligned}
& a=\frac{\left(\rho_{i} p_{i}\right) D_{12}+\left(\rho_{i} \nu_{i}\right) D_{1}+\left(\rho_{i} \omega_{i}\right) D_{2} 2}{D} \\
& \mathrm{~b}=\frac{\left(\rho_{i} \psi_{i}\right) D_{12}+\left(\rho_{i} \nu_{i}\right) \nu_{22}+\left(P_{i} u_{i}\right) D_{23}}{D} \\
& 0=\frac{\left(P_{i} \nu_{i}\right) D_{13}+\left(p_{i} \nu_{i}\right) D_{23}+\left(P_{i} v_{i j}\right) D_{33}}{D},
\end{aligned}
$$

whers

$$
D=\left(\mu_{i j}\right) D_{i 2}+\left(\mu_{i} v_{i}\right) D_{i 2}+\left(\mu_{i} \omega_{i}\right) D_{13}
$$

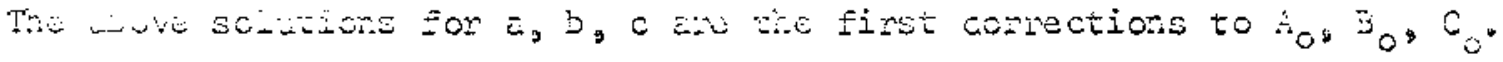

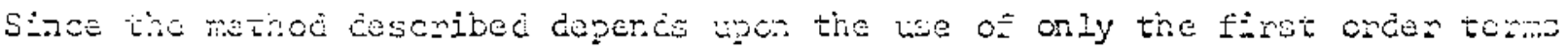

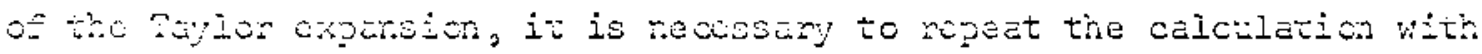

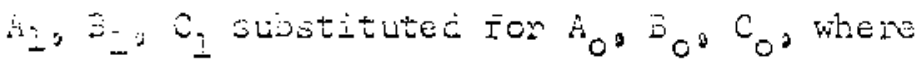

$$
r_{1}=\hat{A}_{0}+a_{2} \quad B_{1}=E_{0}+b_{3} \quad C_{I}=c_{0}+c .
$$


$\underline{-\cdots \cdot 2}$

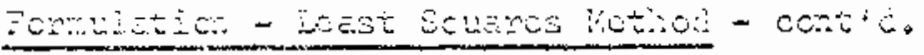

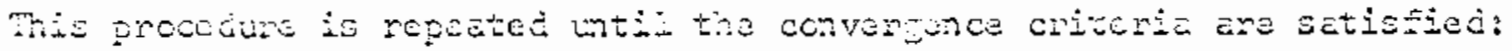

$$
\frac{A-B_{n-1}}{A_{n-1}}<\varepsilon_{1} \quad \frac{B_{n}-\ddot{B}_{n-1}}{B_{n-1}}<\varepsilon_{2} \quad \frac{C_{n}-C_{n-1}}{C_{n-1}}<\varepsilon_{3} .
$$

Nesures of the error in $A, E_{0}$ and $C$ die to inaccuracy in the values of $Y_{i}$ are giver by the guantivies
$A F=\sqrt{\frac{512}{D}}$
$\Delta=\sqrt{\frac{22}{2}}$
$L C=\frac{D_{33}}{D}$
$(43,44 ; 45)$

The standard deviations of the estimatce Ecr $A, 3, C$ are calculated by

$$
\begin{aligned}
& s_{A}=\Delta+\sqrt{\frac{2}{1-3}} \\
& S_{3}=\Delta \frac{2}{x_{-3}} \\
& S_{C}=\Delta q \sqrt{\frac{2}{6-3}} \quad(40.47,40)
\end{aligned}
$$

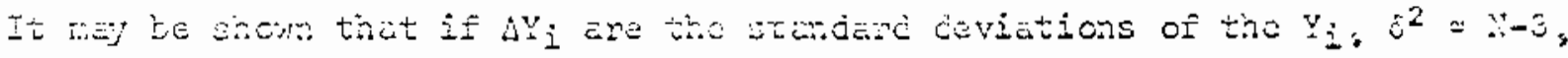
and $B_{B}=\Delta A, S_{B}=\Delta \Xi, S_{C}=\Delta C$.

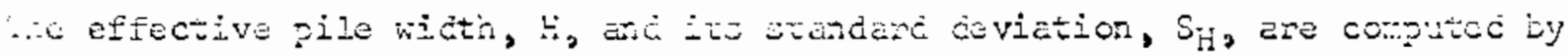

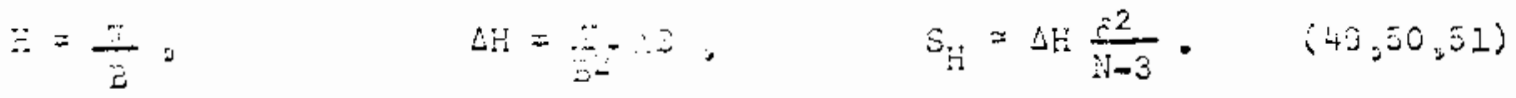

The averge extrapolation, $\bar{\lambda}$, is coputed fincm by

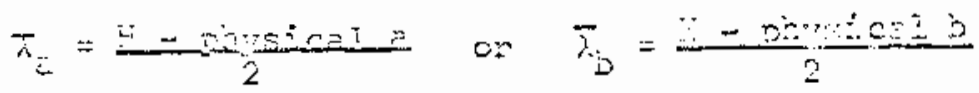

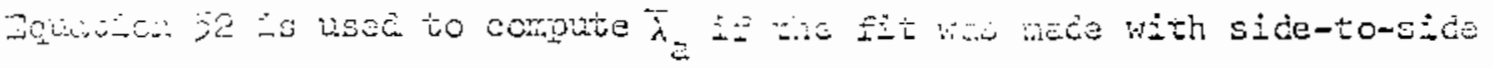

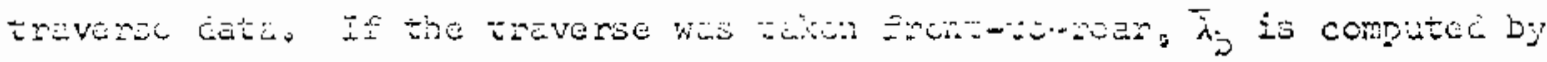

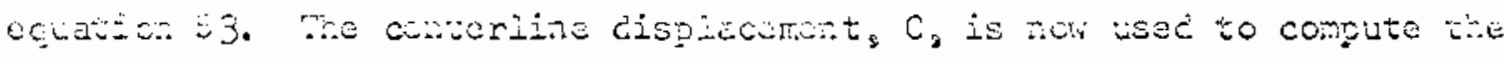

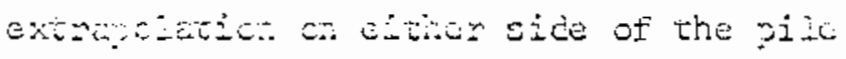

$$
\lambda_{i-i}=\bar{\lambda}_{z}+c \quad \text { or } \quad \dot{\lambda}_{j+}=\bar{\lambda}_{j}+c
$$

$\therefore:$

$$
\therefore=\bar{\lambda}_{c}-c \quad \lambda_{j_{-}}=\bar{\lambda}_{j}-c
$$


$\frac{\cos 2-2}{2}-\cos ^{\prime} \dot{s}^{2}$

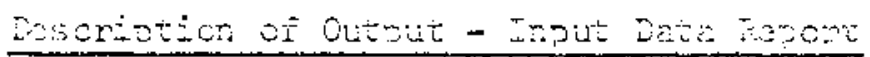

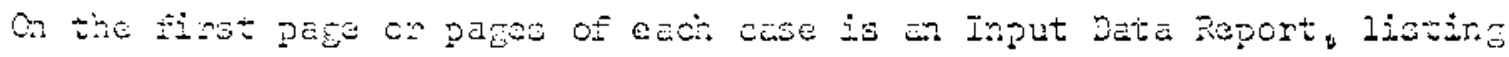
input parameters vith sufficient explanatory material to forn a valuble adition to the permenest output record. This report also provides assistance in tracing possidie trput enors. Included are all identificaticn cards, pile dimensions, source positions and strenghs, detector positions, initia

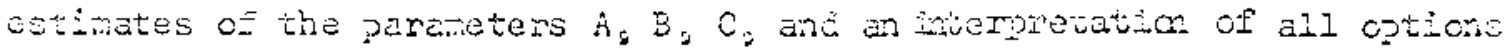
winch were slected.

Description of Outnut - Corrections ondy

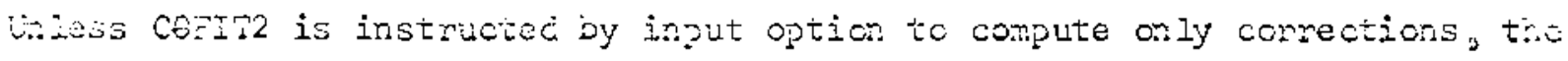
prozar proceds to the Data Reduction Report. If only ccrrections are to De compted, the Input Data kepor is sollower by a listing of corpter cormections, âter which the progrex goes on to the next cese. The ropert of

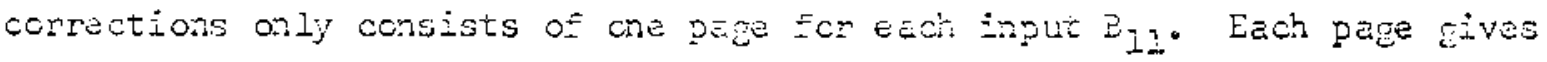
the following information Pon eveny masurement positinon:

20s Kescrement posizion number

$$
\begin{aligned}
& \text { X-PRIIE? } \\
& y-P R I Y=j\left(x^{\prime}, y^{\prime}\right), \text { deteotor pesiticis } \\
& \text { of } \left.\quad C_{e} \text {, whe consetion (2quetion } 20 \text { on } 29\right) \\
& \text { Cit Ch, ammoric correction (Equiticn } 19,25,31 \text {, on 32) } \\
& \cos \quad \mathrm{cos}_{\mathrm{s}}
\end{aligned}
$$

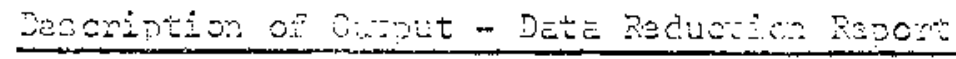

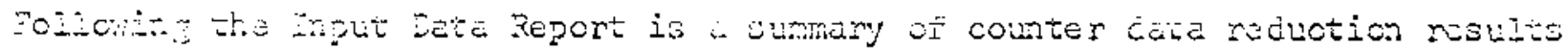

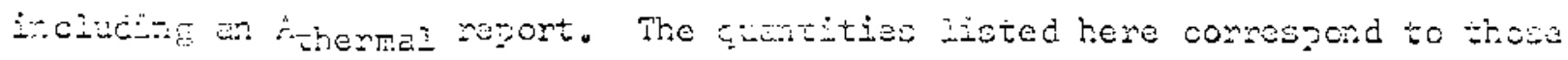

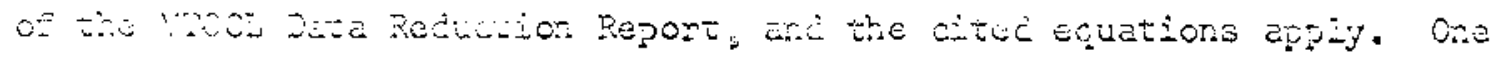


$+2$

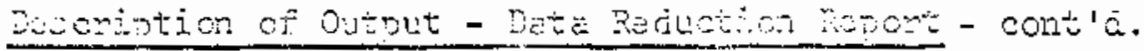

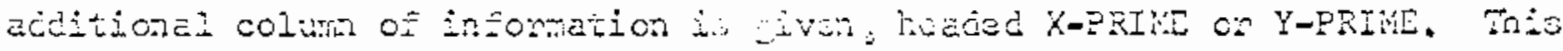

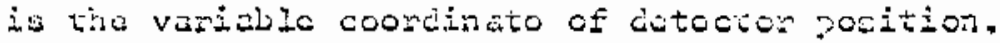

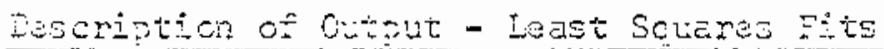

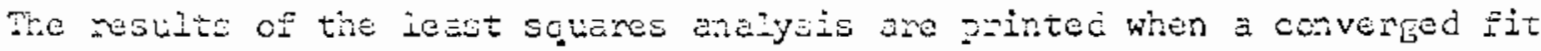

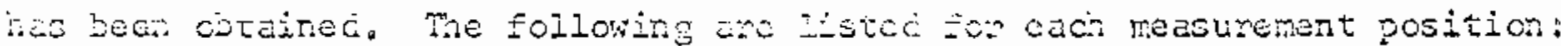

POS

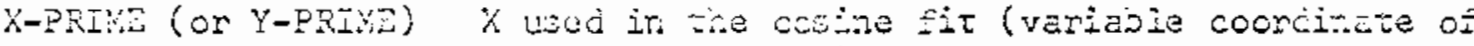

CORK A-TRERUAL

DEITA Y

$Y / \therefore$

$\cos 3(x-c)$

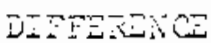

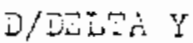

Bulow this ent listed

$\therefore \hat{0}$

is

$5-S U_{j}^{*}-5$

EO

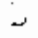

$\because-8 v-3$

93

2

$3-30-6$ detostor positicn)

resuruman positon nuber

Y lisec an tive cosine fit $\left(=A_{\text {in }} C_{e} C_{h}\right)$

il wed in wh cosine fit (Equation ts on as)

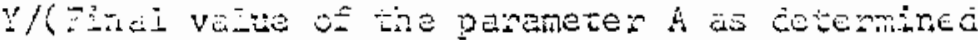

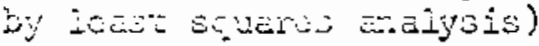

Cos $3(x-C)$ comsted from firal vaines of tho paramsing

$Y / A-\cos (x-6)$

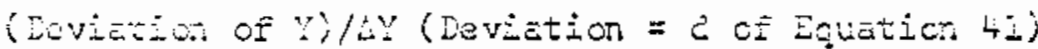

Initiaj estimato of the parameten A

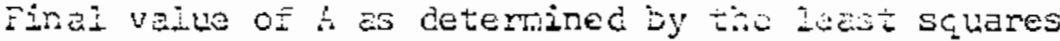
ar.zysis

$S_{\dot{H}}($ Esuction

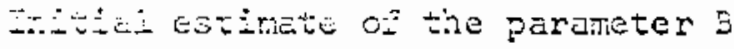

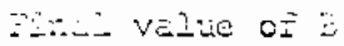

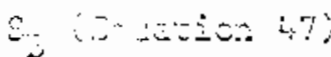

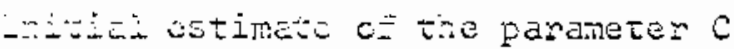

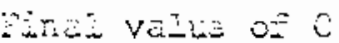

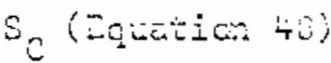




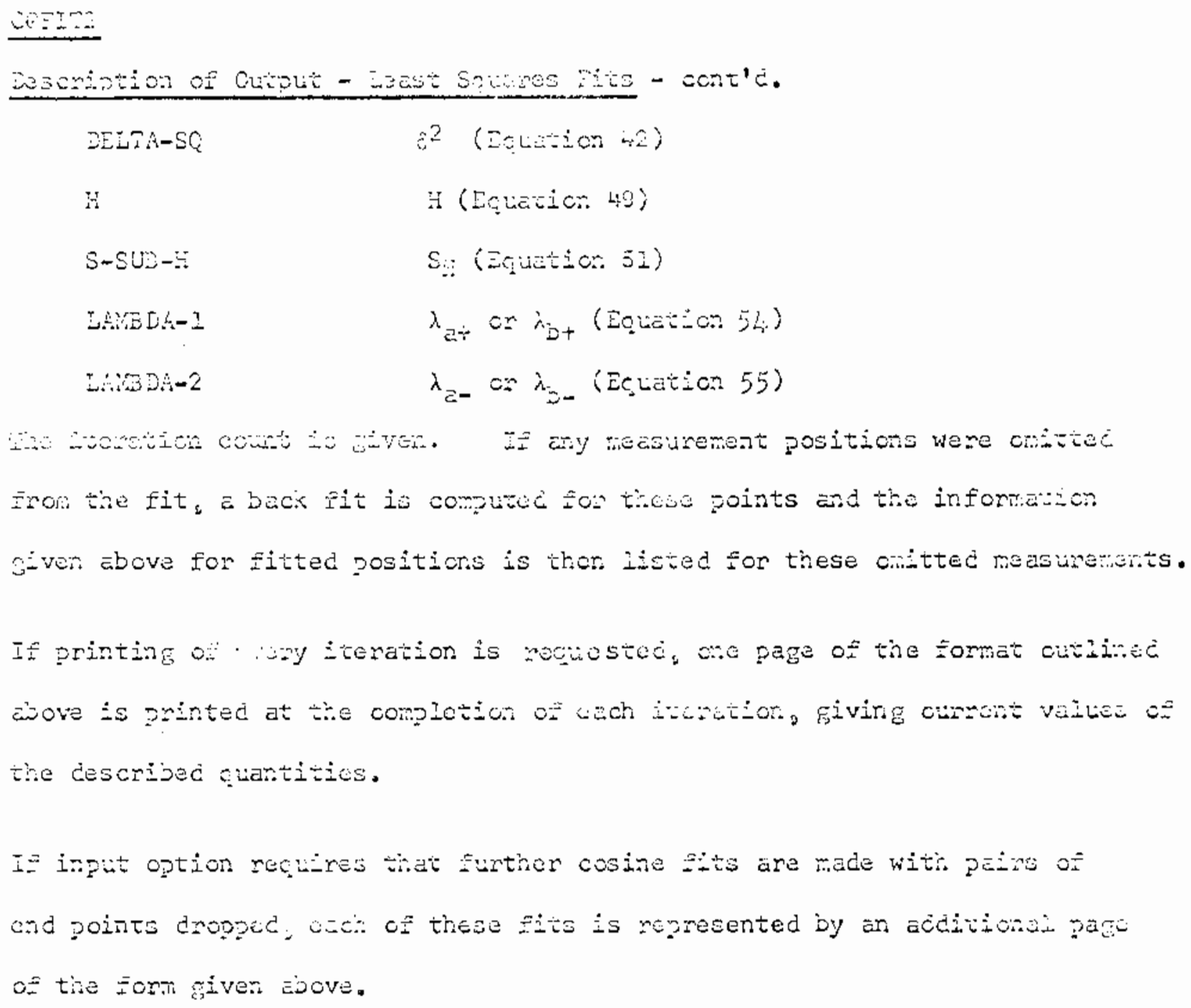


BVTECO

Purpose

The code determines vertical extranolation length, either alone or in conination with the determination of one or both horizontal axtrapolations. Becuse $3 V T \theta c \theta$ (Both UTECe and CEFIT) utilizes the functional portions of both the other codes, traverses in all three directions nay be processed in one pass. The code is designed to accept complete packets of VIOCe or CEFI'2 cards so that these cases may be kept intact for ituture reference. 
$\sin -\cos 20^{\circ} \mathrm{d}$

otions

BVmoso determires ventical extrapolation and may also determine honizotad extrapaition in either on both directions. mis multipie option is implied by the proguar: from the presence on absence of horizontal tnaverse data. Vurical and horizontal options, suoh as the omission of centait dietc points,

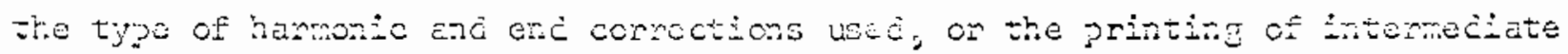

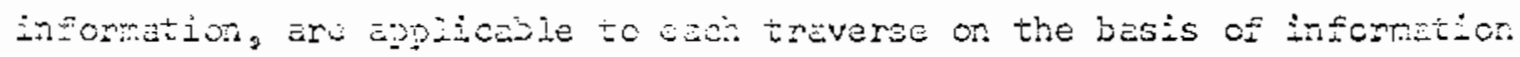

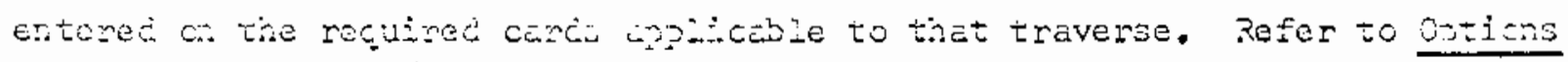
o: Doth VTeCL a.d CePTr.

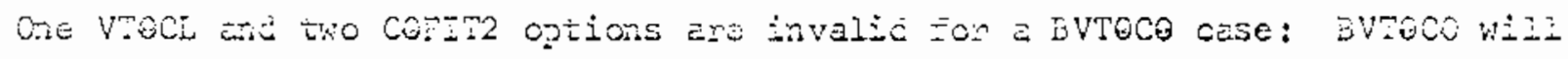
not compute conections only in aither the hontuntal on vertical dinection. ard successivo sets of end points cenot be cropod hom a horizontal treverse $0^{2}=84000000$

Prectins-3eses

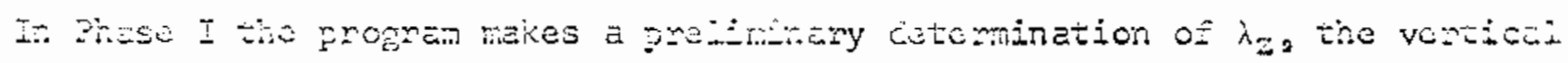

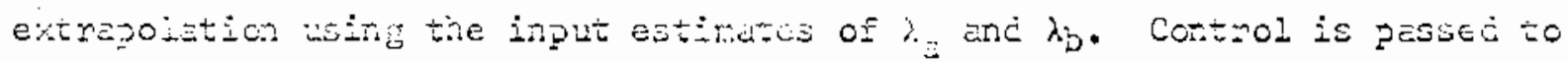

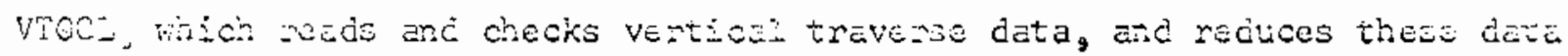

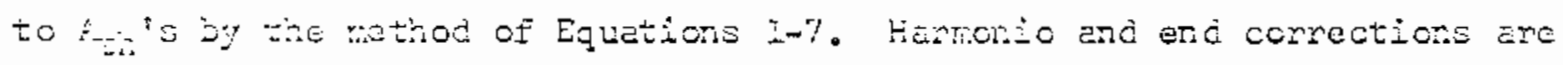

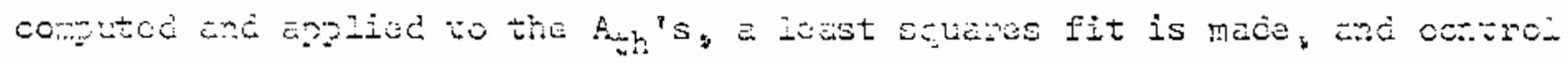

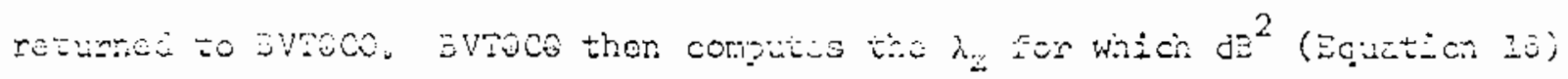

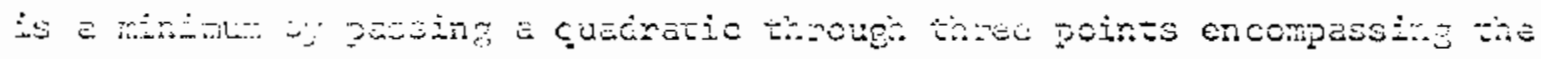

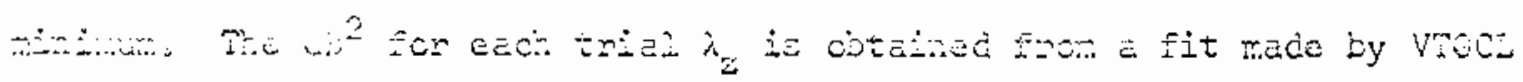

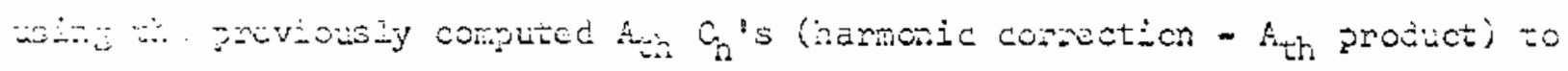

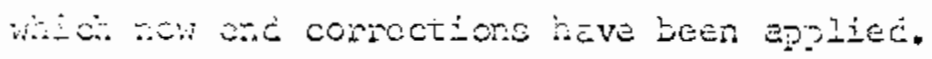

a. thex socificaliy excluced by thout option. 
BVTGCe - cont'd.

Procecure - Phase II

In Phase II, the horizontal extrapolations, $\lambda_{a}$ and $\lambda_{b}$ are determined using, the $\lambda_{z}$ determined by Phase I. Phase II is omitted if no horizontal traverses are included in the case. Similarly, if only one horizontal traverse is included, only the extrapolation measured by that traverse is computed.

Each horizontal traverse is processed by relinquishing control to COFIT2, which reads, checks, and fits the data by the standard cerIT2 procedure, omitting from the least squares cosine fit those points specified by input option. After traverse is completely processed, control is retumed to BVTeCe, which determines by examining following input whether to go on to Phase III or to call CeFIT2 back to process another horizontal case.

Procecure - Phase III

The final determination of $\lambda_{z}$ is made in Phase III. If the case includes no horizontal traverse. Phase III is omitted since the preliminary detemination of $\lambda_{z}$ made in Phase $I$ is also the final one. Phase III uses the best known values of $\lambda_{a}$ and $\lambda_{b}$; that is, the input estimate of either is used only if none was computed from horizontal traverse data.

The procedure for final determination of $\lambda_{2}$ is identical to that of the preliminary determination in Phase I, except that the vertical traverse data are already reduced to $A_{t h}$ 's.

Formiliation

All equations for data reduction, harmonic and end corrections, and methods $0_{2}^{\circ}$ ic ust squares are as given under VTOCL and CөFIT2 formulation. 
SViece $-\operatorname{cont} ' d$.

Description of Output - Phase I

sice from additional heading information, Phase I output is substantially

the same as standard VTӨCL output through the Input Data Report and the Data Reduction Report. Following are reports of each least squares flt computed during the seareh for a minimum $d^{2}$. Each of these gives the values of $\lambda_{a}, \lambda_{b}$, and $\lambda_{z}$ with which it was computed. A summary of these fits is then given listing for each fit:

EFFECTIV $8 \quad z$ (effective pile height) used in this fit

311 (IN)

(OUT) $\}$ Input and output $B_{11}$ 's

BUCKLING Output B (Equation 14)

LAMBDA $z(C M),) \lambda_{z}$ (in cr. and inches), vertical extrapolation used (IN.) $y^{\prime}$ in this fit

D $\mathrm{B}-\mathrm{SQ} \quad \mathrm{dB}^{2}$ (Equation 16 )

The last report of Phase $I$ is the results of the fit made with the $\lambda_{z}$ which is prosicted to produce a minimum $\mathrm{dB}^{2}$.

\section{Descrigtion of Output - Phase II}

The output of Phase II consists of one set of COFIT2 output for each horizontal traverse of BVTeCe case.

Description of Output - Phase III

Phase III output is identical in form to that of Phase I. It consists of a series of fits to the vertical data, using the values of $\lambda_{a}$ and $\lambda_{b}$ computed in Phace II. The last two pages of Phase III are a summary of fits and the final fit made with the best values of $\lambda_{a}, \lambda_{b}$, and $\lambda_{z}$. 


\section{$-3 \div-$}

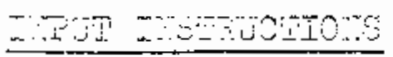

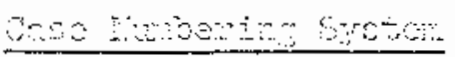

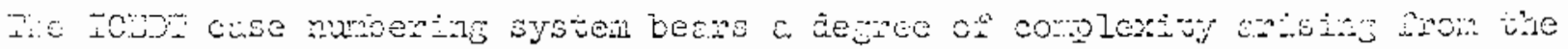

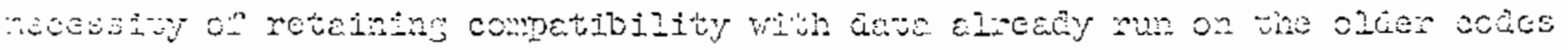

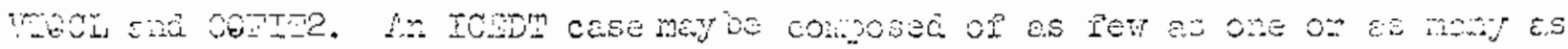

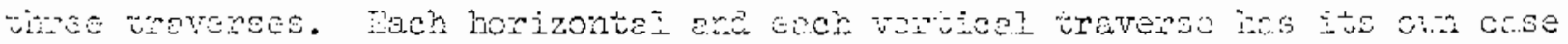

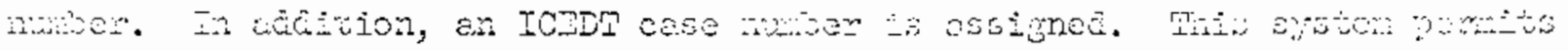

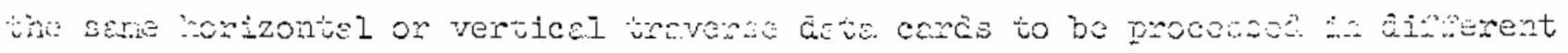

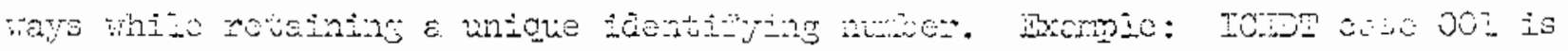

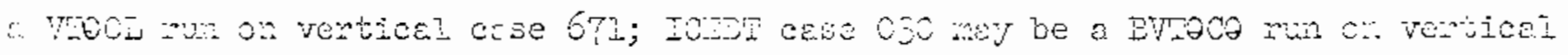

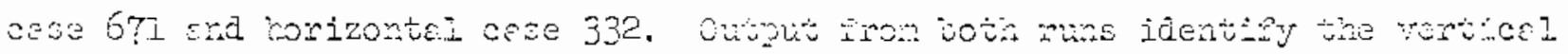

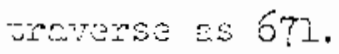

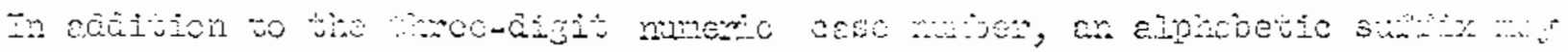

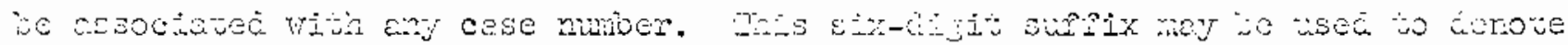
romen, comectione, otc.

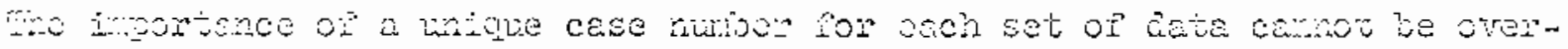

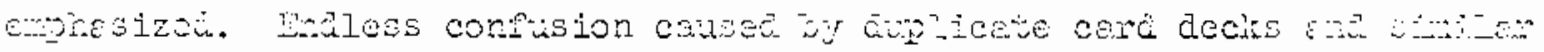

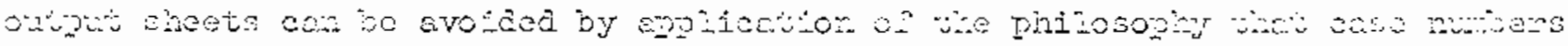

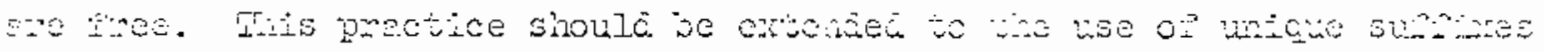

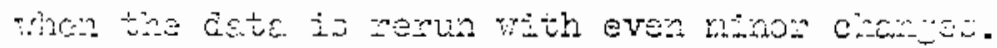




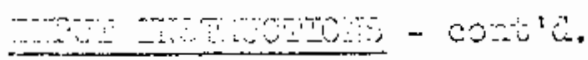

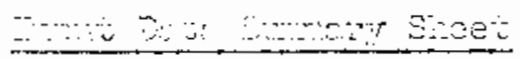

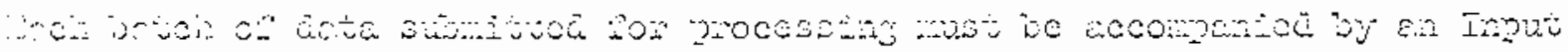

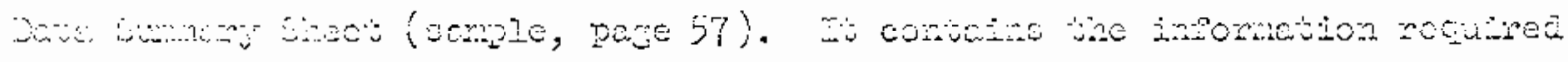

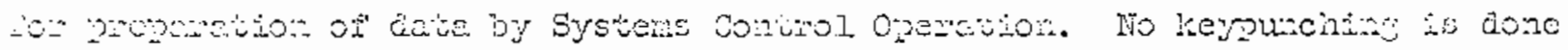

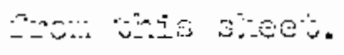

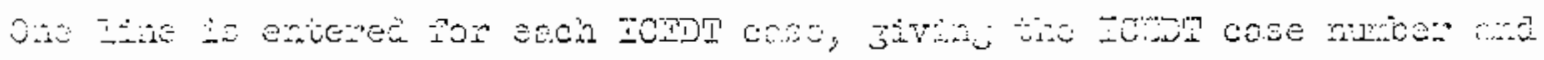

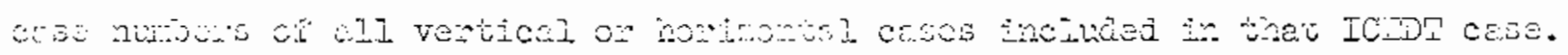

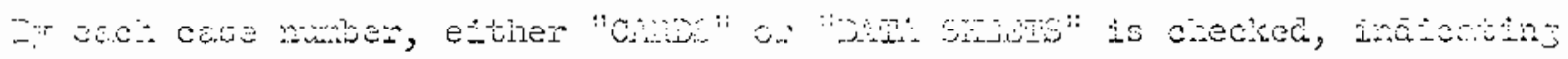

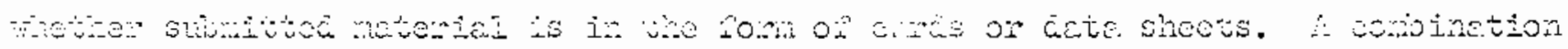

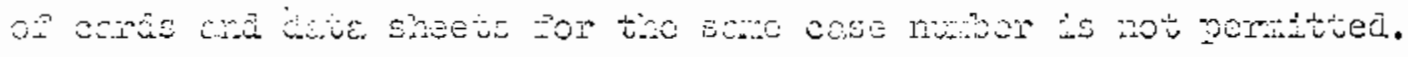

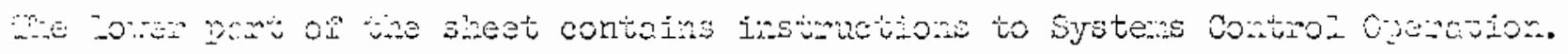

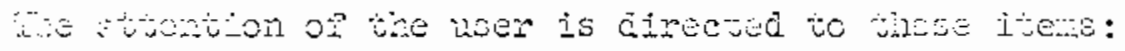

I*E: I:

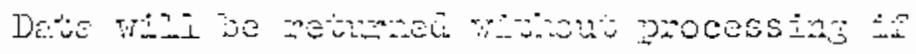

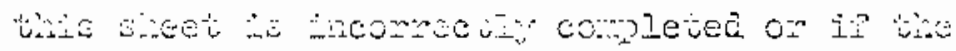

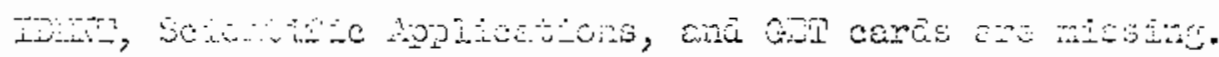
- 20.

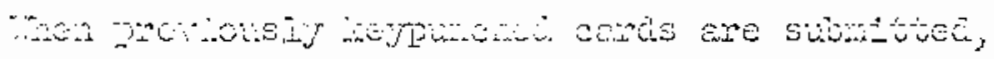

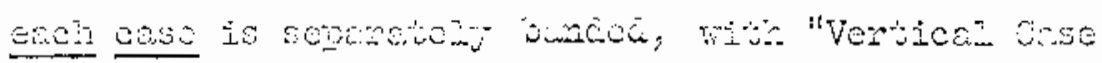

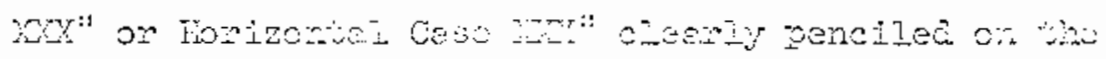

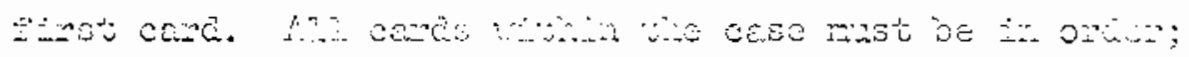

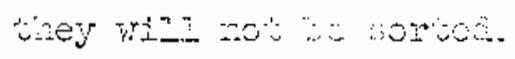

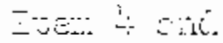
coctiots:

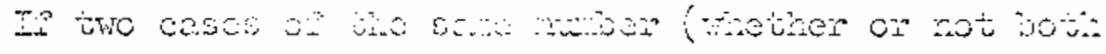

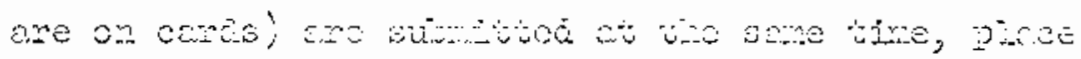

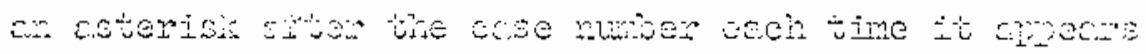

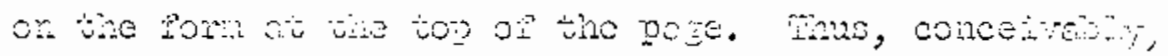

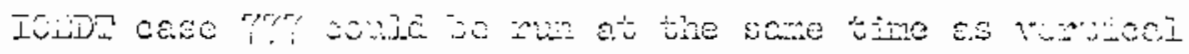

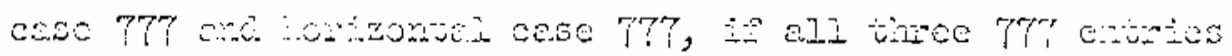
or tide fon ase stanos. 
ind

$\because 20000-80001$

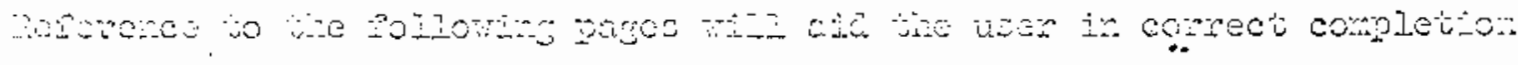

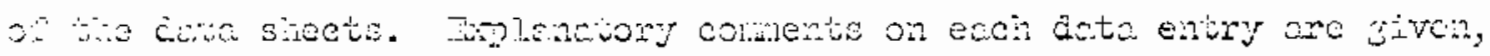

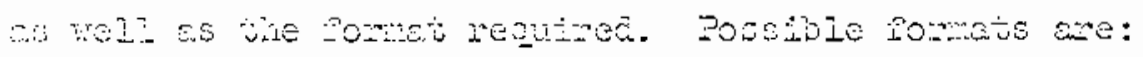

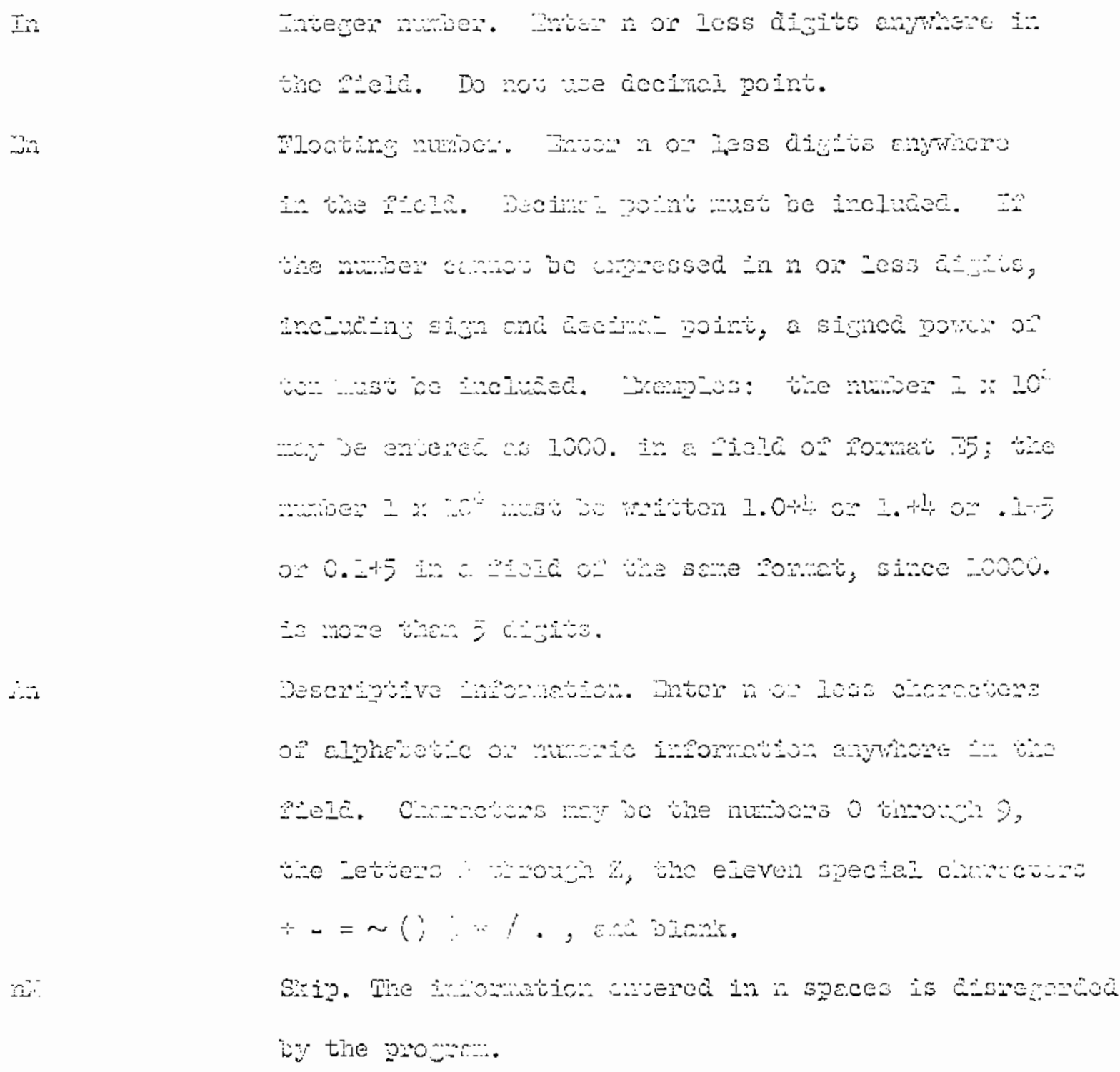


-

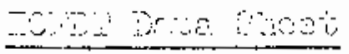

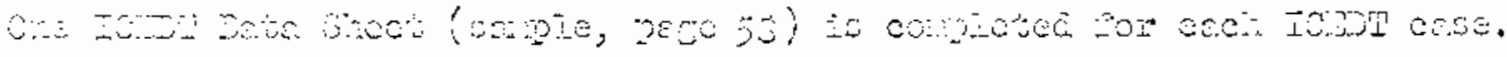

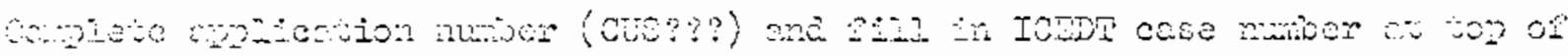

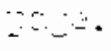

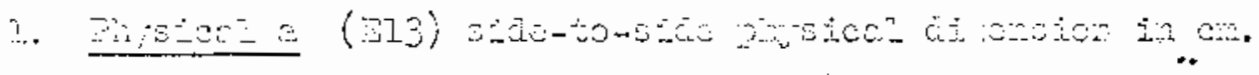

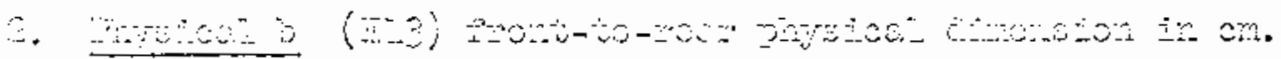

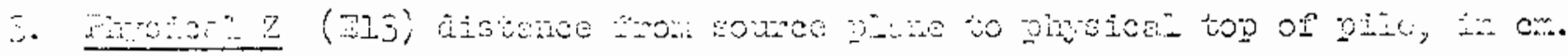

$\because$ mased at presento $(3-3)$.

5. cose. If oter une $\mathrm{g}$, ow 0 -

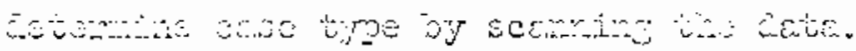

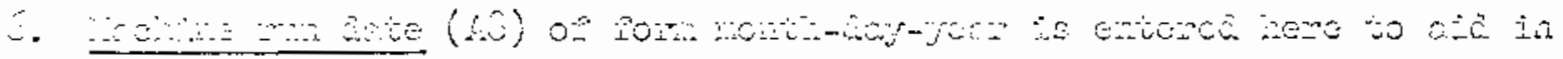

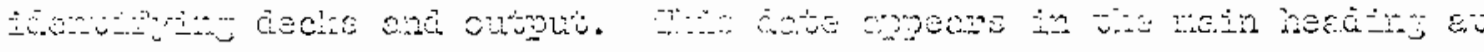

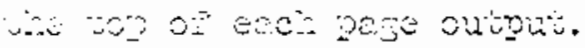

$\because$. -

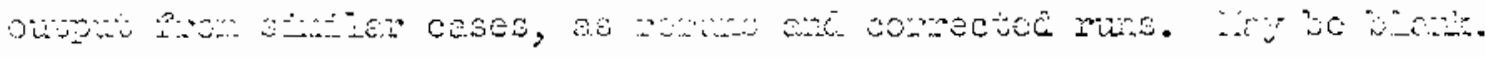
Min os own.

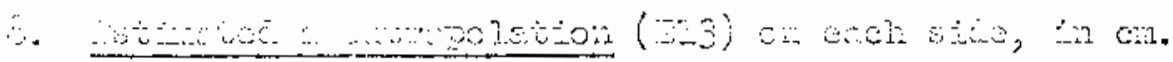

S.

20.

H.

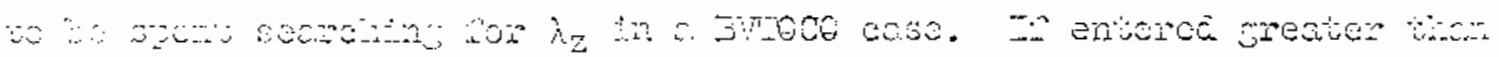
\#. G. and esses.

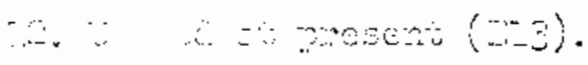

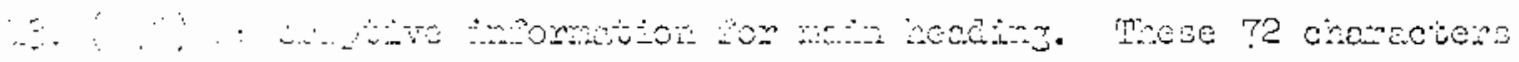

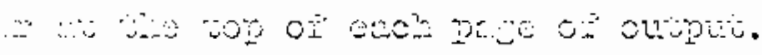




\section{$-\hat{3 i-}$}

A.w.

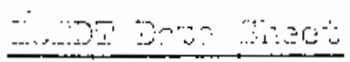

-

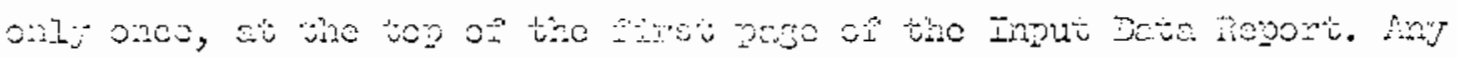

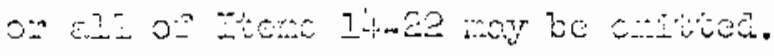




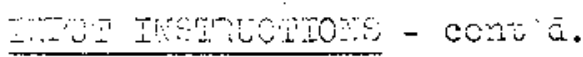

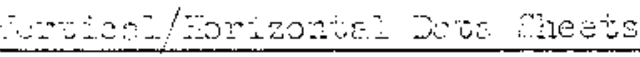

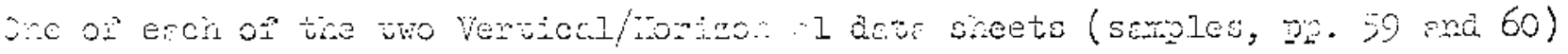

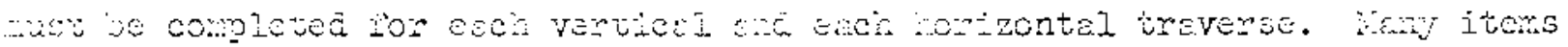

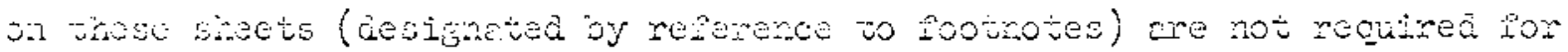

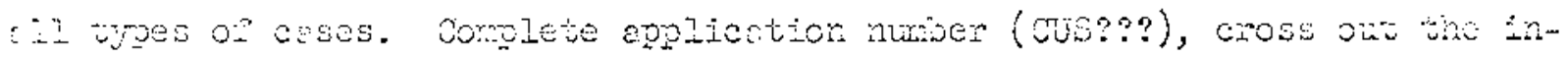

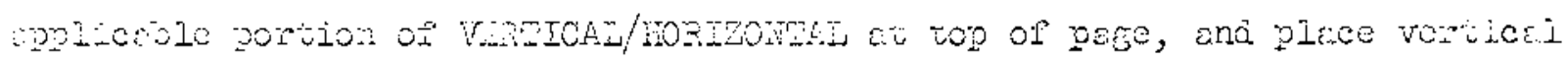

in romizonel cose nuber in spece bating.

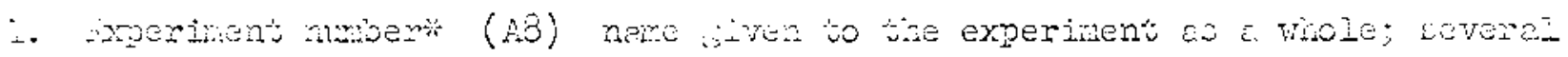

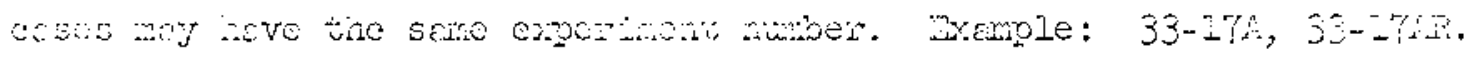

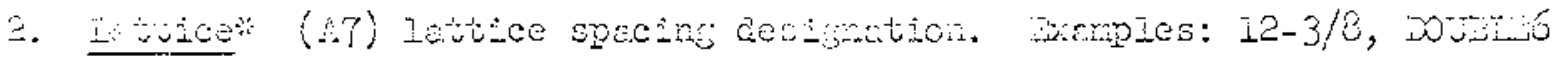

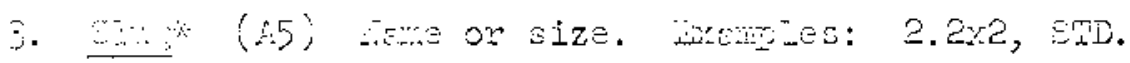

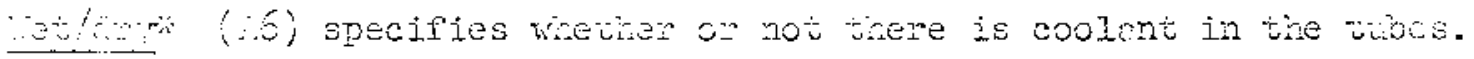

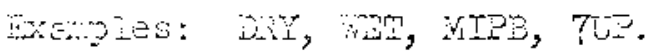

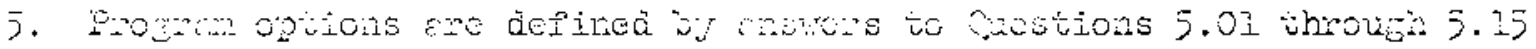

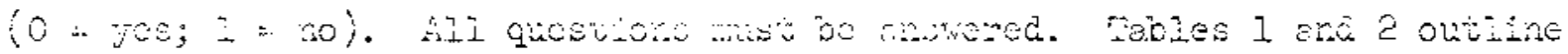

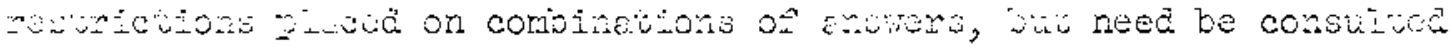

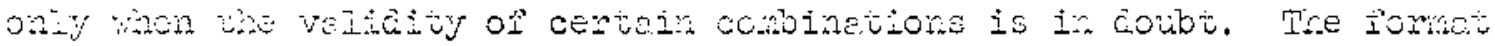
Sor exch Eanera

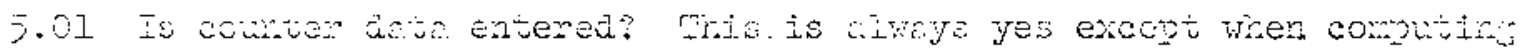

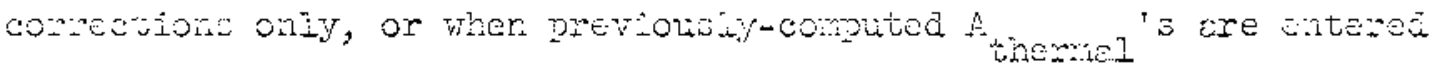

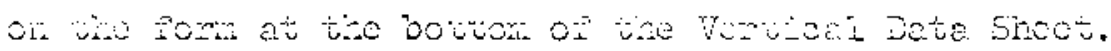

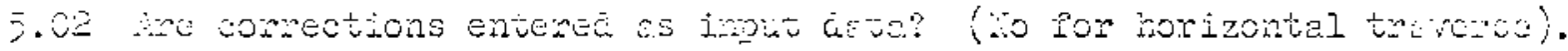

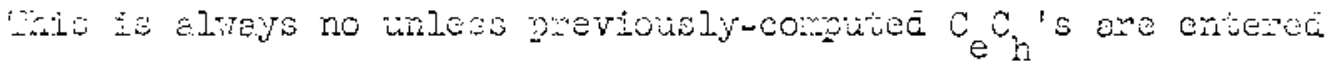

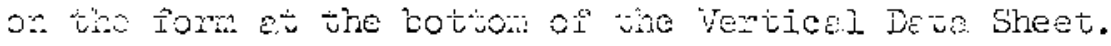




\section{INPUT INSTRUCTIONS}

\section{Vertical/Horizontal Data Sheets - cont'd.}

5.03 Cadmium shutter method? The answer to this question determines whether $\mathrm{J}_{\mathrm{nm}}$ is computed by Equation 34 or 35 in computation of fast source $\mathrm{C}_{\mathrm{e}} \mathrm{C}_{\mathrm{h}}$.

5.04 Is a trial $B_{11}$ suggested? (Yes for C-cases). The program makes its own initial estimate if this is answered no for a verttcal traverse.

5.05 Calculate corrections only? If yes, harmonic and end corrections are computed and printed usling the $\mathrm{B}_{11}$ from Question 26 , and according to instructions given by Questions $5.03,5.06,5.07,5.11$, and 5.12. The $B_{11}$ is then increased by the $B_{11}$ increment (question 27), the number of $\mathrm{B}_{11}{ }^{\mathrm{S}} \mathrm{s}$ (Question 10) decreased by one, and another set of corrections computed with the incremented $B_{11}$ if the number of $B_{11}$ 's $>0$. Th1s procedure is repeated until the number of $B_{11}$ 's is reduced to zero. See example given for question 27. Note: if Question $5.05=0$ for a horizontal case, $x^{\prime}$ or $y^{\prime}$ must be entered on the Horizontal Data Sheet as explained on page 50 .

5.06 Use 2uregion harmonic corrections? This determines the method of computing $C_{h}$. Yes indicates that a base region is present under the measurement region.

5.07 Use 2-region end corrections? This determines the method of computing $C_{e}$. Yes indicates that another region is present above the measurement region.

5.08 All corrections $=1.0 ?$ (No for vertical traverse). Yes sets $C_{e} C_{h}=1.0$ at all points of a horizontal traverse.

5.09 Print intermediate information? If yes, certain intermediate portions of the end and harmonic correction calculations are printed. It should never be necessary to use this as long as the program remains in its relatively stable state. 


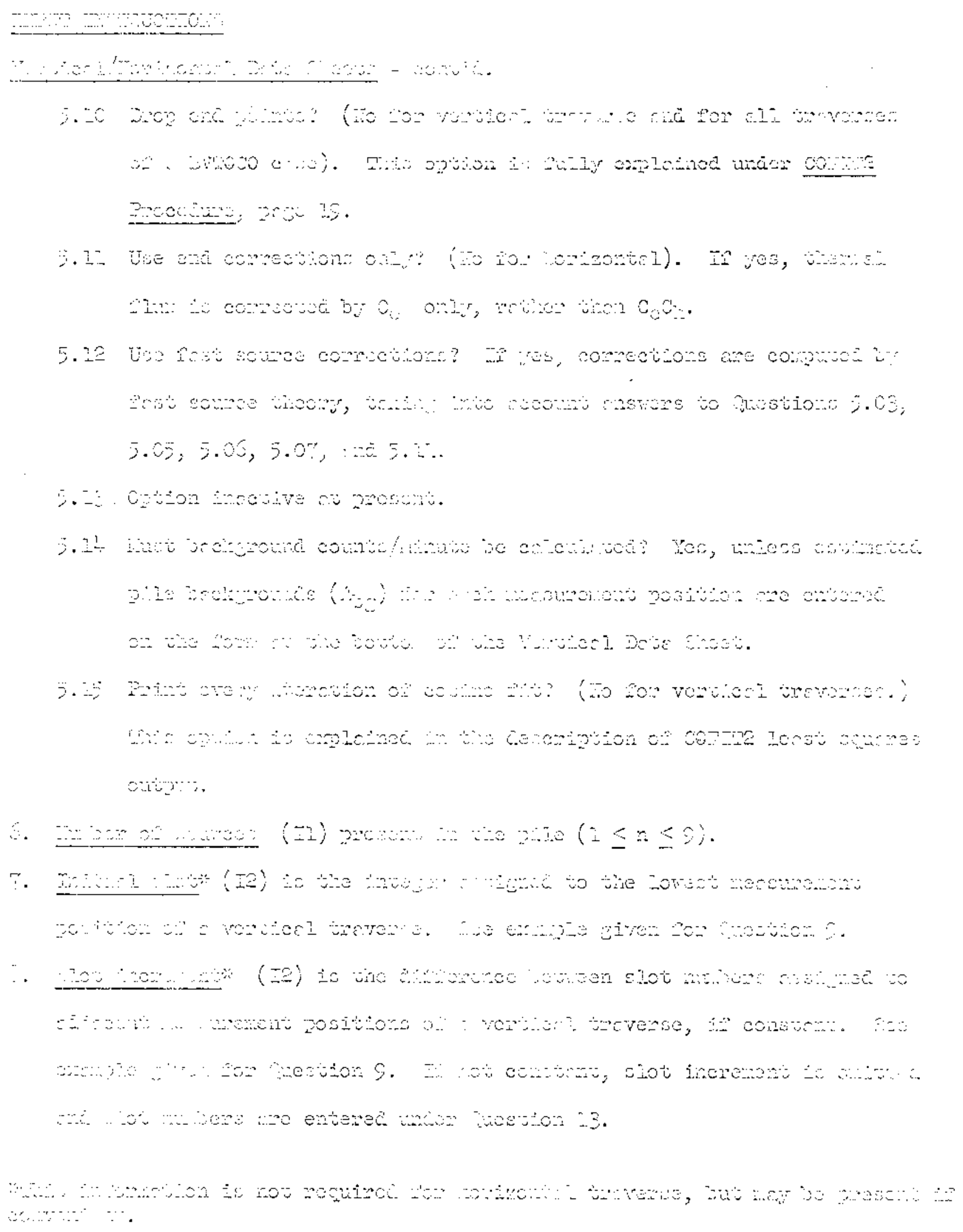




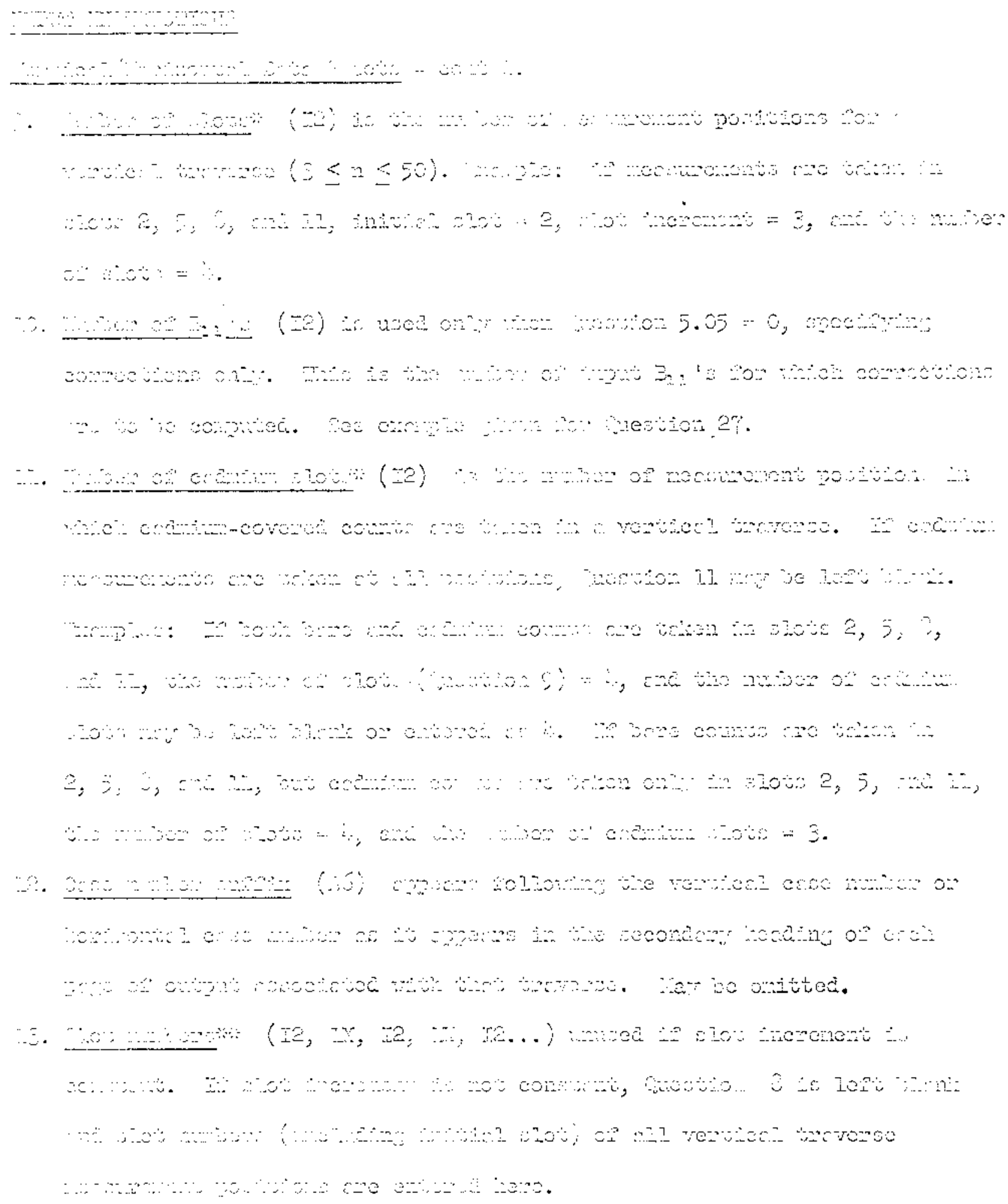




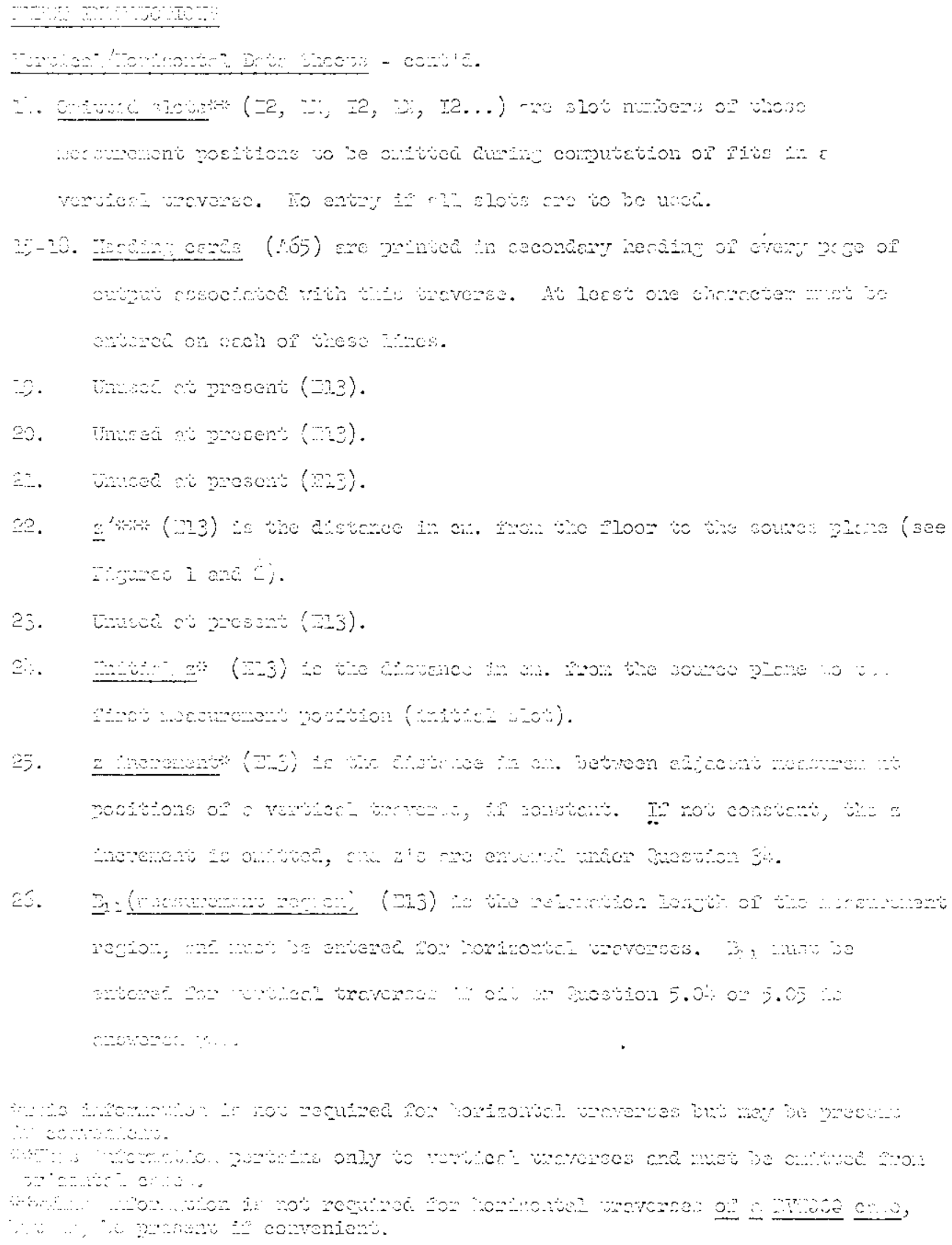




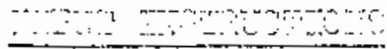

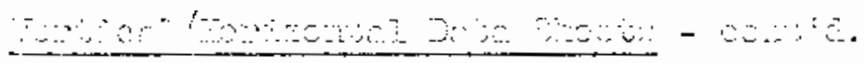

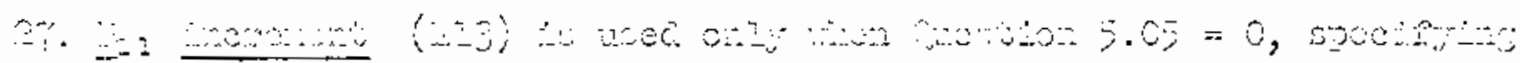

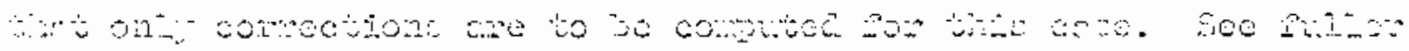

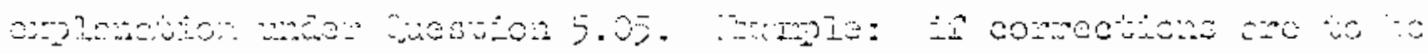

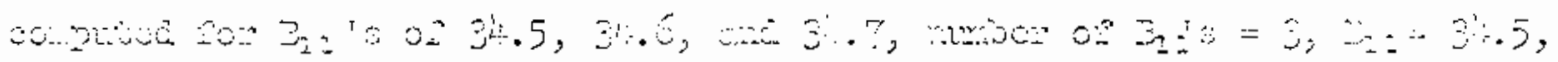

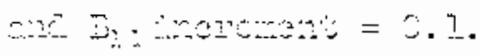

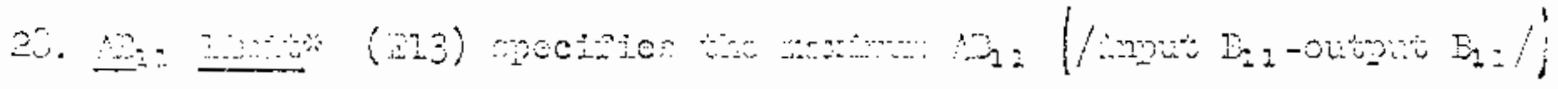

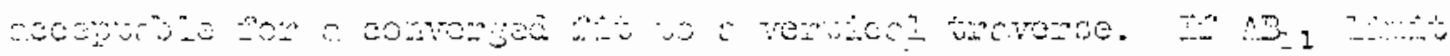

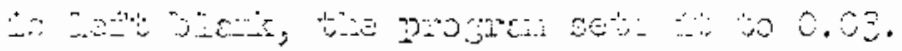

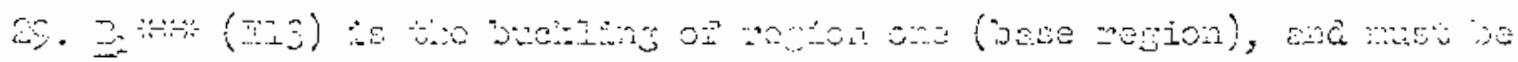

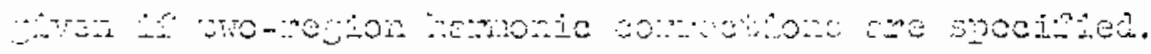

So.

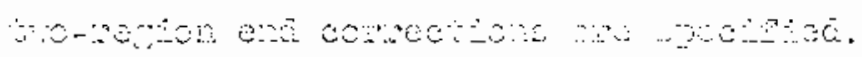

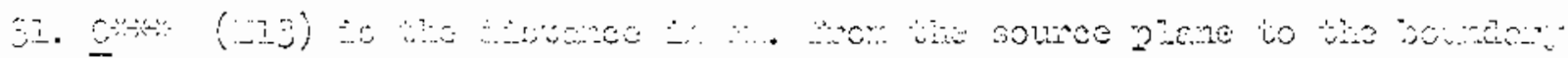

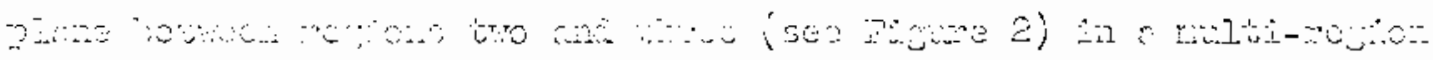

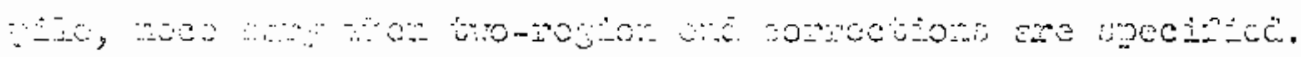

2ar a

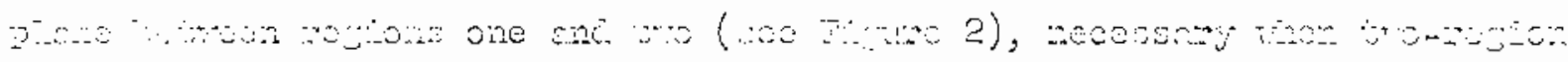

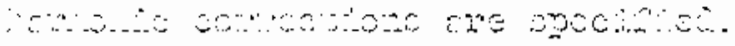

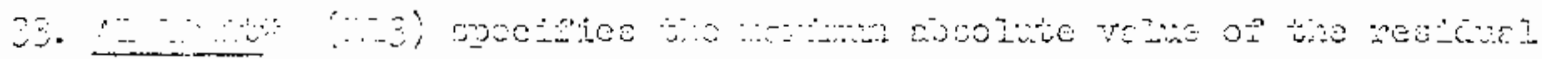

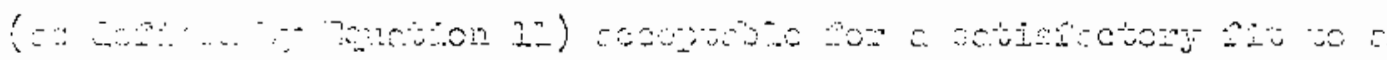

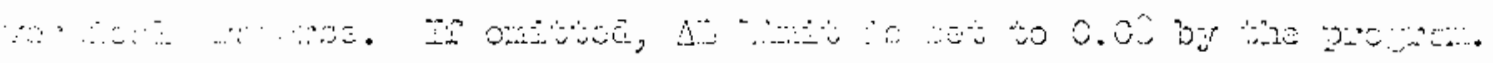

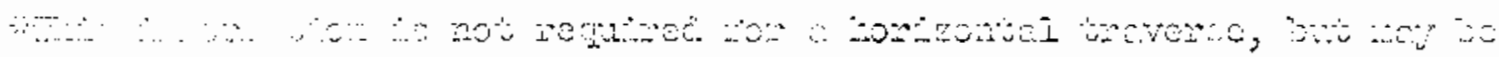

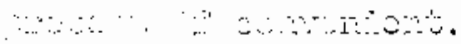

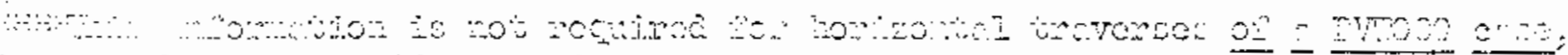

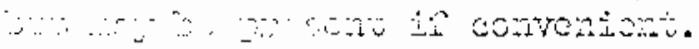


10

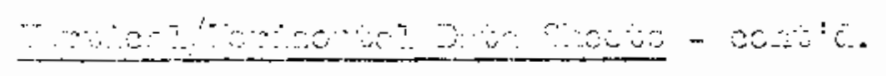

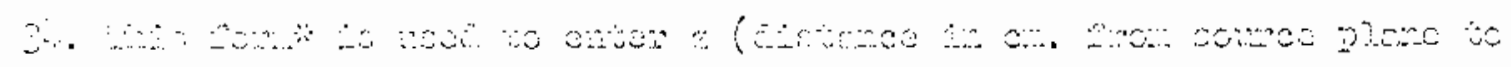

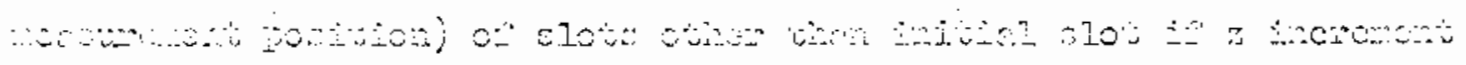

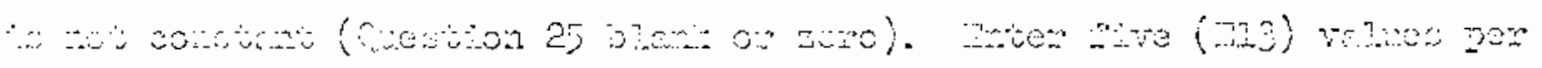

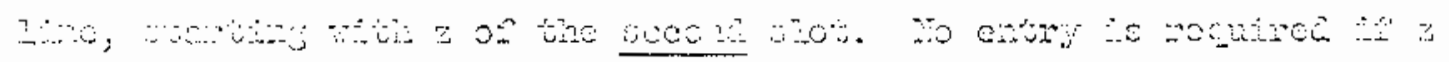

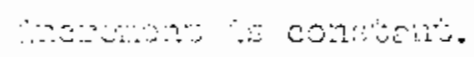

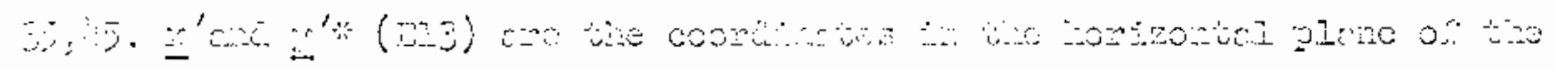

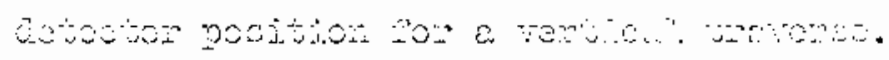

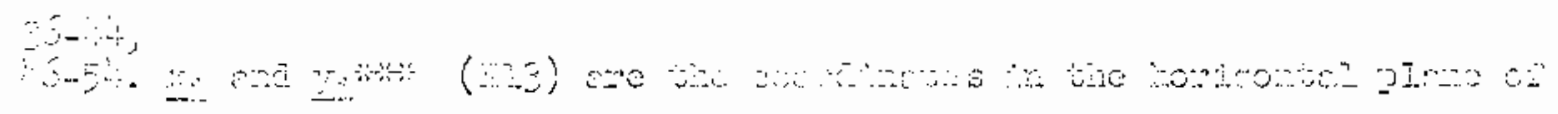

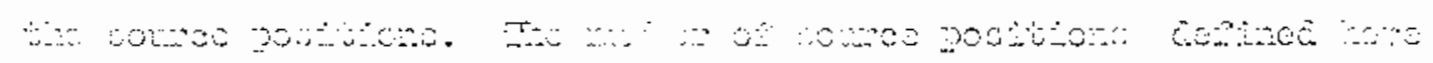

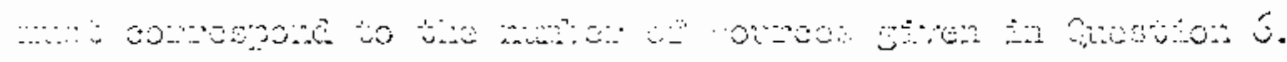

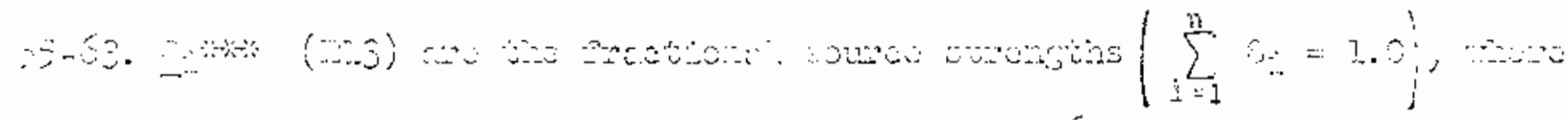

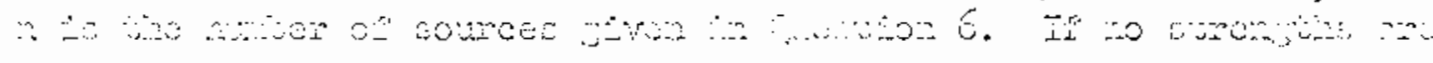

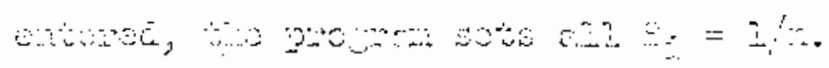

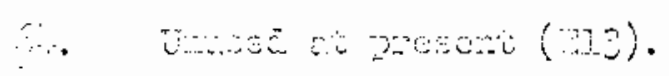

$6,65.70$ a

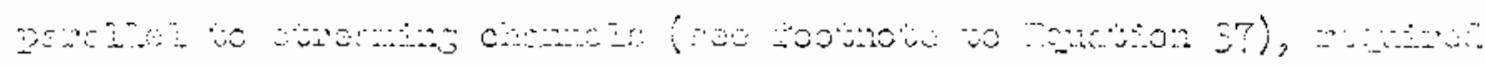

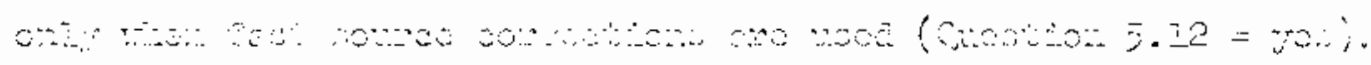

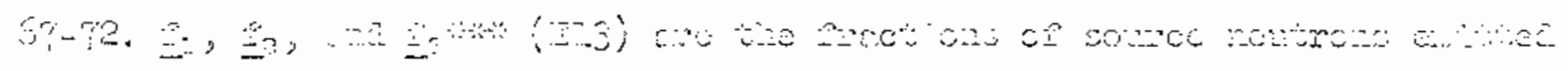

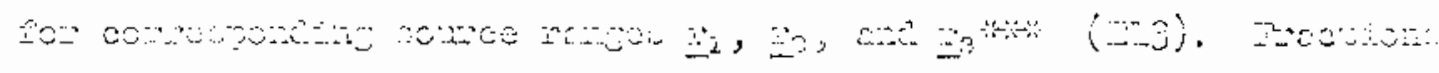

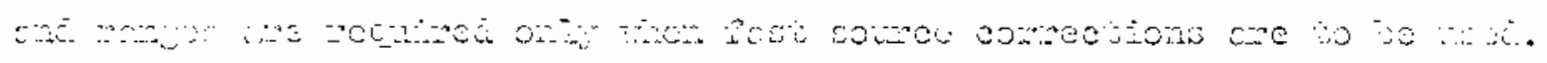

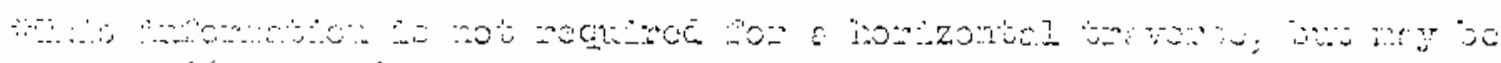

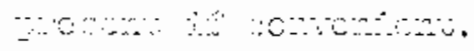

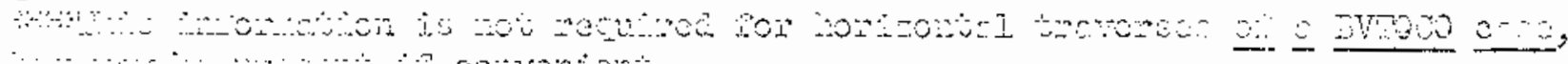

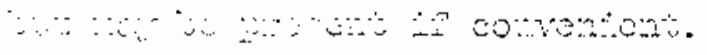




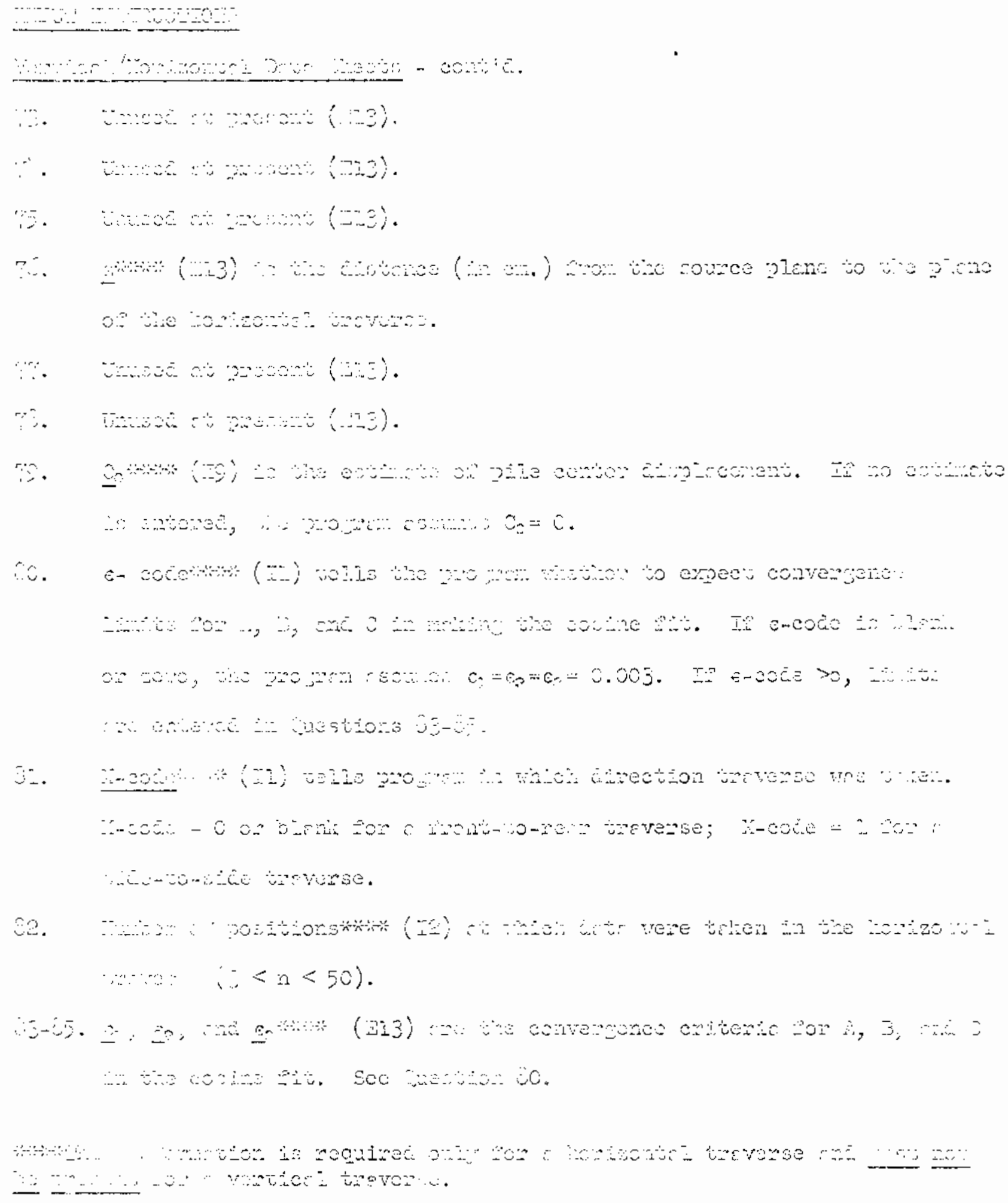




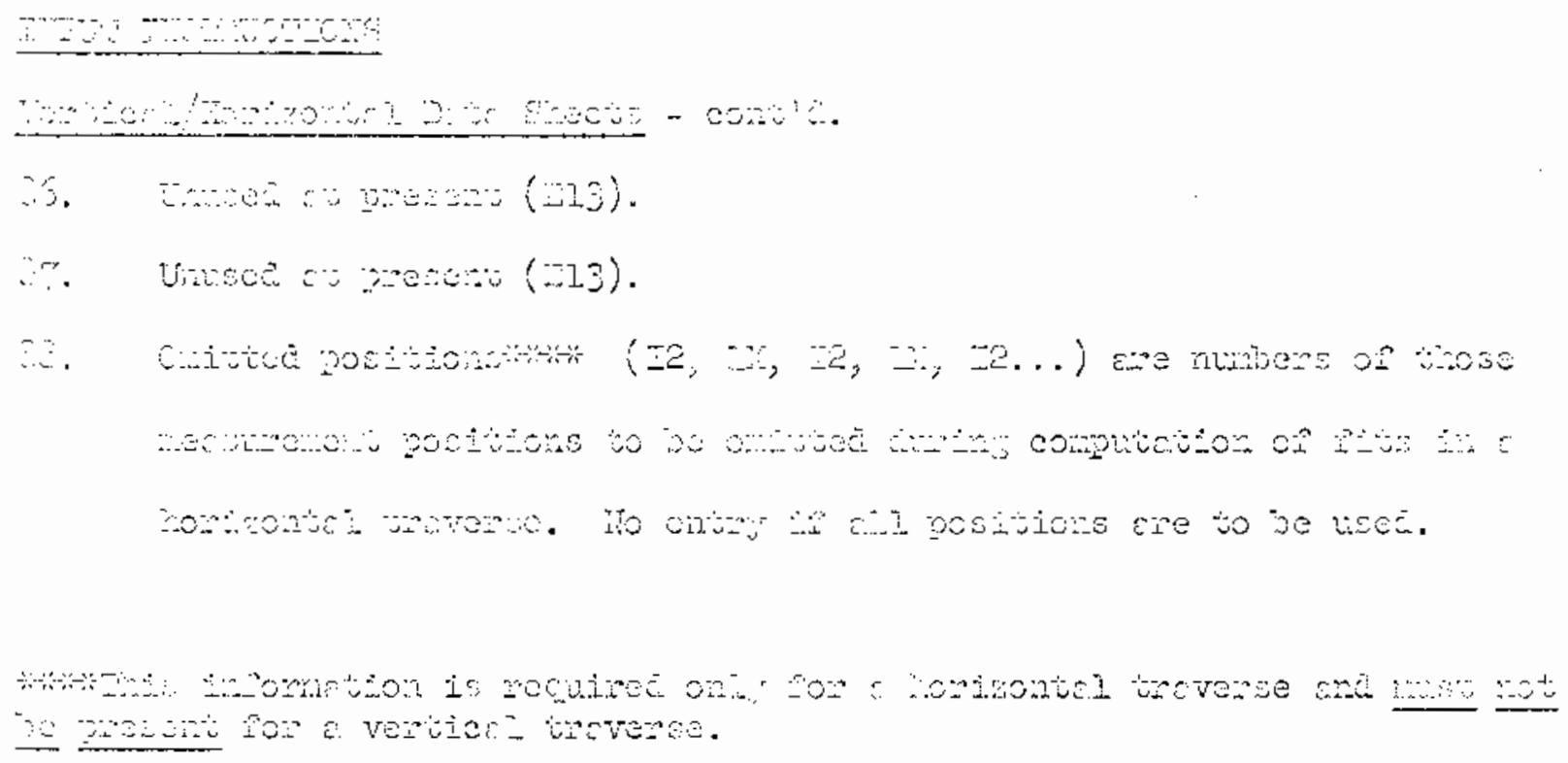




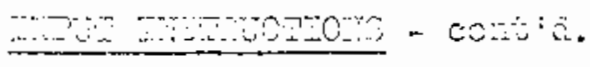

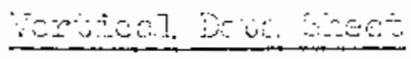

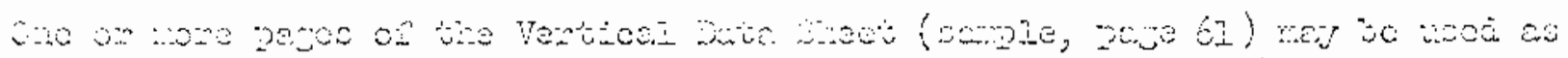

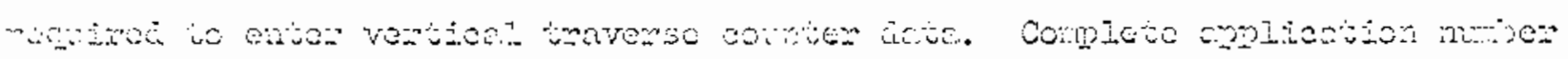

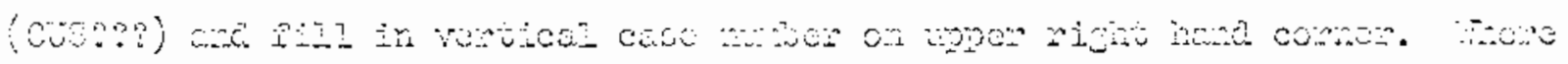

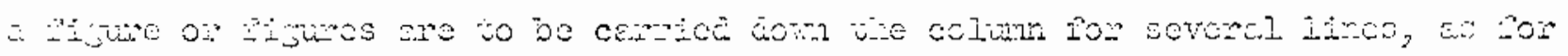

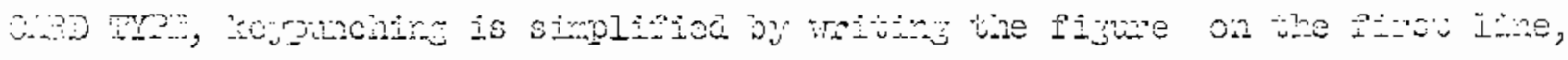

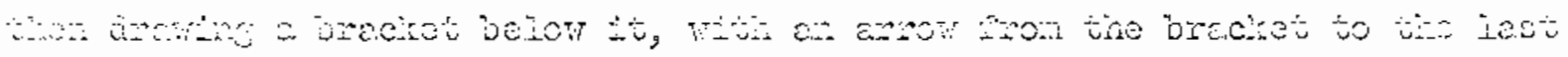
repecues 7 itic.

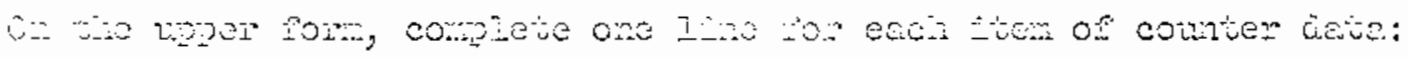

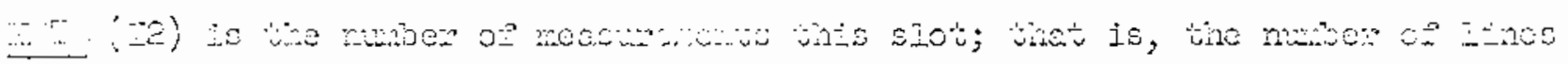

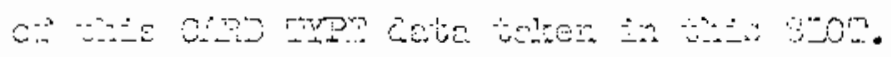

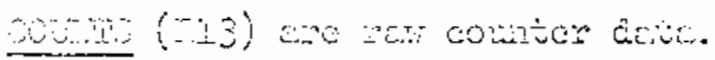

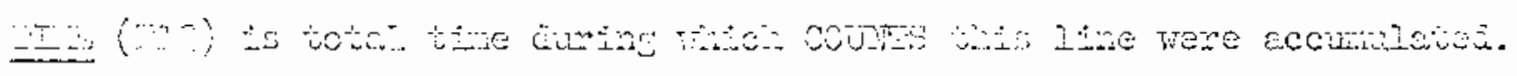

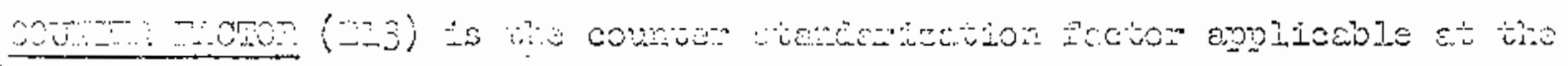
wine cown he tins nese trisen.

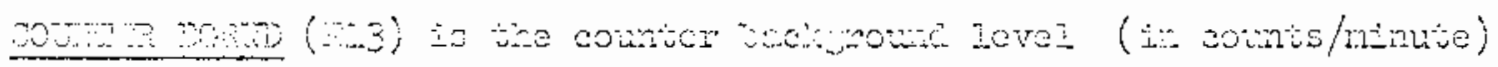

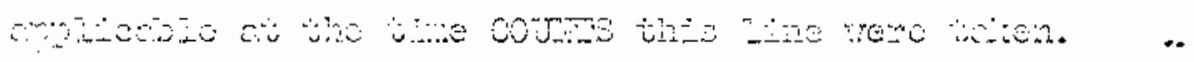

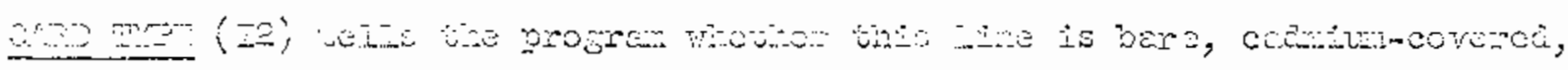

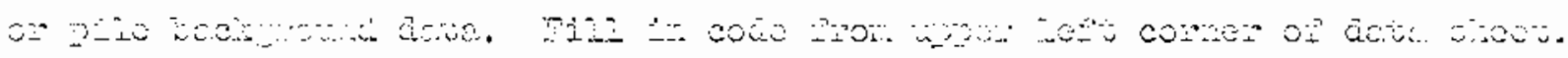
IIon (

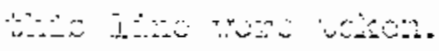




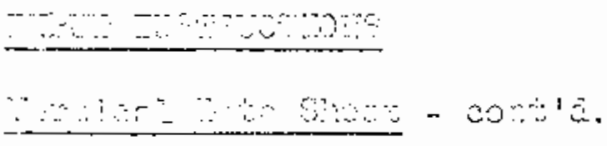

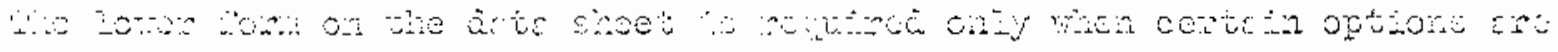

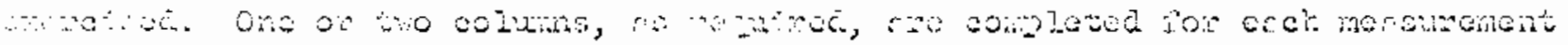

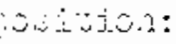

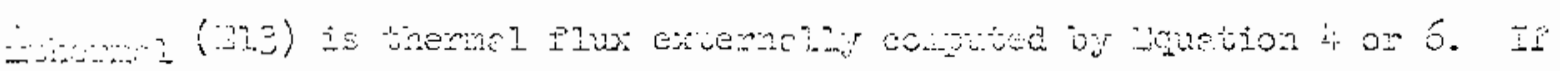

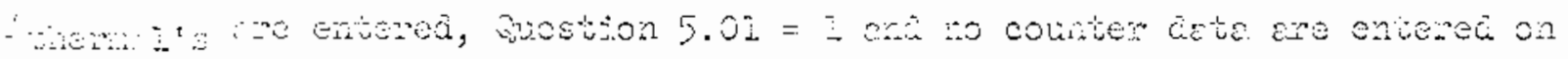
in: 20.020

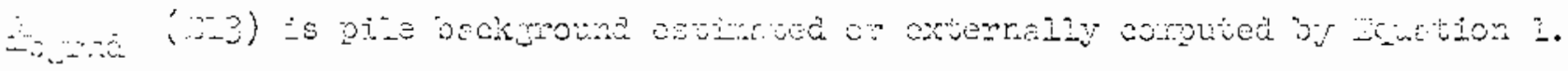

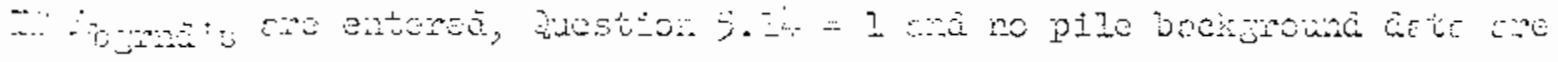

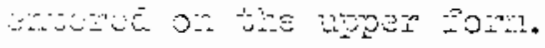

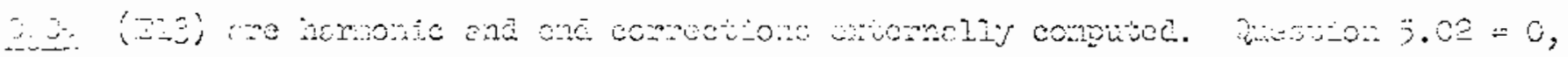

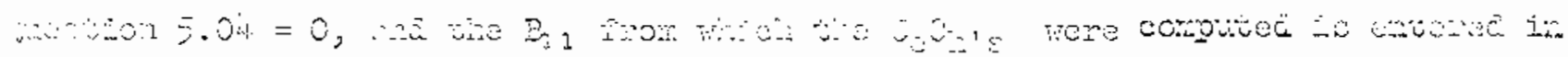
Qutsion 25

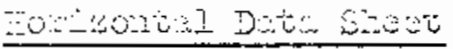

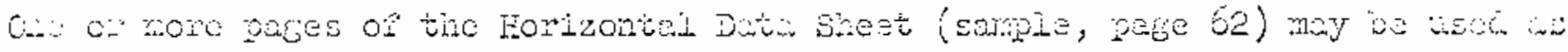

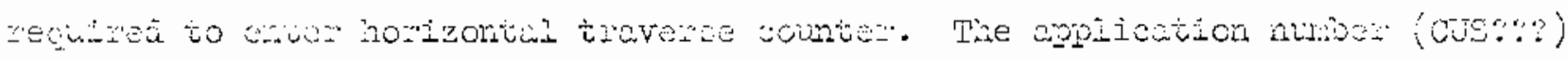

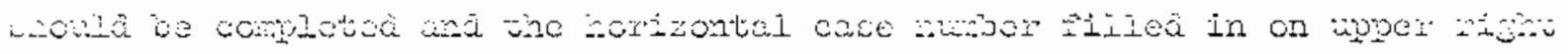

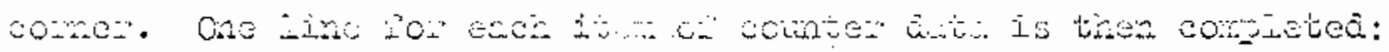

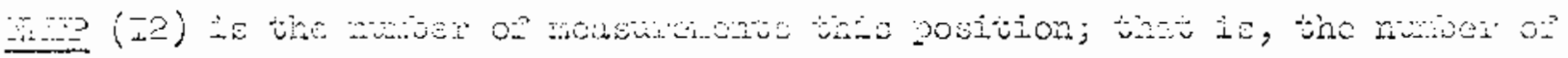

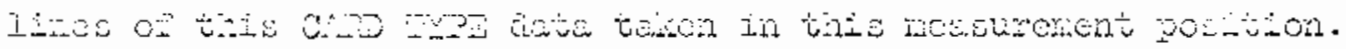

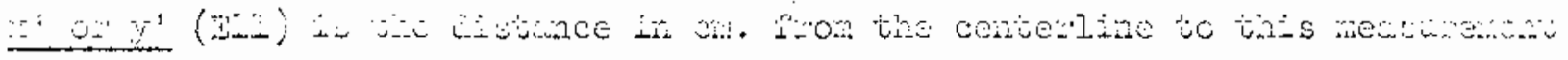

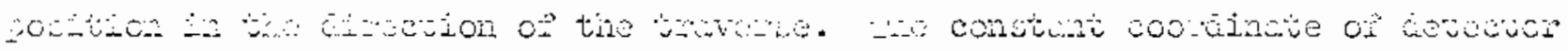

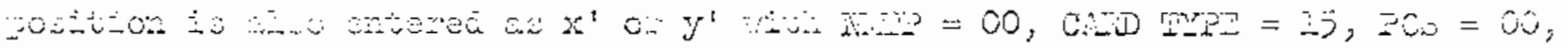




\section{INPUT INSTRUCTIONS}

Horizontal Data Sheet - cont'd.

and all other fields blank. If no measurement is taken in the center position, $A_{0}$ must be estimated and entered as coUNMS on a line having 00 as NMP, 15 as CARD TYPF, and 00 as POS. If both these conditions exist, one card will suffice for both entries. COUNIS (E13) are raw counter data. TIME (E13) is total time during which COUNTS this line were accumulated. COUNTER FACTOR (E13) is the counter standardization factor applicable at the time couNTs this line were taken.

COUNIER BGRND (E13) is the counter background level (1n counts/minute) applicable at the time CoUNTS this line were taken.

CARD TYPE tells the program whether this line is bare, cadmium-covered, or pile background data. Fill in code from upper left corner of data sheet. POS (I2) is a untque number assigned to this measurement position. POSition numbers are two-digit integers, the first of which must be 01 .

When only corrections are being computed (question $5.05=0$ ) for a horizontal case, detector positions must be entered on type 18 cards. The constant coordinate of detector position is entered as described above. one line must then be completed for each measurement position, with detector position as $\mathrm{x}^{\dagger}$ or $\mathrm{y}^{\top}, 18$ as CARD TYPE, as ascending integers as measurement POSitions. 


\section{REFERENCES}

1. S. Glasstone and M. C. Edlund, The Elements of Nuclear Reactor Theory, D. Van Nostrand Company, Princeton, N. J., 1952.

2. D. E. Davenport, G. L. Lynn, and D. C. Pound, Hanford Standard Plle, HWm21793. July, 1951.

3. D. D. Matsumoto, VTӨCL - A 709 Progrem for Reduction of Exponential Pile Data, HW-68806. April, 1961. HW-68806ADD, February, 1962.

4. D. D. Matsumoto, CөFIT2 - A 709 Program for Determining Extrapolation Length from Horizontal Traverse Data, HW-68807. April, 1961. HW-68807ADD, September, 1961.

5. E. Z. Block, "Harmonic and End Corrections for a Three-Region Exponential Pile," Nuclear Physics Research Quarterly Report, April, May, June, 1958, HW-56919, pp. 52-55. July, 1958.

6. C. Metelmann and D. E. Wood, "Fast Source Theory Harmonic Corrections," Nuclear Physics Research Quarterly Report, January, February, March, 1960, HW-64866, pp. 88-91. April, 1960.

7. C. R. Richey and E. Z. Block, Graphite Diffusion Length Measurements at Hanford, HW-45035. September, 1956.

8. G. W. R. Endres and D. E. Wood, "Investigation of Extrapolation Lengths for Graphite Uranium Lattices," Nuclear Physics Research Quarterly Report, July, August, September, 1960, HW-67219, pp. 75-93. October, 1960.

9. B. L. Anderson and T. J. Lawton, CөFIT - A Least Squares Cosine Fitting Program for the IBM-704, WAPD-TM-26. October, 1956. 


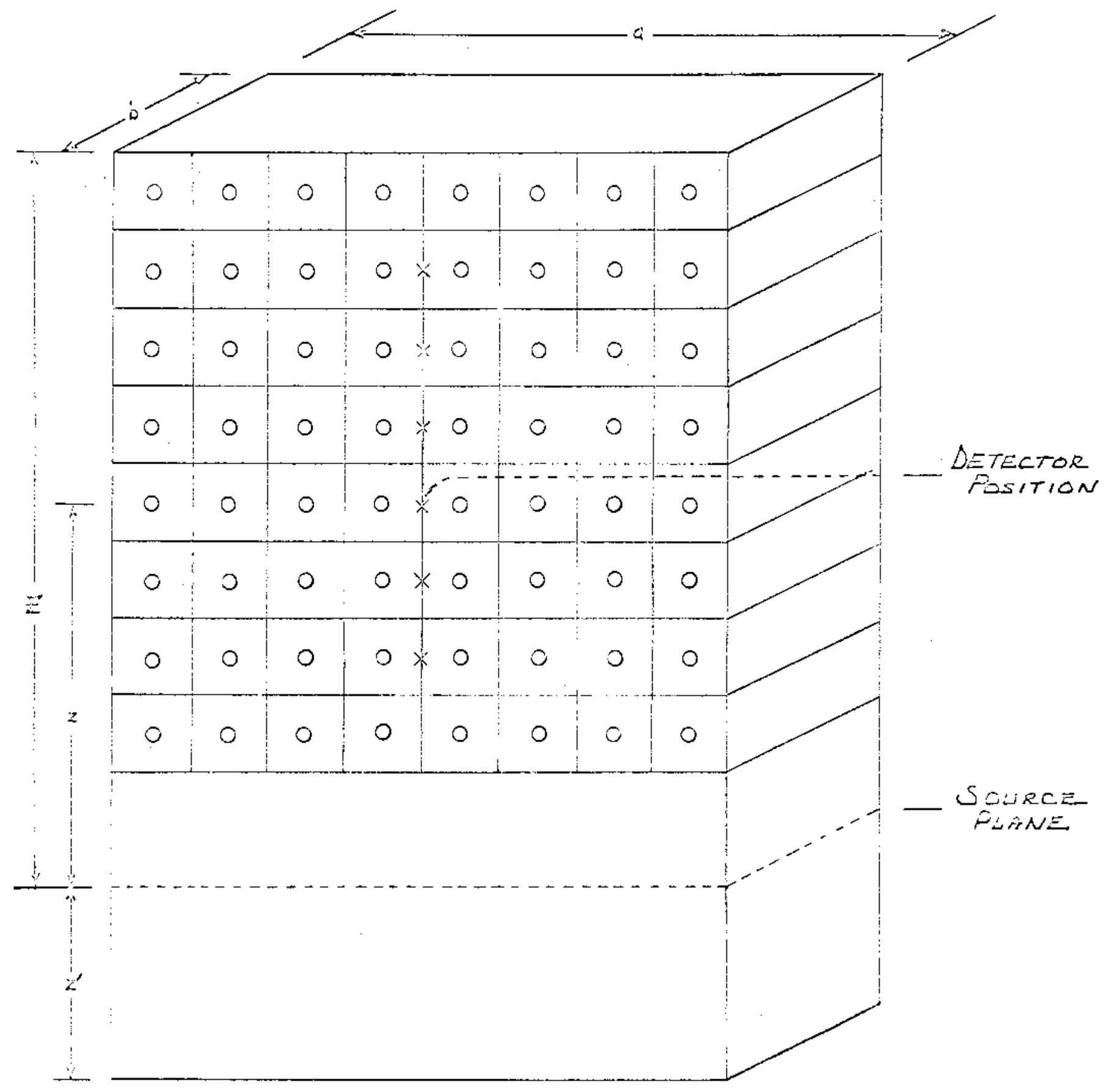




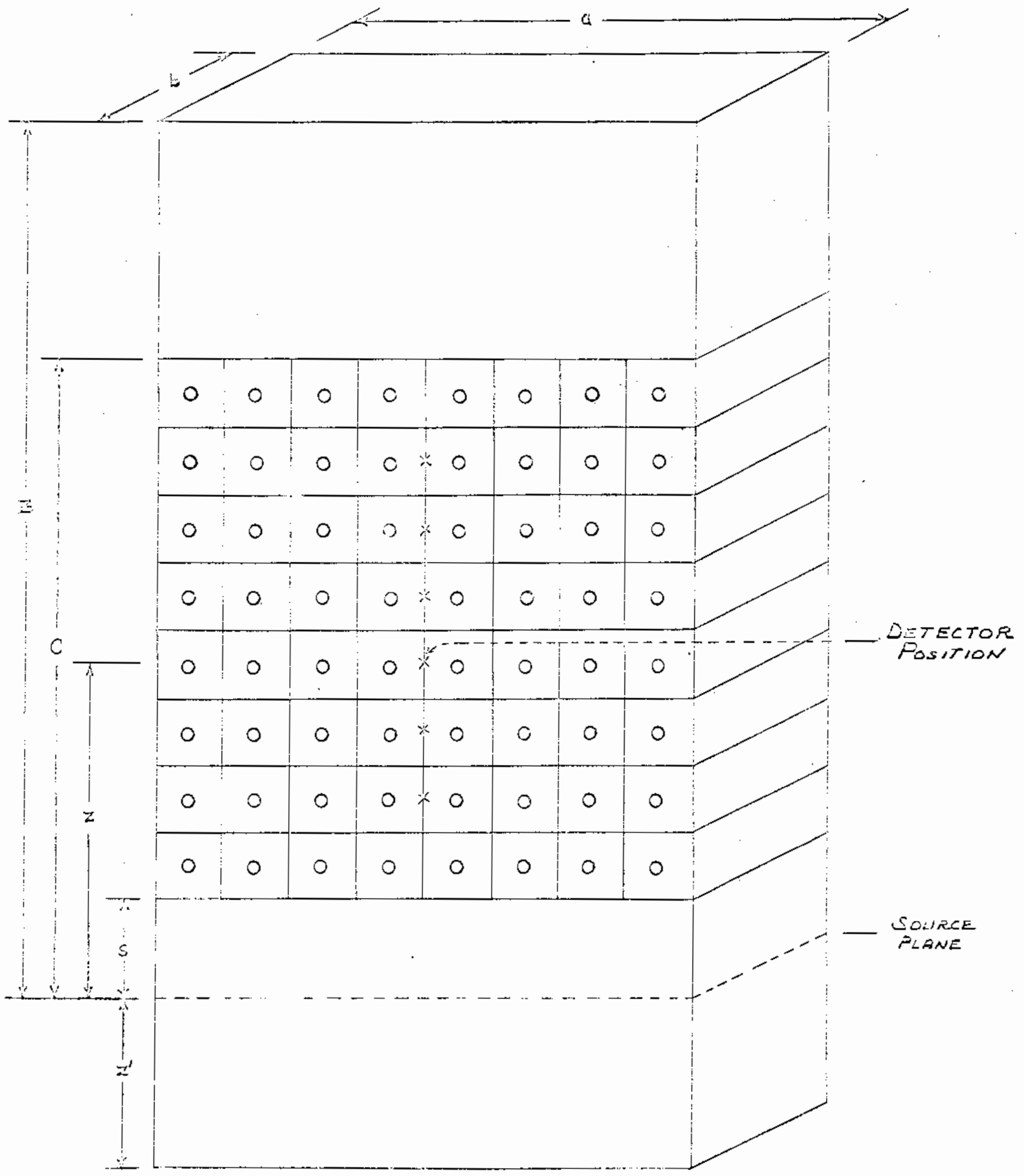

Heve 


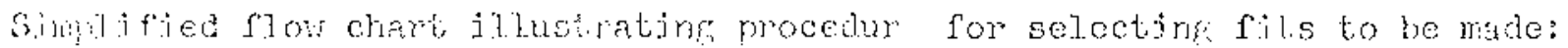

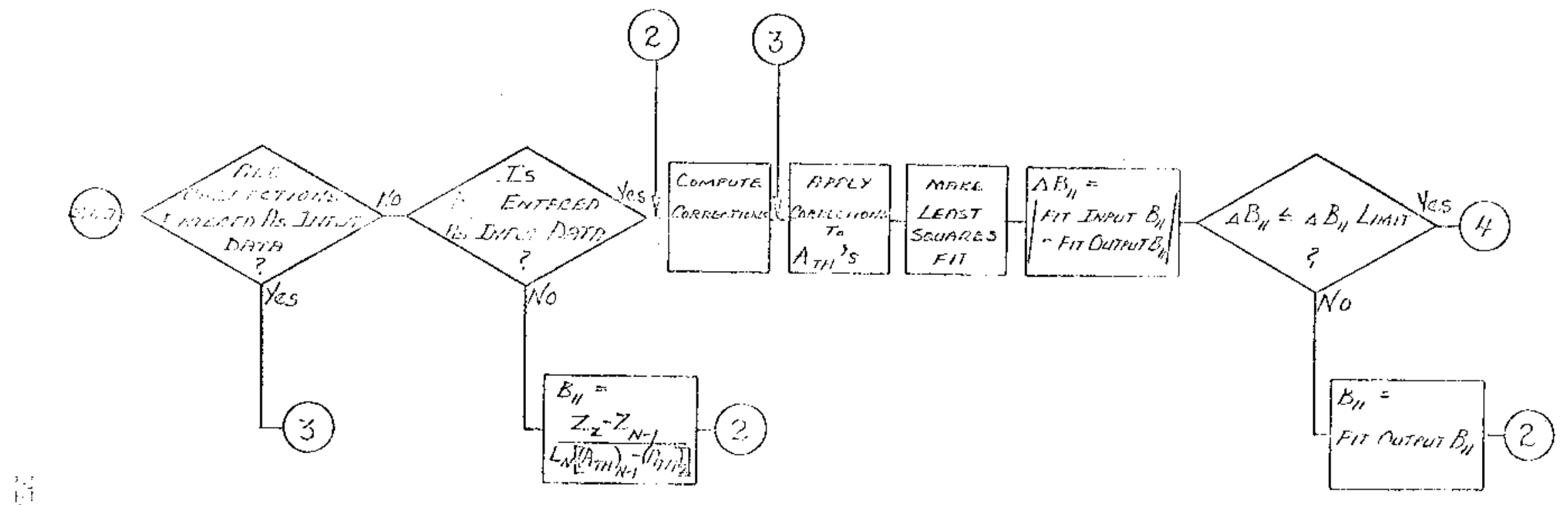

(4)

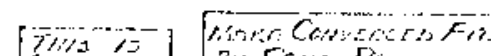

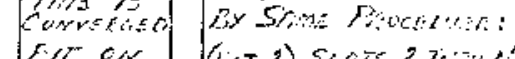

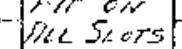
$(F, T)$

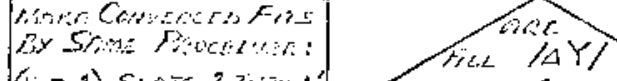

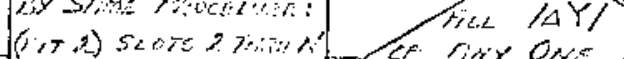

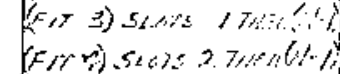

年?
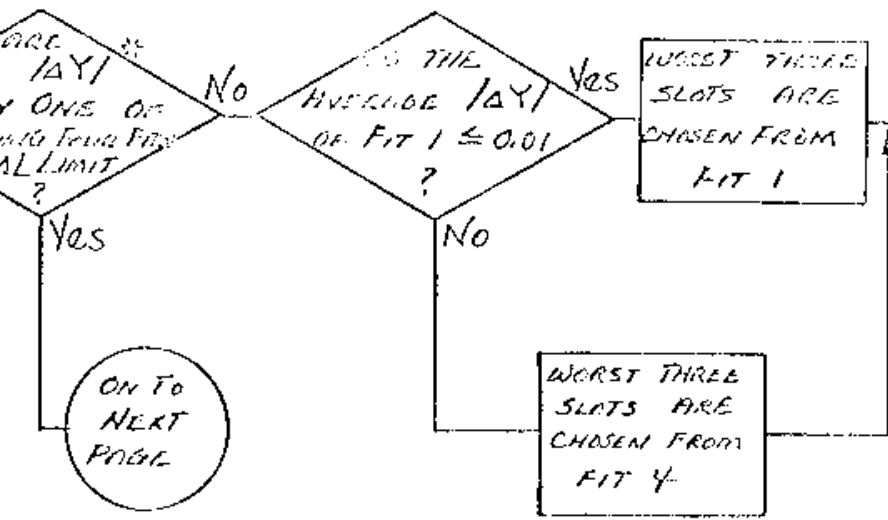

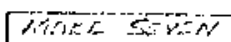
wiper cerviseres

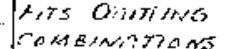

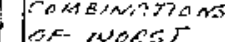
(2/6)

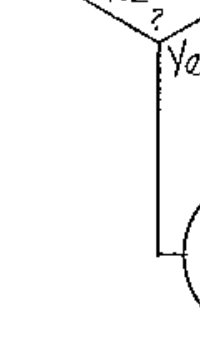

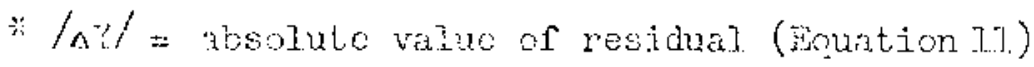


TABLE 1 - VERTICAL TRAVERSE OPTION RESTRICTIONS

\begin{tabular}{|c|c|c|c|c|}
\hline Question & Answer & $\begin{array}{l}\text { Restrictions on } \\
\text { Other Answers }\end{array}$ & $\begin{array}{l}\text { Data Which Must } \\
\text { Be Subritted }\end{array}$ & $\begin{array}{l}\text { Date Which Must } \\
\text { Not Be Submitted }\end{array}$ \\
\hline \multirow[t]{2}{*}{5.01} & 0 & $5.05=1$ & $\begin{array}{l}\text { Counter data on Vertical } \\
\text { Data Sheet; see also } 5.14 .\end{array}$ & Ath's on 11-cards. \\
\hline & I & $5.14=2$ & ** & $\begin{array}{l}\text { Counter data on } \\
\text { Vertical Data Sht. }\end{array}$ \\
\hline \multirow[t]{2}{*}{5.02} & 0 & $5.05=1$ & $\begin{array}{l}\mathrm{C}_{e} \mathrm{C}_{h} \text { for each slot on } 11- \\
\text { cards, } \mathrm{B}_{11} \text { on } 04 \text {-card. }\end{array}$ & ** \\
\hline & 1 & None & ** & $\mathrm{c}_{\mathrm{e}} \mathrm{C}_{\mathrm{h}}$ on 11-cards. \\
\hline \multirow[t]{2}{*}{5.03} & 0 & $5.14=1$ & ** & $\begin{array}{l}\text { Background counts } \\
\text { on 10-cards. }\end{array}$ \\
\hline & 1 & None & $* *$ & $* *$ \\
\hline \multirow[t]{2}{*}{5.04} & 0 & None & $\mathrm{B}_{11}$ on 04 -cerd. & $* *$ \\
\hline & 2 & $5.05=1$ & $* *$ & $\mathrm{~B}_{11}$ on $04-\mathrm{card}$ \\
\hline \multirow[t]{2}{*}{5.05} & 0 & $\begin{array}{l}5.01=1,5.02=1 \\
5.04=0,5.14=1\end{array}$ & 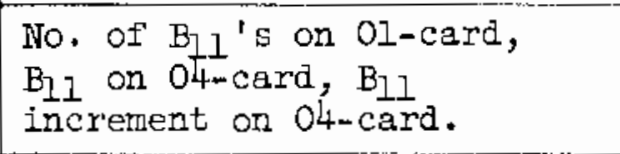 & $\begin{array}{l}\text { Counter data on } \\
\text { Vertical Data } \\
\text { Sheet. }\end{array}$ \\
\hline & 1 & None & ** & $\begin{array}{l}\text { No, of } B_{11}{ }^{\prime} \text { s on } \\
\text { Ol-card, } \text { P }_{17} \text { in- } \\
\text { crement on } 04 \text {-card }\end{array}$ \\
\hline \multirow[t]{2}{*}{5.06} & 0 & $5.1 .1=1$ & $B_{1}$ on 05 -card, s on 05-card. & ** \\
\hline & 1 & None & $* *$ & $\begin{array}{l}\text { B on 05-card, } \\
\mathrm{s} \text { on } 05 \text {-card. }\end{array}$ \\
\hline \multirow[t]{2}{*}{5.07} & 0 & None & $\mathrm{B}_{3}$ on 05-card, $\mathrm{C}$ on 05-card. & $* *$ \\
\hline & 1 & None & ** & $\begin{array}{l}\mathrm{B}_{3} \text { on } 05 \text {-card, } \\
\mathrm{C} \text { on } 05 \text {-card. }\end{array}$ \\
\hline 5.08 & 1 & \multicolumn{3}{|c|}{ Option inactive for vertical traverses; code assumes 1.} \\
\hline 5.09 & $0 / 1$ & None & ** & $* *$ \\
\hline 5.10 & 1 & \multicolumn{3}{|c|}{ Option inactive for vertical traverses; code assumes 1 . } \\
\hline \multirow[t]{2}{*}{5.11} & 0 & $5.06=1,5.12=1$ & *** & $* *$ \\
\hline & 1 & None & ** & $* *$ \\
\hline \multirow[t]{2}{*}{5.12} & 0 & $5.11=1$ & All data on 12 - \& 13-cards. & ** \\
\hline & 1 & None & $* *$ & $12-$ and 13 -cards. \\
\hline 5.13 & 1 & \multicolumn{3}{|c|}{ Option inactive; code assumes 1.} \\
\hline \multirow[t]{3}{*}{5.14} & 0 & $5.01=0,5.05=1$ & Background counts on 10-cds. & $A_{t h}$ on 11 -cards. \\
\hline & 1 & $\begin{array}{l}5.01=1 \text { Ox } \\
5.03=0\end{array}$ & ** & $\begin{array}{l}\text { Background counts } \\
\text { on } 10 \text {-cards. }\end{array}$ \\
\hline & 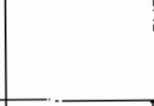 & $\begin{array}{l}5.01=0 \text { and } \\
5.03=1\end{array}$ & Ath on Il-cards. & $\begin{array}{l}\text { Background counts } \\
\text { on 10-cards. }\end{array}$ \\
\hline 5.15 & 1 & \multicolumn{3}{|c|}{ Option inactive on vertical traverses; code assumes 1.} \\
\hline
\end{tabular}


APPENDIX B - cont' $\mathrm{d}$.

Table 2- Horizontal Traverse Option Restrictions

\begin{tabular}{|c|c|c|c|c|}
\hline Question & Answer & $\begin{array}{l}\text { Restrictions on } \\
\text { Other Answers }\end{array}$ & $\begin{array}{l}\text { Data Which lisust } \\
\text { Ee Submitted }\end{array}$ & $\begin{array}{l}\text { Data Which liust } \\
\text { Not Ee Submitted }\end{array}$ \\
\hline \multirow[t]{2}{*}{5.01} & 0 & $5.05=1$ & $\begin{array}{l}\text { Counter data on Horizontal } \\
\text { Data Sheet. }\end{array}$ & 满 \\
\hline & 1 & $5.05=0$ & 致 & $\begin{array}{l}\text { Counter data on } \\
\text { Horiz. Data Sheet. }\end{array}$ \\
\hline 5.02 & 1 & \multicolumn{3}{|c|}{ Option inactive for horizontal traverse; code assumes 1} \\
\hline \multirow[t]{2}{*}{5.03} & 0 & None & Background data on 17-cards. & *is \\
\hline & 1 & None & * * & $\begin{array}{l}\text { Eackground data } \\
\text { on 17-cards. }\end{array}$ \\
\hline \multirow[t]{2}{*}{5.04} & 0 & None & $\mathrm{B}_{11}$ on $\mathrm{O} 4$-card. & 并 \\
\hline & 1 & $5.05=1$ & $\% *$ & $B_{11}$ on $04-c a r d$ \\
\hline \multirow[t]{2}{*}{5.05} & \multirow[b]{2}{*}{1} & $5.04=0$ & $\begin{array}{l}\text { No. of } \mathrm{B}_{71} \text { 's on Ol-card, } \\
\mathrm{B}_{11} \text { on } 04-\mathrm{tard}, \mathrm{B}_{11} \text { incre- } \\
\text { ment on } 04 \text {-card, detector } \\
\text { positions on } 18 \text {-cards. }\end{array}$ & $\begin{array}{l}\text { Counter data on } \\
\text { Horiz. Data Sheet. }\end{array}$ \\
\hline & & None & 米 & $\begin{array}{l}\text { No. of } \mathrm{B}_{7}{ }^{\prime} \mathrm{s} \text { on } \\
\text { ol-card, }{ }^{1} \mathrm{~J}_{4} \text { in- } \\
\text { crement on } \mathrm{O}_{4}-\mathrm{cd}, \\
\text { detector positions } \\
\text { on 18-card. }\end{array}$ \\
\hline \multirow[t]{2}{*}{5.06} & 0 & $5.11=1$ & $\mathrm{~B}_{1}$ and $\mathrm{s}$ on $05-\mathrm{card}$. & $\because \%$ \\
\hline & 1 & Lione & $\because *$ & $B_{1}$ and $s$ on $05-c d$ \\
\hline \multirow[t]{2}{*}{5.07} & 0 & None & $\mathrm{B}_{3}$ and $\mathrm{C}$ on $05-\mathrm{card}$ & $* *$ \\
\hline & 1 & None & $* \%$ & $B_{3}$ and $\mathrm{C}$ on $05-\mathrm{cd}$ \\
\hline \multirow[t]{2}{*}{5.08} & 0 & $5.04=1,5.05=1$ & $\because *$ & $* *$ \\
\hline & 1 & None & * & $* x$ \\
\hline 5.09 & $0 / 1$ & None & 觔 & $* * *$ \\
\hline \multirow[t]{2}{*}{5.10} & 0 & $5.05=1$ & 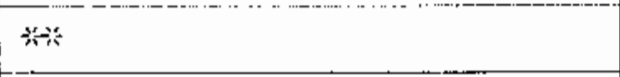 & 秋 \\
\hline & $I$ & None & $\therefore$ & 苏 \\
\hline 5.11 & 1 & Option inactive for & horizontal traverse; code ass & umes I \\
\hline \multirow[t]{2}{*}{5.12} & 0 & Tone & All data on $12-$ and 13-cas. & 然 \\
\hline & 1 & None & 㣰 & $12-$ and $13-$ cards. \\
\hline 5.13 & I & \multicolumn{3}{|c|}{ Option inactive for horizontal traverse; code assumes 1} \\
\hline 5.14 & $0 / 1$ & \multicolumn{3}{|c|}{ Question inapplicable; code refers to Question 5.03 for answor. } \\
\hline 5.15 & $0 / 1$ & None & * & 兴 \\
\hline
\end{tabular}




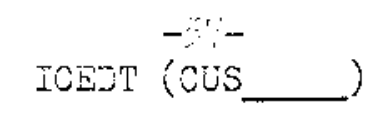

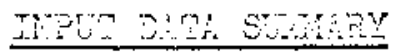

(Siswotos

(Date)

\begin{tabular}{|c|c|c|c|c|c|c|c|c|c|c|c|}
\hline \multicolumn{3}{|c|}{ ALDO CASE } & \multicolumn{3}{|c|}{ 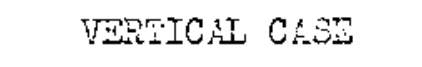 } & \multicolumn{3}{|c|}{ GRZZONAR CASA } & \multicolumn{3}{|c|}{ CORTZOXVAI CASE } \\
\hline $\begin{array}{c}C . S 2 \\
30 \\
\end{array}$ & aring & $\begin{array}{l}\text { DATA } \\
\text { TRTS }\end{array}$ & $\begin{array}{c}\text { C.SE } \\
1 \mathrm{O} .\end{array}$ & CARDS & $\begin{array}{c}\text { DAIA } \\
\text { SHESTS }\end{array}$ & $\begin{array}{l}6.59 \\
\mathrm{NO} .\end{array}$ & CBRDS & $\begin{array}{l}\text { DATA } \\
\text { SHEES }\end{array}$ & $\begin{array}{l}\text { CASO } \\
\mathrm{NO} .\end{array}$ & CAPLS & $\begin{array}{c}\text { DETA } \\
\text { SHEETS }\end{array}$ \\
\hline & & & & & ! & & & & & & \\
\hline & & & & & 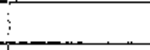 & & & & & & \\
\hline & & & & & & & & & & 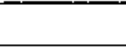 & 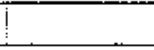 \\
\hline & & & & & & & & & & 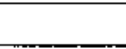 & \\
\hline & & & & & & & & & & & ! \\
\hline & & & & & & & & & & & \\
\hline & & & & & & & & & & & \\
\hline & & & & & & & & & & & \\
\hline & & & & & & & & & & & \\
\hline & & 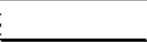 & & & & & & & & & \\
\hline & & & & & & & & & & & \\
\hline & & 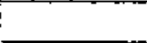 & & & i & & & & & & \\
\hline & & & & & 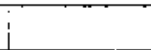 & & & & & & \\
\hline & & & & & & & & & & & \\
\hline & & & & & i & & & & & & \\
\hline & & & & & $\mathrm{f}$ & & & & & & \\
\hline & & & & & & & & & & & \\
\hline & & & & & & & & & & & \\
\hline
\end{tabular}

OOnet: AII case numbers are in columins bó-68.

1. Check subnitted material. In it cloos not conrespond to sumary above, burie up

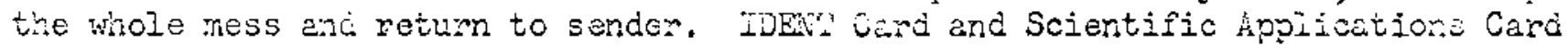
should be inclüied, also.

2. SIl submitted carcis to Step 5, frey are soriced, banded, and labeled.

3. Repunch and verify from 211 accompanying data sheets. ICEDT cards to Step $5 ;$ VERTCAL and ZORIZT ML cards to Steo ts.

4. Sort* keypunched VERTICH and HORTZONT:I Carce on colums 66-72.

5. Hake up data deck for each TCDin case a foljows:

a. ICWDT cards.

b. Ore on no WRRTCHL cases, as tacicatec above.

c. Cre, two, or ro HORIZONifL casce, as indicated above.

6. iny rumber of cases may be run at one time, in order insted above.

7. Uje SPL ICDDI cick on 7090 .

3. Gre-pert paper is sufficient for outplit. If muli-part paper is used, deco-iate.

9. Sence report, along with Enput cards, dés sheets, and this sheet, to:

Not any case nuburs are starred, this indicates duplicate case numbers and each case of this nutwer mist be sorted by itsej?. 


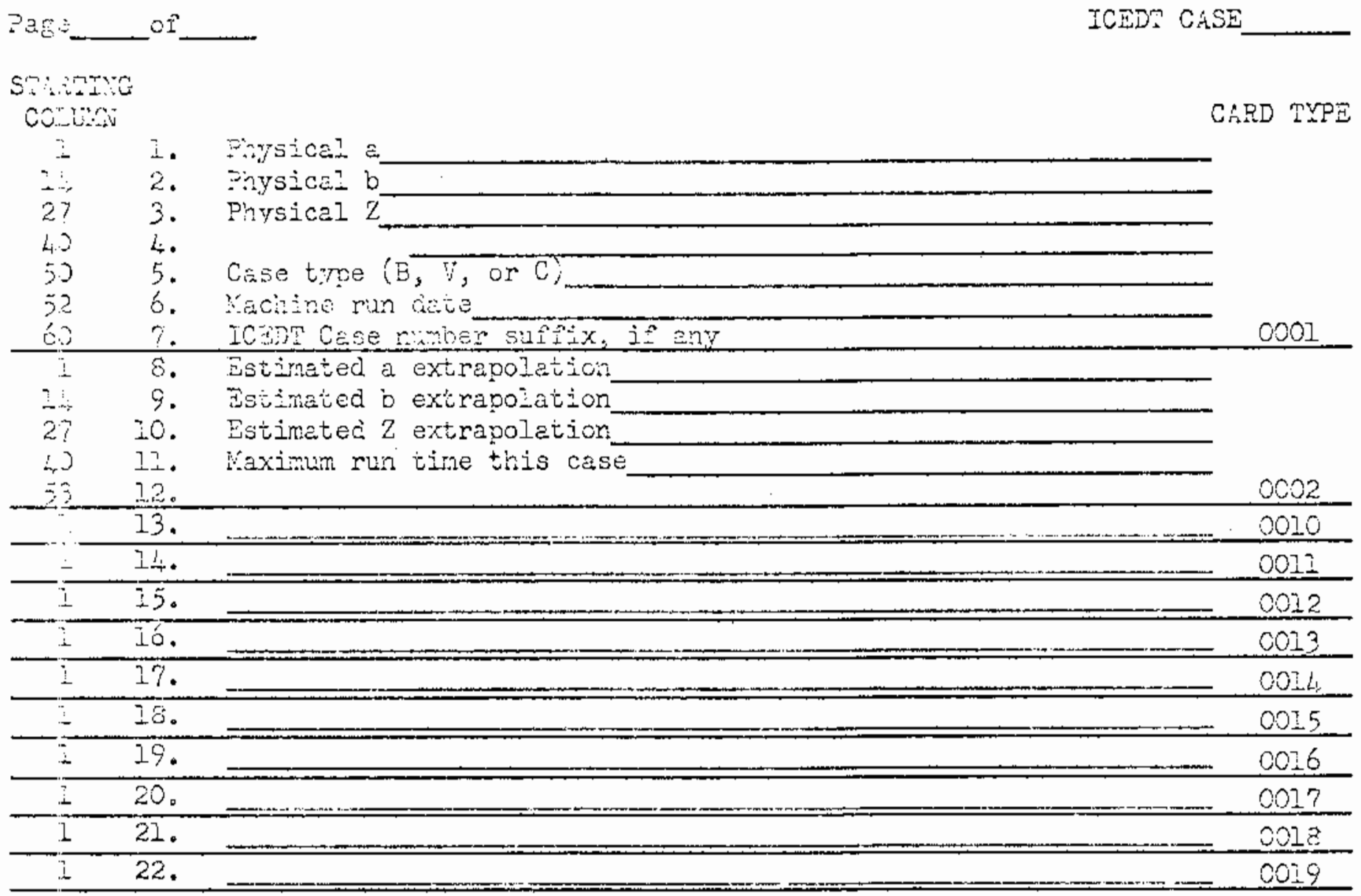

muve: zease purch case rumber in cols. 66-68 and card type in cols. 69-72, of scon carc. Onit cards having no data entered on ther. 
i. 1. Exoriment nuriber

c $\quad \therefore \quad \cdots+$ atice

26 3. Sing

25. 4. Let Ery

5. For cuestions 5.01-5.15, $0=y e s, 1=$ no.

a. $\quad 5.01$ Is counter date entered? (Yes for horizontal)

2s: $\quad 3.02$ ire corrcctions enterec as input data? (No for horizontai)

2i. 5.03 Ccomiun shitter metisod?

$30 \quad 5.04$ Is a trial $B_{11}$ sirogested?

$3 . \quad 5.05$ Calcliate corrections only?

$3 \approx \quad 5.06$ Use 2-resion hamonic corrections?

$\because 5 \quad 5.07$ Jse 2-region end corrections?

32. $5 . \mathrm{AB} \mathrm{AL}$ corrections $=1.0$ (No for verticaij

$3: \quad 5.09$ Print intemediate insormaticn?

$36 \quad 5.20$ Drop end points (No for verucaI anc For B-ceses)

$3^{\prime \prime} \quad 5.11$ Use end comections only" (No for horizontal)

$30 \quad 5.2$ Use fast source corrections?

5. 5.33 option removed _ 2

if 5.14 Wust background colnts/rinlute be calculated?

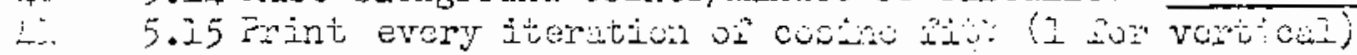

6. Number of sources

4. 7. Initial sot

3. Siot increint

$4 " 9 . \quad$ Number of 5 lots

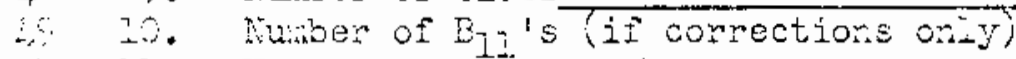

$5 . \quad \therefore$. Number of cacrium slots

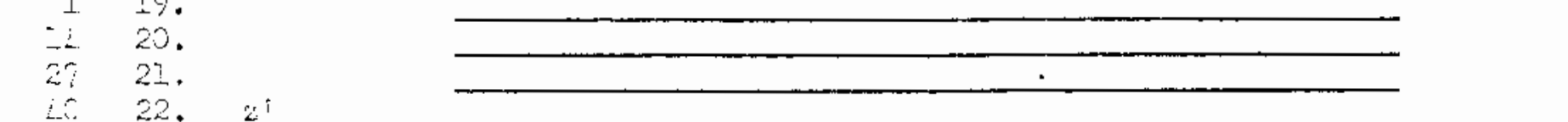




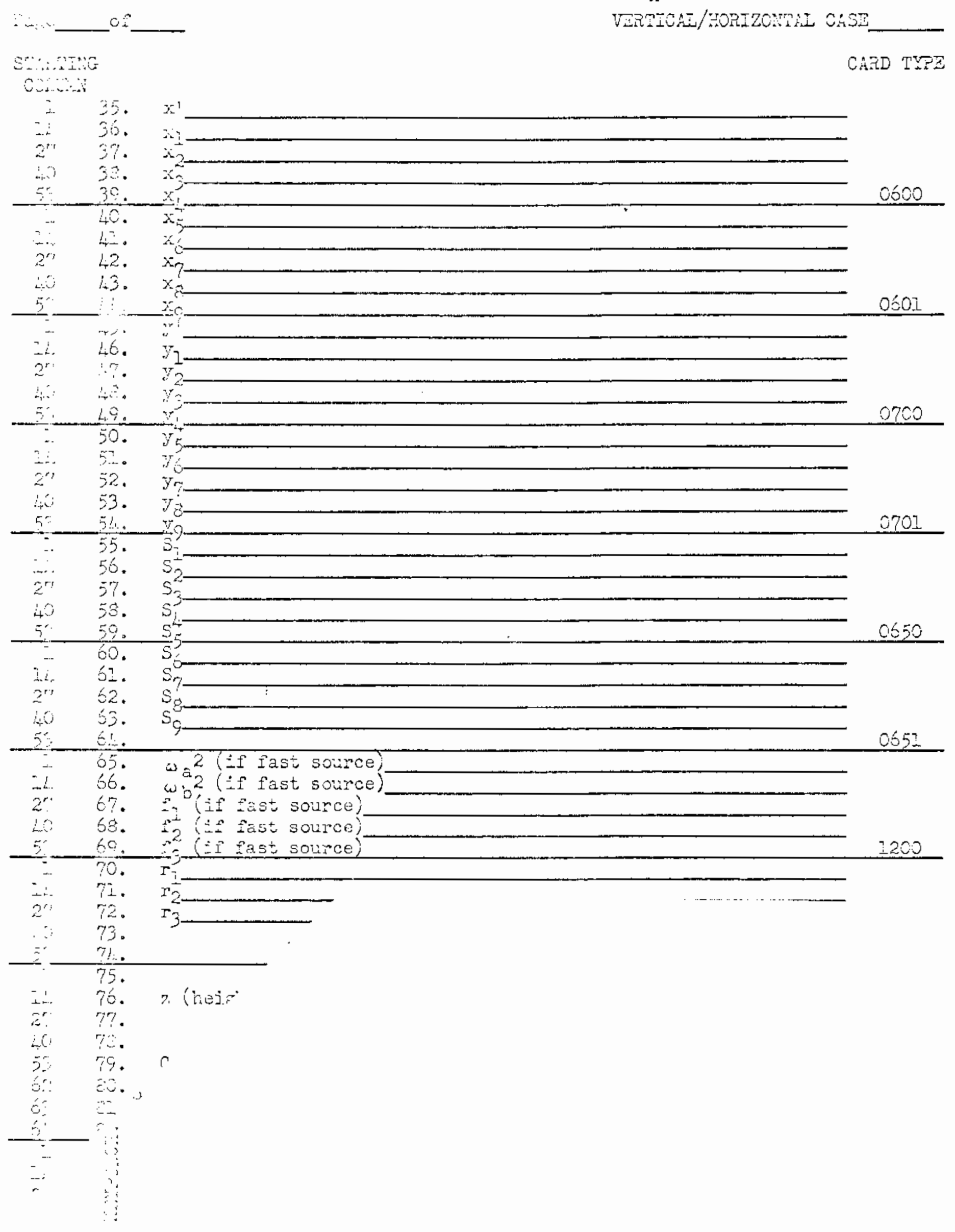




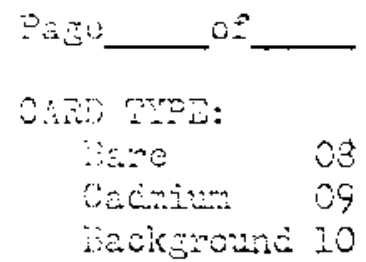
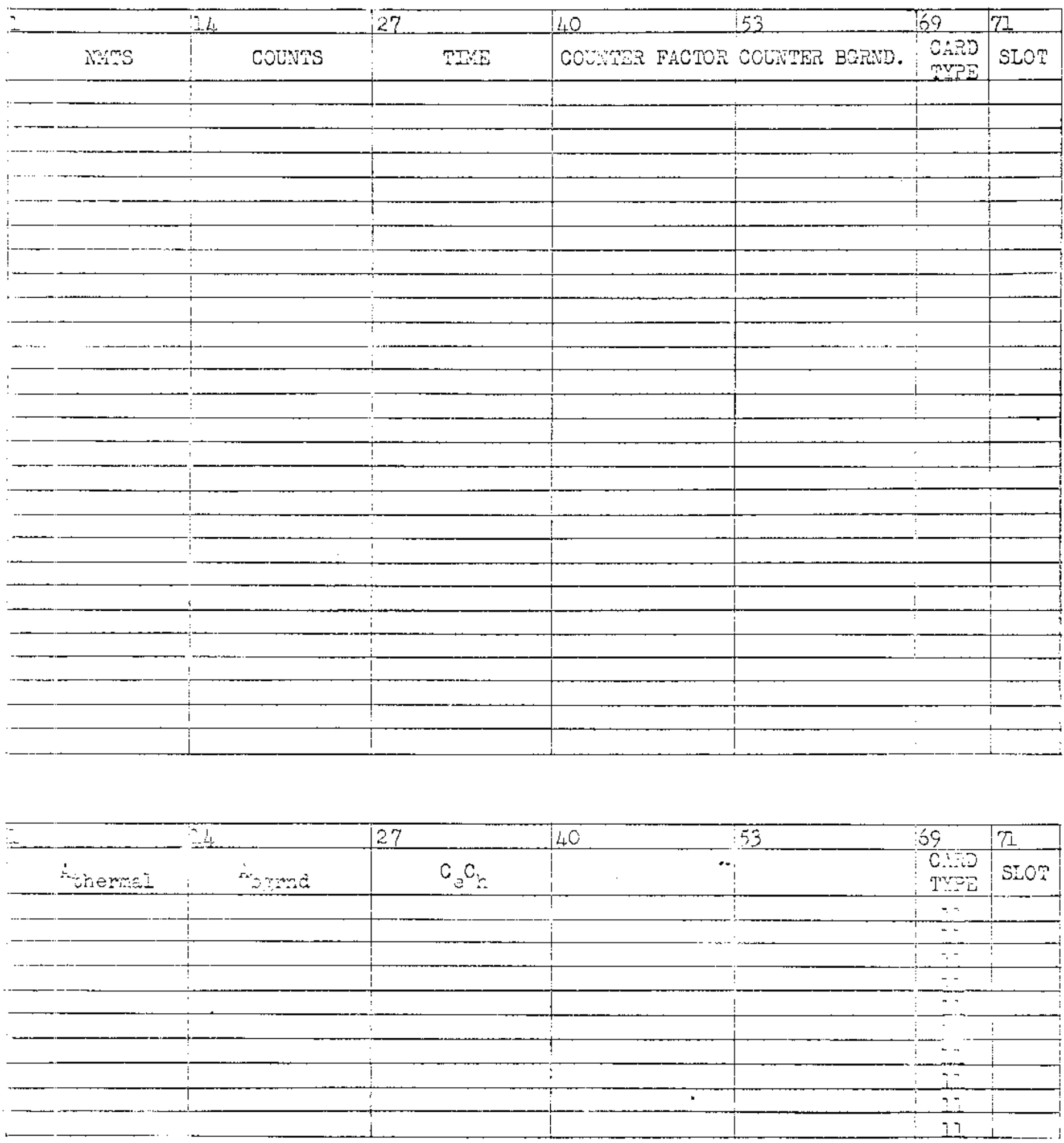


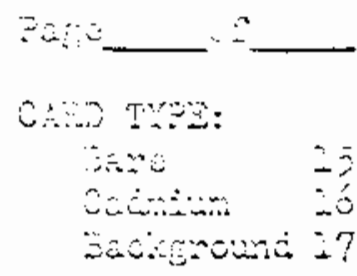

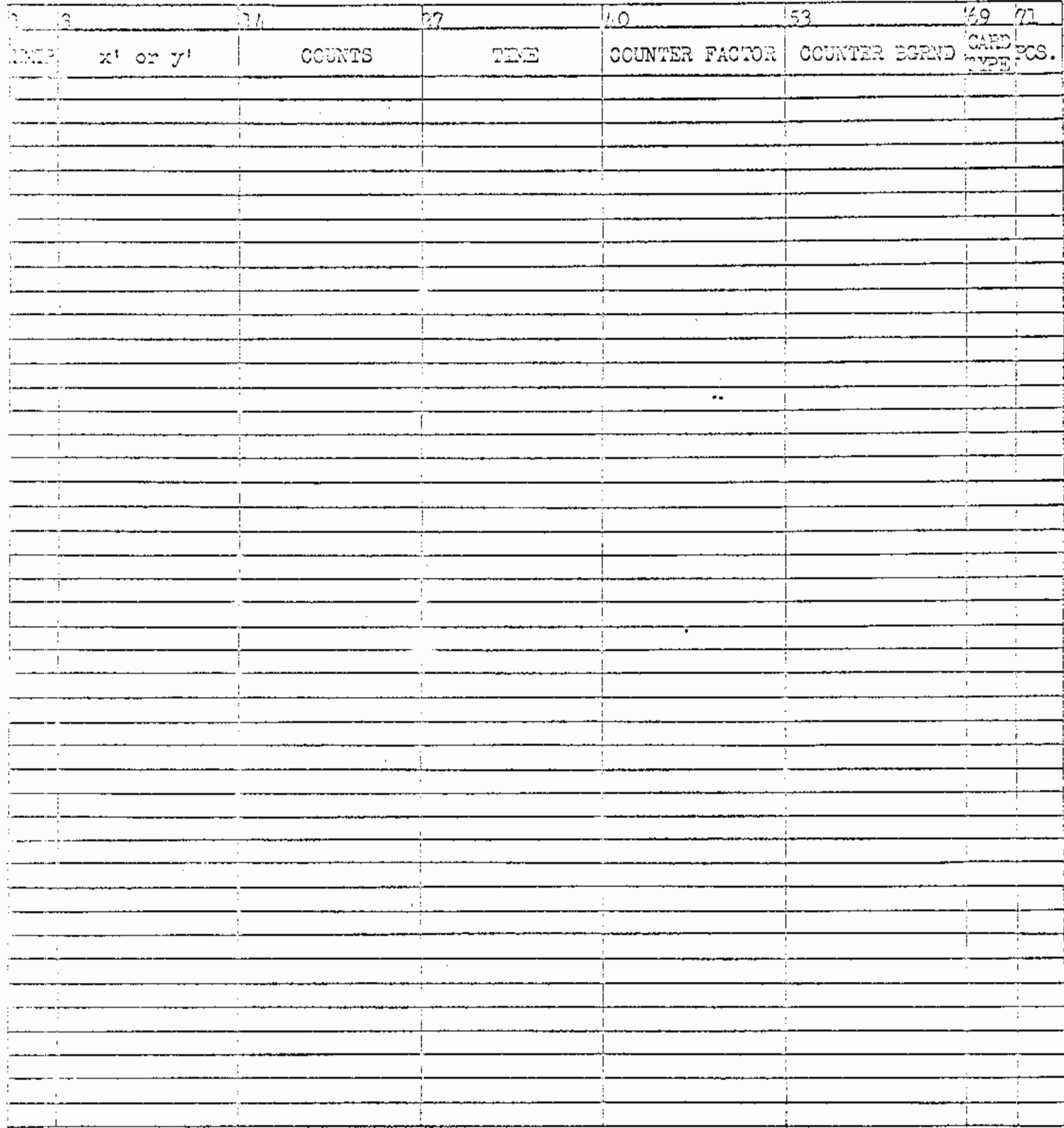


INTERISL DISTRIBUTICN

Copy lumber

$1-10$.
11.
12.
13.
14.
15.
$16-22$.
23.
$24-25$.

R. A. Bennett

J. L. Carter

L. C. Davenvort

F. G. Darson

R. it. teinenan

C. W. Lindenmeier

D. D. nint sumoto

Technical Information

Technical Publications 


\section{EXXTERTAL DISTRIBLTICI}

\section{umber of Copies}

A. I. Babb, University of Washington, Scattle

G. Sogal, Israel Institute of Iecinologr, "eife, Isreel

R. K. Sharp, ADC-RLio

Y. Yeivin, Hebret University of Jeruseler, Israel DTE 